\title{
AKT signaling promotes DNA damage accumulation and proliferation in polycystic kidney disease
}

Sarah E. Conduit ${ }^{1 \pm}$, Elizabeth M. Davies ${ }^{1}$, Lisa M. Ooms ${ }^{1}$, Rajendra Gurung ${ }^{1}$, Meagan J. McGrath $^{1}$, Sandra Hakim ${ }^{1}$, Denny L. Cottle ${ }^{2}$, Ian M. Smyth ${ }^{2}$, Jennifer M. Dyson ${ }^{1}$ and Christina A. Mitchell ${ }^{1 *}$

1. Cancer Program, Monash Biomedicine Discovery Institute, Department of Biochemistry and Molecular Biology, Monash University, Clayton, Australia 3800.

2. Development and Stem Cells Program, Monash Biomedicine Discovery Institute, Department of Biochemistry and Molecular Biology, Department of Anatomy and Developmental Biology, Monash University, Clayton, Australia 3800.

\# Corresponding author: Christina A. Mitchell

Cancer Program, Monash Biomedicine Discovery Institute, Department of Biochemistry and Molecular Biology, Monash University, Clayton, Victoria, Australia, 3800.

Email: christina.mitchell@monash.edu, Phone: +61-3-9905-4318, Fax: +61-3-9544-0183

${ }^{ \pm}$Current address; UCL Cancer Institute, University College London, 72 Huntley Street, London WC1E 6BT, UK. 


\section{Abstract}

Polycystic kidney disease (PKD) results in the formation of renal cysts that can impair function leading to renal failure. DNA damage accumulates in renal epithelial cells in PKD but the molecular mechanisms are unclear and are investigated here. Phosphoinositide 3kinase (PI3K)/AKT signaling activates mammalian target of rapamycin complex 1 (mTORC1) and hyperactivation of mTORC1 is a common event in PKD, however, mTORC1 inhibitors have yielded disappointing results in clinical trials. Here we demonstrate AKT and mTORC1 hyperactivation in two representative murine PKD models (renal epithelial-specific Inpp5e knockout and collecting duct-specific $P k d 1$ deletion) and identify a downstream signaling network that contributes to DNA damage accumulation. Inpp5e- and Pkdl-null renal epithelial cells showed DNA damage including double-stranded DNA breaks associated with increased replication fork numbers, multinucleation and centrosome amplification. mTORC1 activated CAD, which promotes de novo pyrimidine synthesis, to sustain cell proliferation. AKT, but not $\mathrm{mTORC1}$, inhibited the DNA repair/replication fork origin firing regulator TOPBP1, which impacts on DNA damage and cell proliferation. Notably, Inpp5eand $P k d 1$-null renal epithelial cell spheroid formation defects were rescued by AKT inhibition. These data reveal that AKT hyperactivation contributes to DNA damage accumulation in multiple forms of PKD and cooperates with mTORC1 to promote cell proliferation. Hyperactivation of AKT may play a causal role in PKD by regulating DNA damage and cell proliferation, independent of mTORC1, and AKT inhibition may be a novel therapeutic approach for PKD. 


\section{Introduction}

Polycystic kidney disease (PKD), the most common inherited renal disease, is characterized by renal tubule dilations that form cysts which reduce renal function and can cause renal failure. Tolvaptan, the only approved treatment, slows but does not halt or reverse disease progression (1). PKD is most frequently associated with autosomal dominant PKD (ADPKD, OMIM 173900, 613095) and autosomal recessive PKD (ARPKD, OMIM 263200, $617610)$ but is also observed in syndromic ciliopathies. PKD1, encoding Polycystin $1(\sim 85 \%$ of subjects), and PKD2, encoding Polycystin 2, are mutated in ADPKD, whereas PKHD1 (encoding Fibrocystin) and rarely DZIP1L (encoding DAZ interacting protein 1-like) mutations cause ARPKD (2-4). Numerous genes associated with primary cilia are mutated in ciliopathy syndromes including INPP5E, which encodes an inositol polyphosphate 5phosphatase (4-7). Common cyst promoting mechanisms including activation of mTORC1, extracellular signal regulated kinase and receptor tyrosine kinases, metabolic defects and DNA damage have been implicated in all forms of PKD (8).

DNA damage is emerging as a possible disease promoting mechanism in many PKD models (9-17). Cells and kidneys with depletion of the syndromic PKD genes CEP290, NEK8, CEP164 or SDCCAG8 exhibit double-stranded DNA breaks (9-13). ADPKD cells and mouse models also show double-stranded breaks and cytogenetic abnormalities (14-17). PKD gene mutations are hypothesized to impair the cellular response to DNA damage leading to double-stranded break accumulation. Chemical induction of DNA damage also disrupts renal epithelial cell 3D architecture, a model of cystic kidney disease phenotypes $(10,18)$. Therefore, emerging evidence suggests DNA damage in renal epithelial cells impedes the processes required to maintain renal architecture, thereby contributing to cystic disease (10). However, the underlying mechanisms that drive DNA damage in PKD remain unclear. DNA is highly susceptible to damage during S phase as protein-DNA complexes, DNA secondary 
structure or modifications halt replication fork progression $(10,19)$. Stalled replication forks may be repaired by the DNA damage response or collapse into double-stranded breaks (19). Distinct roles in DNA damage prevention or repair have been reported for each ciliopathy gene product examined to date. CEP290 and NEK8 depletion reduced replication fork velocity and induced collapse and asymmetry $(9,10.) \mathrm{S}$ phase progression is slowed in SDCCAG8 knockout cells (11). ZNF423 and CEP164 localize to nuclear foci in response to DNA damage (12). No studies have examined the mechanisms driving DNA damage in ADPKD and the signaling pathways that contribute to DNA damage accumulation in distinct forms of PKD are unclear (14-17).

Following receptor activation, phosphoinositide 3-kinase (PI3K) is activated and generates the membrane bound lipid phosphatidylinositol 3,4,5-trisphosphate $\left(\mathrm{PI}(3,4,5) \mathrm{P}_{3}\right)$ which recruits and activates the serine threonine kinase AKT and its activating kinase PDK1 (20-22). AKT activates many effectors including mTOR, a serine-threonine kinase that forms two distinct signaling complexes, mTORC1 and mTORC2 (22-28). Activated mTORC2 forms a positive feedback loop leading to additional activating phosphorylation of AKT (22, 28, 29). mTORC1 activation of S6K regulates cell growth, metabolism and promotes de novo pyrimidine synthesis $(27,30-32)$. Hyperactivation of mTORC1 is commonly observed in PKD and agents that inhibit mTORC1, such as Rapamycin and Everolimus have shown promising results in animal models of $\operatorname{PKD}(33,34)$ but translation into human clinical use has proved challenging (35-40).

Here, we explored the molecular mechanisms promoting DNA damage accumulation in PKD using murine models of syndromic PKD and ADPKD and identify the serinethreonine kinase AKT as a regulator of DNA damage. Hyperactivation of AKT inhibited DNA repair proteins and increased replication fork numbers leading to DNA damage accumulation. AKT also functions with increased mTORC1 signaling to promote cell 
proliferation. These studies suggest a possible future avenue for treatment of PKD may to be lower the levels of AKT activation by PI3K or AKT inhibitor treatment. 


\section{Results}

DNA damage accumulates in renal epithelial cells in PKD

To examine the molecular mechanisms responsible for DNA damage accumulation in PKD we used representative syndromic and ADPKD murine models. INPP5E is an inositol polyphosphate 5-phosphatase that hydrolyses $\mathrm{PI} 3 \mathrm{~K}$ generated $\mathrm{Ptd} \operatorname{Ins}(3,4,5) \mathrm{P}_{3}$ and suppresses AKT and mTORC1 signaling (41-43). INPP5E mutations cause the ciliopathies MORM (OMIM 610156) and Joubert syndrome (OMIM 213300) which is associated with renal cysts $(5-7,44,45)$. We previously deleted Inpp5e specifically in the renal epithelium by crossing Inpp5e floxed mice (LoxP sites flank exons two to six) with Ksp1.3-Cre (hereafter KspCre) mice to generate $\operatorname{Inpp} 5 e^{f l f l} ;$ KspCre mice, a syndromic PKD model $(43,46)$. The Ksp promoter drives Cre recombinase expression in branching ureteric buds and the collecting duct, loop of Henle and distal tubule epithelium from E11.5 (47, 48). We reported Inpp $5 e^{f l f l} ;$ KspCre mice developed PKD from postnatal day (P)7 with numerous cysts (Figure S1A) and renal failure by P21 (43). Most cysts arose from the collecting duct (Figure S1B) and some from the distal tubule/loop of Henle (43), consistent with other KspCre-induced PKD models (49).

We also utilized $P k d l^{f l f l} ;$ Hoxb7Cre mice, an orthologous ADPKD model. Pkdl encodes Polycystin 1, a transmembrane protein that forms a receptor/ion channel complex with Polycystin 2 (50). Pkd ${ }^{f l f l}$ mice contain LoxP sites flanking exons two to four (51) and Hoxb7Cre is expressed in the epithelium of the embryonic mesonephric duct from E9.5 and its derivatives (collecting ducts, ureter) (52). Consistent with a previous report (53), $P k d l^{f l f l}$;Hoxb7Cre mice exhibited enlarged kidneys and collecting duct-derived cysts by P7 (phenotype at P11 shown in Figure S1C).

Inpp5e- and $P k d 1$-null cystic kidneys were evaluated for evidence of DNA damage. Phosphorylation of histone $\mathrm{H} 2 \mathrm{AX}$ at S193 (known as $\gamma \mathrm{H} 2 \mathrm{AX}$ ) is a marker of double-stranded 
breaks, which signals the DNA damage response machinery to initiate repair (54). Models with depletion of some PKD genes exhibit increased $\gamma \mathrm{H} 2 \mathrm{AX}$ signals (9-13). Double-stranded breaks were assessed in developing (P7) and established (P21) cysts using $\gamma \mathrm{H} 2 \mathrm{AX}$ immunohistochemistry. Inpp $5 e^{f l / f l} ; K s p C r e$ kidneys exhibited an increased proportion of collecting duct cells with $\gamma \mathrm{H} 2 \mathrm{AX}$ nuclear foci compared to controls, suggesting the accumulation of double-stranded DNA breaks (Figure 1A-C). We were unable to assess $\gamma \mathrm{H} 2 \mathrm{AX}$ signals prior to cyst formation at $\mathrm{P} 7$ due to the high proliferation rate of the developing kidney where many cells were $\gamma \mathrm{H} 2 \mathrm{AX}$ immunopositive, however, slower progressing cystic models exhibit DNA damage from early in progression $(9,10)$. As doublestranded breaks can be repaired or accumulate if repair fails (55), we evaluated whether the double-stranded breaks in Inpp $5 e^{f l f l} ; K s p C r e$ cyst lining epithelial cells were associated with multinucleation. The Inpp $5 e^{f l f l} ;$ KspCre cystic epithelium exhibited multinucleated cells in vivo which were not observed in control kidneys (Figure 1D). DNA damage can induce centrosome amplification (56). A cell contains one centrosome following mitosis that is duplicated during $\mathrm{S}$ phase for mitotic spindle formation during the next division (55). Centrosome number was assessed in primary renal epithelial cells (pRECs) isolated from P16 control and Inpp $5 e^{f l f l} ;$ KspCre kidneys by $\gamma$-tubulin immunostaining. The number of Inpp5enull pRECs exhibiting centrosome amplification ( $>2$ centrosomes) was increased compared to controls (Figure 1E and Figure S1D), consistent with other PKD models (9). This analysis was extended to the $P k d 1$-null model which also showed increased $\gamma \mathrm{H} 2 \mathrm{AX}$ positive collecting duct epithelial cells relative to control at P11 (Figure 1F and Figure S1E) and multinucleated cyst lining epithelial cells (Figure 1G).

A recent study using HeLa cells reported INPP5E is required for the spindle assembly checkpoint (SAC) which ensures kinetochores attach to the mitotic spindle before chromosome segregation (57). To determine whether Inpp5e-null pRECs exhibit SAC defects 
(characterized by the formation of multiple small nuclei following mitotic completion in the presence of microtubule perturbation), Inpp5 $e^{f l / f l} ; K s p C r e$ and control pRECs were treated with Nocodozole to destabilize the microtubules and activate the SAC. A functional SAC will arrest cells in prometaphase. The proportion of cells which were multinucleated, arrested prior to mitosis or at the SAC (mitotic arrest) was scored. Very few cells of either genotype escaped the SAC (multinucleated morphology) with no significant difference between genotypes (Figure S1F), indicating SAC insufficiency is unlikely to contribute to DNA damage in Inpp5e-null pRECs. Indeed, the percentage of Inpp5e $e^{f l / f l} ; K s p C r e$ cells exhibiting pre-mitotic arrest was slightly increased and mitotic arrest reduced compared to controls (Figure S1F), suggesting DNA damage in Inpp $5 e^{f l f l} ;$ KspCre cells may occur earlier in the cell cycle than the SAC.

\section{Proliferation and replication forks are increased in PKD models}

DNA is most liable to damage during $\mathrm{S}$ phase (19) and cell proliferation is a key feature of PKD which promotes cyst expansion (58). Inpp $5 e^{f l f l} ;$ KspCre cystic and control kidney sections were immunostained with proliferating cell nuclear antigen (PCNA) antibodies to determine whether Inpp5e-null cystic collecting duct cells are proliferative. At P7 cell proliferation was increased in cystic epithelial but not normal tubules in Inpp $5 e^{f l f l} ;$ KspCre kidneys (Figure 2A). The percentage of PCNA positive collecting duct cells was also increased in established cysts at P21 (Figure 2A). Increased cell proliferation was also observed with Inpp5e deletion as assessed by phosphorylated histone (pHistone) H3 immunostaining in collecting duct cells (Figure S2A). Apoptosis of cyst lining epithelial cells contributes to PKD progression and can be induced by DNA damage (59-61). Inpp $5 e^{f l f l} ;$ KspCre kidneys exhibited few cleaved caspase 3 immunopositive apoptotic cells in 
the collecting duct and interstitium, similar to Inpp $5 e^{+/+} ; \mathrm{KspCre}$ (Figure S2B), indicating DNA damage observed in Inpp5e-null renal epithelia does not induce apoptosis.

DNA damage is most likely during replication, as forks can stall, collapse and form double-stranded breaks $(10,19)$. Therefore, increased replication fork numbers during $\mathrm{S}$ phase increases the probability of a defect and DNA damage accumulation (62). Depletion of several syndromic PKD genes induces replication fork defects $(9,10)$. During G1, potential origins of replication are licensed, however, not all origins fire in S phase and those that do are precisely spatially and temporally regulated (63). A short pulse of the thymidine analogue Bromodeoxyuridine (BrdU) labels $\mathrm{S}$ phase cells at each replication fork where it is incorporated. The mean fluorescence intensity (MFI) of the thymidine analogue signal is proportional to the number of replication forks (62). Inpp $5 e^{+/+} ; K s p C r e$ and Inpp $5 e^{f l f f l} ;$ KspCre pRECs were treated with BrdU for 45 minutes and the BrdU MFI per S phase nucleus measured, revealing increased BrdU MFI per nucleus in Inpp $5 e^{f l f l} ; K s p C r e$ cells (Figure 2B). To directly assess replication fork number, the number of BrdU puncta per $\mathrm{S}$ phase nucleus was scored. Wild type S phase cells exhibit an average of 100 replication fork foci (62), therefore we scored the number of $\mathrm{S}$ phase cells with more or less than $100 \mathrm{BrdU}$ foci, revealing an increased number of Inpp5 $e^{f l f l} ;$ KspCre pRECs with $>100$ BrdU puncta per nucleus compared to controls (Figure S2C). These data are consistent with the presence of more replication forks in Inpp5e-null cells. In Inpp $5 e^{f l f l} ; K s p C r e$ pRECs the percentage of cells with DNA damage ( $\gamma \mathrm{H} 2 \mathrm{AX}$ positive) that were in $\mathrm{S}$ phase (BrdU positive) was increased compared to Inpp $5 e^{+/+} ;$KspCre pRECs (Figure 2B), suggesting DNA damage may be associated with the S phase, similar to other PKD gene depletion models (10).

Cell proliferation and replication forks were also examined in Pkd ${ }^{f l f l}$;Hoxb 7 Cre kidneys. PCNA immunostaining revealed increased collecting duct cell proliferation in $P k d 1^{f l f l}$;Hoxb7Cre kidneys relative to $P k d 1^{f l f l}$ controls at P11 (Figure 2C). The number of 
replications forks per S phase nucleus was also increased with $P k d l$ deletion, evidenced by elevated BrdU MFI in P11 Pkd ${ }^{f l f l}$;Hoxb7Cre pRECs following 45 minute BrdU treatment (Figure 2D). Furthermore, the percentage of DNA damaged cells in S phase was increased with $P k d 1$ deletion, shown by an increased percentage of $\gamma \mathrm{H} 2 \mathrm{AX}$ positive cells that were BrdU positive (Figure 2D). Collectively, these data are consistent with the interpretation that Inpp5e-null and $P k d 1$-null cystic epithelial cells exhibit increased cell proliferation, replication forks and DNA damage.

\section{Hyperactivation of AKT and mTORC1 signaling in PKD}

mTORC1 signaling is almost universally activated in PKD (64), and hyperactivation of one of its regulators, AKT, has been detected in many murine PKD models and human ARPKD kidneys $(33,65-69)$. AKT activates mTORC1 via inhibitory phosphorylation of its negative regulators PRAS40 and the TSC complex (22-26). AKT is activated by T308 and S473 phosphorylation downstream of PI3K signaling (20-22). Notably, in cancer cells and fibroblasts AKT promotes origin firing, inhibits DNA repair at replication forks and cooperates with mTORC1-driven cell proliferation $(62,70-72)$. As we observed DNA damage and increased replication fork numbers in Inpp5e and Pkdl knockout kidneys, we hypothesized AKT hyperactivation may be a common molecular mechanism contributing to DNA damage accumulation in both PKD models. Inpp5e deletion in renal epithelial cells increases PtdIns $(3,4,5) \mathrm{P}_{3}$ levels leading to AKT and mTORC1 hyperactivation (43), however, the mechanisms for mTORC1 activation in Pkdl-null kidneys are less clear.

We characterized the AKT and mTORC1 activation status and downstream signaling networks in the PKD mouse models. We previously reported increased AKT phosphorylation (T308 and S473) and protein expression in P21 Inpp5 $e^{f l f l} ;$ KspCre kidneys (43) and confirmed this observation earlier in disease at P16 via immunoblotting (Figure S3A). Both AKT1 
(S473) and AKT2 (S474) phosphorylation and protein expression were increased in P21 Inpp $5 e^{f l f l} ;$ KspCre kidneys relative to controls (Figure S3B). In addition, phosphorylation of the AKT substrate PRAS40 was increased in P21 Inpp5 $e^{f l f l} ;$ KspCre kidneys (Figure 3A, Figure S3C). Interestingly, pAKT(S473) immunoreactivity was detected in Inpp5e-null cystic epithelial cell nuclei, where it may phosphorylate nuclear targets (Figure 3B). S6K is phosphorylated/activated by mTORC1 $(30,31)$. Phosphorylated and total S6K levels were increased in Inpp5 $5 e^{f l f l} ;$ KspCre kidneys (Figure 3C, Figure S3D). Notably, total AKT and S6K protein expression were elevated in Inpp5e-null kidneys, as observed in other PKD models $(33,66)$. An increase in total and phosphorylated protein kinase levels indicates there is a larger pool of active enzyme to hyperactivate downstream signaling in Inpp 5e-null cystic kidneys.

We also observed increased phosphorylated and total pan-AKT, AKT1 and AKT2 levels (Figure 3D, Figure S4A-B) and hyperactivation of PRAS40 (Figure 3E, Figure S4C) in P11 Pkdl ${ }^{f l f l}$;Hoxb7Cre kidneys compared to controls. Furthermore, phosphorylation and expression of S6K was increased in $P k d l$ knockout kidneys (Figure 3F, Figure S4D), revealing $\mathrm{AKT}$ and $\mathrm{mTORC1}$ hyperactivation, consistent with previous studies of $P k d 1$-null cells $(33,73)$.

\section{AKT-dependent inhibition of DNA repair/origin firing regulators in PKD}

DNA double-stranded breaks occurring at replication forks can be resolved by activation of the DNA damage response and recruitment of repair enzymes. The DNA

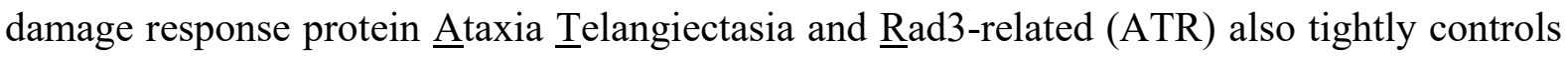
replication fork origin firing in perturbed and unperturbed $S$ phase (74-76). DNA Topoisomerase II Binding Protein 1 (TOPBP1) mediates DNA repair and activates ATR to restrain origin firing and is regulated by $\mathrm{AKT}$, independent of mTORC1 $(70,77)$. AKT 
phosphorylates TOPBP1 at S1159 promoting oligomerization and thereby inhibiting its DNA repair functions, possibly by disrupting chromatin binding $(70,78)$. Consequently, increased AKT activity and its nuclear localization in cystic epithelial cells may increase origin firing and inhibit double-stranded break repair via TOPBP1 inhibition, leading to the accumulation of DNA damage. AKT-dependent TOPBP1 phosphorylation (S1159) was examined in Inpp $5 e^{+/+} ;$KspCre and Inpp5 $e^{f l / f l} ;$ KspCre kidneys, revealing increased pTOPBP1(S1159) immunopositivity in Inpp5 $e^{f l f l} ;$ KspCre epithelial cells in developing (P7) and established (P21) cysts (Figure 4A). Inpp5 $e^{f l f l} ; K s p C r e$ pRECs also exhibited a greater number of pTOPBP1(S1159) positive nuclei relative to control (Figure 4B). Notably, the pan-AKT inhibitor AktX (CAS 925681-41-0) rescued pTOPBP1(S1159) positive Inpp5e $e^{f l f l} ;$ KspCre pREC numbers to control levels (Figure 4B). However, the mTORC1 inhibitor Rapamycin had no effect (Figure 4C) as this inhibitor does not suppress AKT signaling. Furthermore, the pTOPBP1(S1159) distribution in cyst lining epithelial cells was not affected by treating Inpp $5 e^{f l f l} ;$ KspCre mice with the mTORC1 inhibitor Everolimus (Figure 4D), which partially rescued the cystic phenotype and downregulated mTORC1 signaling but not AKT signaling (43). These data are consistent with regulation of TOPBP1 phosphorylation by AKT (70), but not mTORC1.

The percentage of pTOPBP1(S1159) positive $P k d l^{f l f l}$;Hoxb7Cre pREC nuclei was also increased compared to $P k d l^{f l f l}$ control cells (Figure 4E), which was rescued by AKT but not mTORC1 inhibition (Figure S5). pTOPBP1(S1159) immunoreactivity was also enriched in the $P k d 1^{f l f l} ;$ Hoxb7Cre cystic renal epithelium (Figure 4F). Taken together, these data are consistent with AKT-dependent, mTORC1-independent, inhibition of the DNA repair protein/origin firing suppressor TOPBP1 in cystic epithelial cells. 


\section{CAD is hyperactivated downstream of mTORC1 in PKD}

Increased flux through de novo pyrimidine synthesis provides nucleotides required to sustain proliferation in the context of increased replication fork numbers (62). CAD (carbamoylphosphate synthetase (CPS II), aspartate transcarbamoylase, and dihydroorotase activity) catalyzes the first three steps of de novo pyrimidine synthesis. S6K phosphorylates and activates $\mathrm{CAD}(\mathrm{S} 1859)$ downstream of mTORC1 $(28,32)$. Increased mTORC1/S6K activity in the cystic renal epithelium observed here may activate $\mathrm{CAD}$ and thereby promote pyrimidine synthesis to feed into enhanced cell proliferation, although, this has not been reported in PKD. To test for CAD activation, Inpp $5 e^{+/+} ; K s p C r e$ and Inpp $5 e^{f l f l} ; K s p C r e$ kidneys were immunoblotted and immunostained with $\mathrm{pCAD}(\mathrm{S} 1859)$ antibodies. Both $\mathrm{pCAD}(\mathrm{S} 1859)$ and total $\mathrm{CAD}$ protein were increased in Inpp5e-null kidney lysates compared to control (Figure 5A, Figure S6A), indicating there is a larger pool of active CAD available to stimulate pyrimidine synthesis. $\mathrm{pCAD}(\mathrm{S} 1859)$ immunopositive cells were observed in the developing (P7) and established (P21) cystic epithelium (Figure 5B). To determine whether CAD activation in Inpp5 $e^{f l f l} ;$ KspCre kidneys is downstream of mTORC1, pCAD(S1859) levels were assessed in kidney lysates from Inpp $5 e^{f l f l} ;$ KspCre mice treated with vehicle or Everolimus. $\mathrm{pCAD}(\mathrm{S} 1859)$ relative to $\mathrm{GAPDH}$ levels were significantly reduced in Everolimus treated kidneys (Figure 5C, Figure S6B), indicating pharmacological mTORC1 inhibition reduces CAD activation, but protein expression is not significantly affected. Furthermore, both mTORC1 inhibition using Rapamycin and AKT inhibition using the allosteric pan-AKT inhibitor MK2206 reduced CAD phosphorylation in Inpp $5 e^{f l f f} ;$ KspCre pRECs (Figure 5D). Complete loss of CAD phosphorylation was observed with Rapamycin treatment. Immunostaining revealed Everolimus reduced $\mathrm{pCAD}(\mathrm{S} 1859)$ immunopositive cells in the Inpp $5 e^{f l f l} ;$ KspCre cystic epithelium (Figure 5E). 
Pkd1 ${ }^{f l f l}$;Hoxb7Cre kidneys also showed increased pCAD(S1859) and total CAD protein (Figure 5F, Figure $\mathrm{S} 6 \mathrm{C}$ ) and $\mathrm{pCAD}(\mathrm{S} 1859)$ immunopositive cystic epithelial cells (Figure 5G). AKT inhibition reduced and mTORC1 inhibition abolished CAD phosphorylation in $P k d l^{f l f l}$;Hoxb7Cre pRECs relative to vehicle controls (Figure $5 \mathrm{H}$ ).

Collectively these data are consistent with a model that mTORC1 activation of S6K, downstream of $\mathrm{AKT}$, in PKD leads to CAD phosphorylation and activation, which in turn promotes de novo pyrimidine synthesis providing a substrate for DNA replication at increased replication forks, to sustain cell proliferation. Consistent with this hypothesis, both AKT (using MK2206) and mTORC1 (using Rapamycin) inhibition reduced Inpp $5 e^{f l f l} ;$ KspCre and $P k d 1^{f l f l} ;$ Hoxb 7 Cre $\mathrm{pREC}$ proliferation as measured by the percentage of pHistone $\mathrm{H} 3$ and BrdU positive cells as a read out for cells in $\mathrm{G} 2 / \mathrm{M}$ and $\mathrm{S}$ phases respectively (Figure S7).

\section{AKT inhibition rescues renal epithelial cell spheroid formation and DNA damage accumulation}

mTORC1 inhibitors have been ineffective in PKD clinical trials, possibly due to trial design issues, outcome measures, high dropout rates due to toxicity and/or complex changes in the signaling network(s) in the treated kidneys (35-40). mTORC1 signaling feeds back to inhibit AKT, therefore mTORC1 inhibition often results in further AKT hyperactivation (see model Figure 7) $(79,80)$. Indeed, a recent study showed dual PI3K/mTORC1 blockage was more effective than mTORC1 inhibition in an ADPKD model (69). Everolimus treated Inpp $5 e^{f l f l} ;$ KspCre kidneys exhibited increased pAKT compared to controls, which may have contributed to the partial phenotypic rescue (43). The signaling network identified here in PKD suggests AKT is a central mediator that contributes to DNA damage accumulation, increased replication fork numbers and inhibits repair. Therefore, AKT inhibition may be 
more effective at suppressing cyst progression than mTORC1 inhibitors. To directly test the effect of AKT versus mTORC1 on DNA damage accumulation, Inpp $5 e^{\text {flflf }} ;$ KspCre and Pkd1 $1^{\text {flfl }}$;Hoxb7Cre pRECs were treated with AKT and mTORC1 inhibitors and the proportion of $\gamma \mathrm{H} 2 \mathrm{AX}$ immunopositive cells scored. Notably, the AKT inhibitor MK2206 reduced the number of $\gamma \mathrm{H} 2 \mathrm{AX}$ positive pRECs in both models (Figure 6A-B), whereas Rapamycin mediated mTORC1 inhibition had no effect (Figure 6A-B), supporting the interpretation the AKT plays a role in DNA damage in PKD.

Renal epithelial cell 3D spheroid formation is a well-characterized assay for renal architecture, as cells assemble into polarized structures with hollow lumens that model renal tubule formation. The spheroid model is more amenable than in vivo systems to genetic and/or pharmacological manipulation (81). Spheroid formation is an established model for cystic kidney disease as depletion of PKD-causing genes, including multiple genes linked to DNA damage, and the chemical induction of DNA damage disrupt renal epithelial cell spheroid architecture $(9,10,18)$. P16 Inpp5 $e^{f l f l} ; K s p C r e$ and P11 Pkd1 $1^{f l f l}$;Hoxb7Cre pREC spheroid morphology was assessed in the presence or absence of MK2206 In 3D pREC spheroid cultures from controls, $30-35 \%$ of structures exhibited a hollow lumen surrounded by a single layer of epithelial cells (Figure 6C-D). In contrast, only $\sim 10 \%$ of Inpp $5 e^{f l f l} ;$ KspCre and Pkd1 flflf $;$ Hoxb7Cre pREC spheroids exhibited a hollow lumen and many structures were solid balls of cells with an actin rich core (Figure 6C-D). Spheroids of all genotypes were variable in size, cell number and cell morphology (Figure 6C-D). Notably, MK2206 treatment increased the percentage of Inpp5e $e^{\text {fllfl }}$;KspCre and Pkd1 flffl $;$ Hoxb 7 Cre spheroids exhibiting the characteristic hollow lumen morphology to levels similar to controls (Figure 6C-D), suggesting AKT hyperactivation may contribute to cyst progression, and in vitro AKT inhibition can revert $3 \mathrm{D}$ renal epithelial architecture. It remains unclear and appears unlikely that AKT inhibition in this experimental model directly resolves structural 
DNA damage within an individual cell, rather AKT inhibition may select for the incorporation of genomically unperturbed cells into spheroids. This proposed model is reminiscent of the effect of AKT and ROCK inhibition in constitutively active PI3K $\alpha$ mutant tumor cells, whereby the proportion of cells with centrosome amplification was rescued via unknown mechanisms (82). Furthermore, cyclin dependent kinase inhibitor treatment rescued centrosome amplification in Cep290 gene trap renal cells, a PKD model (9). 


\section{Discussion}

DNA damage is emerging as a common event in PKD that may contribute to cyst progression by disrupting the processes that maintain 3D renal architecture (9-17). However, the molecular events that lead to DNA damage accumulation in PKD are unclear (9). Here, using syndromic PKD and ADPKD models we demonstrate AKT and mTORC1 signaling are increased in both forms of PKD, consistent with previous studies $(33,43,64-69)$, and identify the downstream signaling network that contributes to DNA damage. Enhanced AKT signaling, independent of mTORC1, inhibited TOPBP1 a key regulator of DNA repair and suppressor of replication fork origin firing, which in turn impacted on DNA damage and increased cell proliferation (proposed model Figure 7). mTORC1-dependent hyperactivation of the pyrimidine synthesis enzyme CAD also contributed to increased cell proliferation (proposed model Figure 7). Notably AKT inhibition rescued Inpp5e-null and Pkd1-null spheroid formation defects, suggesting it may be a possible therapeutic option for PKD. These studies reveal enhanced AKT signaling independent of mTORC1 plays a significant role in PKD.

We and others have shown PI3K/AKT pathway hyperactivation in PKD models (33, 43, 64-69) and dominant active PI3K $\alpha$ induces renal cysts in mice (83). Therefore, we explored whether AKT hyperactivation contributes to DNA damage accumulation and proliferation in PKD and confirmed Inpp $5 e^{f l f l} ;$ KspCre and Pkd ${ }^{f l / f l} ;$ Hoxb7Cre kidneys exhibit increased AKT signaling (both AKT1 and AKT2), including increased nuclear pAKT(S473) in Inpp $5 e^{f l f l} ;$ KspCre kidneys. The mechanism for AKT activation in Inpp5e-null cells is well defined (43), and although it is less clear in Pkd1-null cells this may relate to increased secreted growth factors in the cystic environment (84-86). DNA damage is most likely to occur at replication forks as they can stall and collapse into double-stranded breaks (19). AKT phosphorylates and inhibits TOPBP1 and CHK1, key regulators of origin firing and 
double-stranded break repair $(70-72,77,87)$. TOPBP1 activates ATR to inhibit origin firing and thereby limits replication fork numbers (77). Renal epithelial cells from both PKD models here showed increased inhibitory TOPBP1 phosphorylation, that was rescued by AKT but not mTORC1 inhibition. Increased replication fork numbers per S phase nucleus were observed in Inpp5 $e^{f l / f l} ; K s p C r e$ and $P k d I^{f l f l} ;$ Hoxb7Cre pRECs compared to controls. Furthermore, in both models the DNA damage was associated with S phase and was rescued by AKT inhibition. Previous reports showed DNA damage in CEP290 and NEK8 depleted cells also occurs at replication forks $(9,10)$. Therefore, we propose TOPBP1 inhibition by AKT increases replication forks, the site at which DNA is most susceptible to damage, and prevents repair of double-stranded breaks, collectively promoting DNA damage accumulation (proposed model Figure 7). It is possible that phosphorylation/inhibition of CHK1 at S280 by AKT $(71,72)$ also contributes to increased origin firing and impaired DNA repair in PKD, however, the lack of specific pCHK1(S280) antibodies precludes this analysis. In addition, we cannot exclude the possibility that other yet to be identified AKT effectors also contribute to DNA damage accumulation. Interestingly, some evidence suggests the DNA damage response kinases ATR, ATM and DNA-PK phosphorylate AKT in the context of DNA damage (88-90), however, it is not clearly established whether AKT can be activated in a $\mathrm{PI} 3 \mathrm{~K} / \mathrm{PI}(3,4,5) \mathrm{P}_{3}$-independent manner (22).

mTORC1 signaling through $\mathrm{S} 6 \mathrm{~K}$ activates $\mathrm{CAD}$ to stimulate de novo pyrimidine synthesis (32). In our study, Inpp $5 e^{f l f f l} ;$ KspCre and Pkd1 $1^{f l f l}$;Hoxb7Cre cystic kidneys exhibited increased $\mathrm{S} 6 \mathrm{~K}$ and $\mathrm{CAD}$ phosphorylation and expression. Increased $\mathrm{CAD}$ phosphorylation was mTORC1-dependent in both models. The increased production of nucleotides from de novo pyrimidine synthesis coupled with increased replication fork numbers may support rapid cystic epithelial cell proliferation, which is known to contribute 
to cyst expansion in PKD (58) (proposed model Figure 7). Indeed, AKT and mTORC1 inhibition reduced Inpp $5 e^{f l / f l} ;$ KspCre and $P k d I^{f l f l} ;$ Hoxb7Cre pREC proliferation.

We propose AKT inhibition may rescue effects mediated directly by hyperactive AKT signaling and downstream via mTORC1 to reduce DNA damage, promote repair and inhibit cell proliferation and may therefore be a more effective approach compared to mTORC1 inhibitors which have shown limited efficacy in PKD trials (35-40). We tested this hypothesis in a proof of principle experiment, revealing AKT inhibition rescues Inpp5e-null and Pkdl-null spheroid morphology, possibly via rescue of DNA damage or via selective pressure that promotes the incorporation of non-damaged cells into spheroids. However, we cannot exclude the possibility that inhibition of other AKT effectors also modulates spheroid architecture. Identifying the optimal timing of AKT inhibition during disease progression may be essential, as downregulating AKT may repair double-stranded breaks, and has been shown to rescue the proportion of cells with centrosome amplification within a population (82), but this is unlikely to rescue multinucleation or centrosome amplification in an individual cell. Furthermore, the need to treat for long time periods will require careful assessment of safety. However, AKT inhibitors have been well tolerated in solid tumor clinical trials $(91,92)$.

In summary, our data are consistent with the contention that activation of AKT inhibits DNA repair and enhances replication fork numbers leading to DNA damage accumulation and cooperates with mTORC1 signaling to promote cell proliferation in PKD. This signaling network is activated in both murine syndromic PKD and ADPKD models, consistent with a common mechanism for the accumulation of DNA damage. These results may help to explain why mTORC1 inhibitors have been ineffective in PKD and suggest AKT as a novel therapeutic target. 


\section{Materials and Methods}

\section{Antibodies and reagents}

Antibodies and organelle stains were: actin (IB: 1:5000, \#MS-1295) from Thermo Fisher Scientific (Waltham, Massachusetts, USA), pAKT(S473) (immunoblot (IB) 1:1000, 4058), pAKT(T308) (IB 1:1000, 2965), AKT (IB 1:1000, 4685), pAKT1(S473) (IB: 1:1000, 9018), AKT1 (IB: 1:1000, 2967), pAKT2(S474) (IB: 1:1000, 8599), AKT2 (IB: 1:1000, 5239), $\mathrm{pCAD}(\mathrm{S} 1859)$ (IB 1:1000, immunohistochemistry-paraffin IHC-P 1:100, 12662), CAD (IB 1:1000, 11933), cleaved caspase 3 (IHC-P 1:300, 9664), pHistone H3 (IHC-P 1:200, IF: 1:1600, 3377), PCNA (IHC-P 1:4000, 2568), pPRAS40(T246) (IB: 1:1000, 2997), PRAS40 (IB: 1:1000, 2691), pS6K (IB: 1:1000, 9234), S6K (IB: 1:1000, 9202), pS6(S235/236) (IB: 1:1000, 4851), S6 (IB: 1:1000, 2217) and $\gamma H 2 A X$ (IHC-P 1:800, IF 1:200, 1:800, 2577) from Cell Signaling Technologies (Danvers, Massachusetts, USA), $\gamma$ tubulin (IF 1:00, ab11316) from Abcam (Cambridge, Massachusetts, USA), pAKT(S473) (IHC-P 1:500, 700392) and GAPDH (IB 1:50,000, AM4300) from Life Technologies (Carlsbad, California, USA) and pTOPBP1(S1159) (IF 1:400, AP3774a) from Abgent (San Diego, California, USA). Alexa-Fluor-488/555-conjugated mouse and rabbit secondary antibodies (IHC-P 1:400/1:800, IF 1:600) and Alexa-Fluor-488 Phalloidin (1:500) were from Life Technologies. HRP-conjugated mouse and rabbit secondary antibodies (IB 1:10,000) were from GE Healthcare (Chicago, Illinois, USA) and Millipore (Burlington, Massachusetts, USA). Fluorescein conjugated DBA (IHC-P 1:250, FL-1031) was from Vector Laboratories (Burlingame, California, USA). All other reagents were from Sigma-Aldrich (St. Louis, Missouri, USA) unless specified. 


\section{Mouse strains}

Monash University, Monash Animal Research platform animal ethics committee approved procedures using mice. We generated and previously described

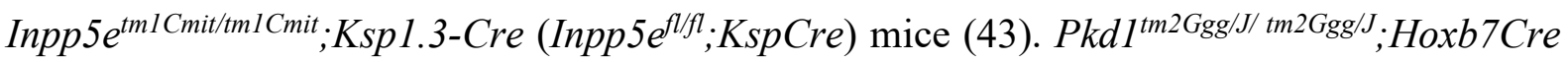
$\left(P k d 1^{f l f l} ; H o x b 7 C r e\right)$ mice were obtained from Professor Ian Smyth. Pkd1 ${ }^{\text {tm2 } 2 G g g / J /}$ (JAX \#010671) were previously reported (51). All mouse stains used were on the C57BL/6 background.

Genotyping was performed using PCR analysis of genomic DNA with the following primers: For Inpp5e $e^{f l f l} ;$ KspCre mice, Inpp5e Fl WT 5': GAGAAGCTGATAGATGGCTAGG, Inpp5e $\mathrm{Fl}$ WT AACCAGAAGACCTCATCAAACC, Ksp1.3-Cre 5' AGGTTCGTTCACTCATGGA, Ksp1.3-Cre 3' TCGACCAGTTTAGTTACCC, for Pkd fllfl; Hoxb7Cre mice, Pkdl 5': CCT GCC TTG CTC TAC TTT CC, Pkd1 3': AGG GCT TTT CTT GCT GGT CT, Global Cre 5': GCG GTC TGG CAG TAA AAA CTA TC, Global Cre 3': GTG AAA CAG CAT TGC TGT CAC TT, Internal Control (Cre) 5': CTA GGC CAC AGA ATT GAA AGA TCT, Internal Control (Cre) 3': GTA GGT GGA AAT TCT AGC ATC ATC C.

For Everolimus treatment male Inpp $5 e^{f l f l} ; K s p C r e$ mice used. Mice were treated orally from P8 to P20 with daily $4 \mathrm{mg} / \mathrm{kg}$ Everolimus (Novartis, Basel, Switzerland) or vehicle and killed at P21 for analysis (43). During the treatment period mice were monitored three times per day according to Monash University animal ethics guidelines.

\section{Isolation and culture of primary renal epithelial cells}

pRECs were isolated as described previously (93). Briefly, P11 (Pkdl $1^{f l f l}$ and

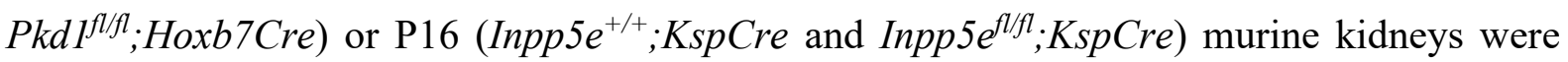
placed in $4^{\circ} \mathrm{C}$ PBS with $0.1 \%$ (w/v) streptomycin and 100 units $/ \mathrm{ml}$ penicillin (Sigma-Aldrich, 
P4458) and the capsule and ureter removed. The kidney was minced with a scalpel and digested using $0.2 \%$ collagenase A (Sigma-Aldrich, 10103578001) in PBS for 30 minutes at $37^{\circ} \mathrm{C}$ with agitation. Horse serum was added to the cell preparation and samples were vortexed. The tissues was allowed to settle and the supernatant containing isolated cells were centrifuged for 7 minutes at $200 \mathrm{~g}$. Cells were washed with PBS and centrifuged at $200 \mathrm{~g}$ for 7 minutes. Finally, cells were resuspended in pREC media (DMEM/F12 (Life Technologies, 11330) containing ITS-X (Life Technologies, 51500-056), 1.3 ng/ml T3 (Sigma-Aldrich; T5516), $0.04 \mu \mathrm{g} / \mathrm{ml}$ hydrocortisone (Sigma-Aldrich, H0888), $0.02 \mu \mathrm{g} / \mathrm{ml}$ epidermal growth factor (Life Technologies, PMG8044), 1:200 dilution of nystatin suspension (Sigma-Aldrich, N1638), 0.1\% (w/v) streptomycin and 100 units/ml penicillin and $1 \mathrm{mM}$ L-glutamine (SigmaAldrich; 59202C)) and plated on $10 \mu \mathrm{g} / \mathrm{ml}$ collagen (Sigma) coated dishes. For experiments pRECs were seeded onto $1 \mathrm{mg} / \mathrm{ml}$ ECL Cell Attachment Matrix (Millipore) coated cover slips or collagen coated dishes or chamber slides.

BrdU labelling was performed to detect replication forks in $\mathrm{S}$ phase and cell proliferation pRECs using the 5-Bromo-2'-deoxy-uridine Labeling and Detection Kit I (Roche, Basel, Switzerland). Cells were grown in pREC media for 24 or 60 hours +/inhibitors as appropriate and then treated with BrdU for 45 minutes. Cells were then fixed and stained as per the manufacturer's instructions with counter staining for nuclei using DAPI and double-stranded breaks using $\gamma \mathrm{H} 2 \mathrm{AX}$ antibodies.

For AKT and mTORC1 inhibitor studies in 2D culture, pRECs were cultured for 36 hours and treated with $5 \mu \mathrm{M}$ AktX (CAS 925681-41-0, Merck, Darmstadt, Germany), 0.1 $\mu \mathrm{M}, 0.5 \mu \mathrm{M}$ or $1 \mu \mathrm{M}$ MK2206 (Seleckchem, Houston, Texas, USA), $100 \mathrm{nM}$ Rapamycin (Sigma-Aldrich) or vehicle for 24 hours prior to fixation for immunofluorescence. Alternatively, pRECs were cultured overnight and treated with $100 \mathrm{nM}$ Rapamycin (SigmaAldrich) or $1 \mu \mathrm{M}$ MK2206 for 24 hours followed by lysis for immunoblotting. 
For pRECs spheroid formation 10,000 cells were mixed with growth-factor reduced Matrigel (Corning 356231, Corning, New York, USA,) in a 1:1 ratio and plated in 8 well changer-slides. Once the Matrigel polymerized at $37^{\circ} \mathrm{C}$ for $15-30$ minutes, $200 \mu 1$ of pRECs media was added and cells were incubated at $37^{\circ} \mathrm{C}$ for 24 hours. Media was replaced with serum free DMEM/F12 containing $10 \mu \mathrm{M}$ MK2206 or vehicle and cells were cultured for a further 6 days to form spheroids with cleared lumens.

To assess the integrity of the SAC pRECs were cultured for 12 hours and then treated with $400 \mathrm{ng} / \mathrm{ml}$ Nocodozole (Sigma-Aldrich) for 8 hours to disrupt the spindle microtubules and activate the SAC. Cells were fixed with $4 \%$ paraformaldehyde for 20 minutes and stained with DAPI.

\section{Fluorescent staining pRECs}

pRECs were fixed in 4\% paraformaldehyde for 15-20 minutes and permeabilized with $0.1 \%$ Triton $\mathrm{X}-100$ for 90 seconds. Cells were blocked in $1 \%$ bovine serum albumin (BSA) for 30 minutes. The primary antibodies were diluted in 1\% BSA and applied to the cells for 1 hour at room temperature. Cells were washed and incubated with Alexa Fluor conjugated secondary antibodies and DAPI in $1 \%$ BSA at room temperature for 45 minutes- 1 hour, followed by washing. Cells were then either mounted using Fluoromount G (Electron Microscopy Science, Hatfield, Pennsylvania, USA) or left unmounted and stored in PBS containing $\mathrm{NaN}_{3}$.

pREC spheroids were fixed with $2 \%$ paraformaldehyde at room temperature for 20 minutes and permeabilized with $0.5 \%$ Triton $\mathrm{X}-100$ for 10 minutes, prior to rinsing in PBS with $100 \mathrm{mM}$ glycine three times for 10 minutes. Spheroids were blocked in IF buffer (130 $\mathrm{mM} \mathrm{NaCl}, 7 \mathrm{mM} \mathrm{Na} 2 \mathrm{HPO}_{4}, 3.5 \mathrm{mM} \mathrm{NaH}_{2} \mathrm{PO}_{4}, 7.7 \mathrm{mM} \mathrm{NaN}_{3}, 0.1 \%$ BSA, 0.2\% Triton X$100,0.05 \%$ Tween-20) with $10 \%$ goat serum and $20 \mu \mathrm{g} / \mathrm{ml}$ goat anti-mouse $\mathrm{F}(\mathrm{ab}$ ') fragment 
for 2 hours at room temperature prior to staining with Phalloidin and DAPI in IF buffer with $10 \%$ goat serum for 40 minutes at room temperature. Following three 20 minute washes in IF buffer, spheroids were washed once in PBS for 5 minutes and mounted with Fluoromount G.

\section{Histology and Immunohistochemistry}

For histology, formalin fixed, paraffin embedded (FFPE) kidneys were sectioned in the coronal plane, dewaxed and stained with hematoxylin and eosin (H\&E).

IHC (fluorescence) was performed on dewaxed FFPE kidney sections. Heat-induced antigen retrieval was performed in $10 \mathrm{mM}$ citrate buffer $\mathrm{pH} 6$ using a pressure cooker for 5 minutes. The sections were blocked for 1 hour with PBS containing 5\% goat serum and $0.3 \%$ Triton X-100. Sections were incubated with primary antibodies diluted in SignalStain antibody diluent (Cell Signaling Technology) overnight at $4{ }^{\circ} \mathrm{C}$, followed by Alexa Fluor conjugated secondary antibodies and DAPI diluted in PBS with $5 \%$ goat serum and $0.3 \%$ Triton X-100 for 1 hour at room temperature. Following washing, slides were mounted using Fluormount G.

IHC (DAB) was performed using dewaxed FFPE kidney sections via antigen retrieval in $10 \mathrm{mM}$ sodium citrate $(\mathrm{pH}$ 6) (for $\mathrm{pCAD}(\mathrm{S} 1859)$ ) or epitope retrieval solution $(\mathrm{pH} 9)$ (Leica, Wetzlar, Germany) (for pTOPBP1(S1159)) using a pressure cooker for $5 \mathrm{~min}$. A 10 minute $3 \%$ hydrogen peroxide incubation was used to block endogenous peroxidase activity, then the sections were blocked for 1 hour at room temperature with $20 \mathrm{mM}$ Tris- $\mathrm{HCl}, 137$ $\mathrm{mM} \mathrm{NaCl}, 0.1 \%$ Tween-20(TBST)/5\% normal goat serum. The primary antibodies were diluted in SignalStain antibody diluent and incubated at $4{ }^{\circ} \mathrm{C}$ overnight. Secondary antibodies were SignalStain Boost Detection Reagent (Cell Signaling Technology) which was incubated for 30 minutes at room temperature. Staining was then developed with the EnVision SystemHRP (DAB) kit (Dako, Agilent, Santa Clara, California, USA; K4011). Hematoxylin was 
used to counter stain nuclei and sections were dehydrated and mounted using DPX (Labchem, Zelienople, Pennsylvania, USA). pAKT(S473) IHC was performed as we described previously (43).

\section{Microscopy}

Microscopy was performed at Monash Micro Imaging, Monash University. Confocal microscopy was performed using a Leica TCS SP8 microscope with a 63x HC PL APO CS2 (11506350) 1.4 NA oil, 40x HC PL APO CS2 1.10 water objective lens and 20x/0.75 IMM CORR HC PL APO CS2 (506343) HyD detector and Leica LAS X acquisition software, Leica TCS inverted SP5 microscope with a HCX PL APO lambda blue 63.0x1.40 oil objective lens and Leica LAS X acquisition software or a Nikon (Tokyo, Japan) C1 microscope with 60x PlanApo VC DICN2 1.4 NA objective lens, PMT detector, 450/35, 515/30, 605/75 filters or 20x/0.75 MImm Plan Fluor DIC N2 and NIS-Elements acquisition software. Brightfield microscopy was performed using an Olympus (Tokyo, Japan) Provis microscope with 20x UPlanApo 0.8 NA, 40x uPlanApo 1.0 NA, 60x PlanApo 1.4 NA or 100x UPlanApo 1.35 NA objective lenses, DP70 camera and cellSens acquisition software. Widefield fluorescence microscopy was performed using an Olympus dotSlide microscope with 10x UPlanSApo UIS 20.40 NA objective, XC10 camera and VS-ASW-FL acquisition software. Image processing was performed using Image J software (National Institutes of Health, Rockville, Maryland, USA) and was limited to alterations of brightness, subjected to the entire image.

\section{Image analysis}

The percentage of $\gamma \mathrm{H} 2 \mathrm{AX}$, PCNA or pHistone H3-positive collecting duct cells was scored in kidney sections immunostained with the appropriate antibodies and counter stained 
with DBA and DAPI. For each candidate, samples were imaged at the same laser intensity and analyzed using the cell counter tool in ImageJ.

The percentage of pRECs exhibiting centrosome amplification ( $>2$ centrosomes) or immunopositive for $\mathrm{pTOPBP} 1, \gamma \mathrm{H} 2 \mathrm{AX}$, BrdU or pHistone $\mathrm{H} 3$ was scored relative to total nuclei number per field in fixed cells immunostained with the relevant antibodies and DAPI. Cells were imaged at the same laser intensity for each candidate and analyzed using the Image J cell counter tool.

To score the percentage of $\gamma \mathrm{H} 2 \mathrm{AX}$ positive cells which are BrdU positive, pRECs were pulsed with BrdU, immunostained with $\gamma \mathrm{H} 2 \mathrm{AX}$ and $\mathrm{BrdU}$ antibodies, counter stained with DAPI and imaged at the same laser intensity. The number of $\mathrm{BrdU} / \gamma \mathrm{H} 2 \mathrm{AX}$ double positive cells out of the total number of $\gamma \mathrm{H} 2 \mathrm{AX}$ positive cells was scored using the Image $\mathrm{J}$ cell counter tool. The BrdU MFI per nucleus was measured in cells prepared as described above using Image J. BrdU positive cells were identified and the nucleus of these cells defined as the region of interest. The BrdU MFI was measured within the region of interest. To score the number of BrdU puncta per S phase nucleus using ImageJ a region of interest containing the nucleus was defined and a common threshold applied to all images. The analyze particles tool was used to count the number of puncta greater than $0.01 \mu \mathrm{m}$ in each nucleus.

To assess the integrity of the SAC, pRECs were treated with Nocodozole and stained with DAPI. The percentage of nuclei exhibiting the characteristic morphology of pre-mitotic arrest, mitotic arrest or multinucleation was scored out of the total nuclei number per field using the Image J cell counter tool.

Spheroid morphology was scored in cultures stained with Phalloidin and DAPI. All structures containing 3 or more cells were counted and the number of spheroids exhibiting an 
open lumen was calculated as a percentage of the total number of spheroids with 3 or more cells.

\section{SDS-PAGE and Immunoblotting}

For immunoblotting kidney lysates, dissected kidneys were snap frozen in liquid nitrogen and RIPA buffer (50 mM HEPES pH 7.4, $150 \mathrm{mM} \mathrm{NaCl}, 10 \%$ glycerol, $1.5 \mathrm{mM}$ $\mathrm{MgCl}_{2}, 1 \mathrm{mM}$ EGTA, $1 \mathrm{mM} \mathrm{Na} \mathrm{VO}_{4}, 1 \%$ volume/volume (v/v) Triton $\mathrm{X}-100,1 \%$ weight/volume (w/v) sodium deoxycholate, $0.1 \%(\mathrm{w} / \mathrm{v})$ sodium dodecyl sulphate (SDS), 100 $\mathrm{mM} \mathrm{NaF})$ or radioimmunoprecipitation buffer $(20 \mathrm{mM}$ Tris- $\mathrm{HCl}, 150 \mathrm{mM} \mathrm{NaCl}, 1 \mathrm{mM}$ EDTA, $1 \mathrm{mM} \mathrm{Na} 2 \mathrm{VO}_{4}, 50 \mathrm{mM} \mathrm{NaF}, 1 \%$ Triton X-100, 0.5\% deoxycholate, $0.1 \%$ SDS, 100 nM calyculin A, protease inhibitor tablet (Roche;11836153001)) soluble lysates extracted. pREC lysates were prepared by direct lysis in reducing buffer $(62.5 \mathrm{mM}$ Tris-HCl $\mathrm{pH}$ 6.8, 2\% SDS, $10 \%$ glycerol, $50 \mathrm{mM}$ DTT, $0.01 \%$ bromophenol blue). Sodium dodecyl sulfate polyacrylamide gel electrophoresis was used to separate lysates which were transferred to polyvinylidene fluoride (EMD Millipore Corporation, Burlington, Massachusetts, USA) or nitrocellulose (Pall Scientific, Port Washington, New York, USA) membranes for immunoblotting. Densitometry was performed to quantify relative protein levels (ImageQuant software, GE Healthcare).

\section{Statistical Analysis}

GraphPad Prism 7 (San Diego, California, USA) was used for statistical analysis. Graphs represent mean \pm SEM. Differences between groups were considered statistically significant when $p<0.05$. Unless indicated in the figure legend $p$ values were calculated using a two tailed unpaired Student's $t$ test with or without Welch's correction for unequal variance as appropriate (difference in sample variance assessed by the $\mathrm{F}$ test). For multiple 
comparisons one-way or two-way ANOVAs followed by Tukey's post hoc test were used as indicated in the figure legends (difference in sample variance assessed by the BrownForsythe test). The sample size is listed in the figures and figure legends for all experiments.

The sample size selected was based on our and others previous studies $(43,94,95)$. Samples and mice were not excluded from the analysis. Mice were allocated to groups based on their genotype and randomly allocated to each experiment. Investigators were blind to genotype for all image analysis. 


\section{Acknowledgements}

This study utilized Monash Micro Imaging, Monash University, Victoria, Australia and Monash Histology Platform, Department of Anatomy and Developmental Biology, Monash University, Victoria, Australia. This work was supported by the National Health and Medical Research Council (grant number APP1046174).

\section{Conflict of interest statement}

The authors declare no conflict of interest. 


\section{References}

1 Torres,V.E., Chapman,A.B., Devuyst,O., Gansevoort,R.T., Perrone,R.D., Koch,G., Ouyang,J., McQuade,R.D., Blais,J.D., Czerwiec,F.S. et al. (2017) Tolvaptan in Later-Stage Autosomal Dominant Polycystic Kidney Disease. N. Engl. J. Med., 377, 1930-1942.

2 Grantham,J.J. (2008) Clinical practice. Autosomal dominant polycystic kidney disease. N. Engl. J. Med., 359, 1477-1485.

3 Lu,H., Galeano,M.C.R., Ott,E., Kaeslin,G., Kausalya,P.J., Kramer,C., OrtizBruchle,N., Hilger,N., Metzis,V., Hiersche,M. et al. (2017) Mutations in DZIP1L, which encodes a ciliary-transition-zone protein, cause autosomal recessive polycystic kidney disease. Nat. Genet., 49, 1025-1034.

4 Harris,P.C. and Torres,V.E. (2009) Polycystic kidney disease. Annu. Rev. Med., 60, 321-337.

5 Jacoby,M., Cox,J.J., Gayral,S., Hampshire,D.J., Ayub,M., Blockmans,M., Pernot,E., Kisseleva,M.V., Compere,P., Schiffmann,S.N. et al. (2009) INPP5E mutations cause primary cilium signaling defects, ciliary instability and ciliopathies in human and mouse. Nat. Genet., 41, 1027-1031.

6 Sonmez,F., Guzunler-Sen,M., Yilmaz,D., Comertpay,G., Heise,M., Cirak,S. and Uyanik,G. (2014) Development of end-stage renal disease at a young age in two cases with Joubert syndrome. Turk. J. Pediatr., 56, 458-461.

7 Hardee,I., Soldatos,A., Davids,M., Vilboux,T., Toro,C., David,K.L., Ferreira,C.R., Nehrebecky,M., Snow,J., Thurm,A. et al. (2017) Defective ciliogenesis in INPP5E-related Joubert syndrome. Am. J. Med. Genet. A, 173, 3231-3237.

8 Seeger-Nukpezah,T., Geynisman,D.M., Nikonova,A.S., Benzing,T. and Golemis,E.A. (2015) The hallmarks of cancer: relevance to the pathogenesis of polycystic kidney disease. Nat. Rev. Nephrol., 11, 515-534.

9 Slaats,G.G., Saldivar,J.C., Bacal,J., Zeman,M.K., Kile,A.C., Hynes,A.M., Srivastava,S., Nazmutdinova,J., den Ouden,K., Zagers,M.S. et al. (2015) DNA replication stress underlies renal phenotypes in CEP290-associated Joubert syndrome. J. Clin. Invest., 125, 3657-3666.

10 Choi,H.J., Lin,J.R., Vannier,J.B., Slaats,G.G., Kile,A.C., $\quad$ Paulsen,R.D., Manning,D.K., Beier,D.R., Giles,R.H., Boulton,S.J. et al. (2013) NEK8 links the ATRregulated replication stress response and $\mathrm{S}$ phase CDK activity to renal ciliopathies. Mol. Cell, 51, 423-439.

11 Airik,R., Slaats,G.G., Guo,Z., Weiss,A.C., Khan,N., Ghosh,A., Hurd,T.W., BekkerJensen,S., Schroder,J.M., Elledge,S.J. et al. (2014) Renal-retinal ciliopathy gene Sdccag8 regulates DNA damage response signaling. J. Am. Soc. Nephrol., 25, 2573-2583.

12 Chaki,M., Airik,R., Ghosh,A.K., Giles,R.H., Chen,R., Slaats,G.G., Wang,H., Hurd,T.W., Zhou,W., Cluckey,A. et al. (2012) Exome capture reveals ZNF423 and CEP164 mutations, linking renal ciliopathies to DNA damage response signaling. Cell, 150, 533-548.

13 Grampa,V., Delous,M., Zaidan,M., Odye,G., Thomas,S., Elkhartoufi,N., Filhol,E., Niel,O., Silbermann,F., Lebreton,C. et al. (2016) Novel NEK8 Mutations Cause Severe Syndromic Renal Cystic Dysplasia through YAP Dysregulation. PLoS Genet., 12, e1005894.

14 Gogusev,J., Murakami,I., Doussau,M., Telvi,L., Stojkoski,A., Lesavre,P. and Droz,D. (2003) Molecular cytogenetic aberrations in autosomal dominant polycystic kidney disease tissue. J. Am. Soc. Nephrol., 14, 359-366.

15 AbouAlaiwi,W.A., Ratnam,S., Booth,R.L., Shah,J.V. and Nauli,S.M. (2011) Endothelial cells from humans and mice with polycystic kidney disease are characterized by polyploidy and chromosome segregation defects through survivin down-regulation. Hum Mol Genet., 20, 354-367. 
16 Li,M., Qin,S., Wang,L. and Zhou,J. (2013) Genomic instability in patients with autosomal-dominant polycystic kidney disease. J. Int. Med. Res., 41, 169-175.

17 Aboualaiwi,W.A., Muntean,B.S., Ratnam,S., Joe,B., Liu,L., Booth,R.L., Rodriguez,I., Herbert,B.S., Bacallao,R.L., Fruttiger,M. et al. (2014) Survivin-induced abnormal ploidy contributes to cystic kidney and aneurysm formation. Circulation, 129, 660-672.

18 Sang,L., Miller,J.J., Corbit,K.C., Giles,R.H., Brauer,M.J., Otto,E.A., Baye,L.M., Wen,X., Scales,S.J., Kwong,M. et al. (2011) Mapping the NPHP-JBTS-MKS protein network reveals ciliopathy disease genes and pathways. Cell, 145, 513-528.

19 Branzei,D. and Foiani,M. (2010) Maintaining genome stability at the replication fork. Nat. Rev. Mol. Cell Biol., 11, 208-219.

20 Alessi,D.R., James,S.R., Downes,C.P., Holmes,A.B., Gaffney,P.R., Reese,C.B. and Cohen,P. (1997) Characterization of a 3-phosphoinositide-dependent protein kinase which phosphorylates and activates protein kinase B alpha. Curr. Biol., 7, 261-269.

21 Sarbassov,D.D., Guertin,D.A., Ali,S.M. and Sabatini,D.M. (2005) Phosphorylation and regulation of Akt/PKB by the rictor-mTOR complex. Science, 307, 1098-1101.

22 Manning,B.D. and Toker,A. (2017) AKT/PKB Signaling: Navigating the Network. Cell, 169, 381-405.

23 Inoki,K., Li,Y., Zhu,T., Wu,J. and Guan,K.L. (2002) TSC2 is phosphorylated and inhibited by Akt and suppresses mTOR signalling. Nat. Cell Biol., 4, 648-657.

24 Manning,B.D., Tee,A.R., Logsdon,M.N., Blenis,J. and Cantley,L.C. (2002) Identification of the tuberous sclerosis complex-2 tumor suppressor gene product tuberin as a target of the phosphoinositide 3-kinase/akt pathway. Mol. Cell, 10, 151-162.

25 Sancak,Y., Thoreen,C.C., Peterson,T.R., Lindquist,R.A., Kang,S.A., Spooner,E., Carr,S.A. and Sabatini,D.M. (2007) PRAS40 is an insulin-regulated inhibitor of the mTORC1 protein kinase. Mol. Cell, 25, 903-915.

26 Vander Haar,E., Lee,S.I., Bandhakavi,S., Griffin,T.J. and Kim,D.H. (2007) Insulin signalling to mTOR mediated by the Akt/PKB substrate PRAS40. Nat. Cell Biol., 9, 316-323. 27 Ma,Y., Vassetzky,Y. and Dokudovskaya,S. (2018) mTORC1 pathway in DNA damage response. Biochim Biophys Acta. Mol. Cell Res., 1865, 1293-1311.

28 Saxton,R.A. and Sabatini,D.M. (2017) mTOR Signaling in Growth, Metabolism, and Disease. Cell, 169, 361-371.

29 Yang,G., Murashige,D.S., Humphrey,S.J. and James,D.E. (2015) A Positive Feedback Loop between Akt and mTORC2 via SIN1 Phosphorylation. Cell Rep., 12, 937-943.

30 Kim,D.H., Sarbassov,D.D., Ali,S.M., King,J.E., Latek,R.R., Erdjument-Bromage,H., Tempst,P. and Sabatini,D.M. (2002) mTOR interacts with raptor to form a nutrient-sensitive complex that signals to the cell growth machinery. Cell, 110, 163-175.

31 Hara,K., Maruki,Y., Long,X., Yoshino,K., Oshiro,N., Hidayat,S., Tokunaga,C., Avruch,J. and Yonezawa,K. (2002) Raptor, a binding partner of target of rapamycin (TOR), mediates TOR action. Cell, 110, 177-189.

32 Ben-Sahra,I., Howell,J.J., Asara,J.M. and Manning,B.D. (2013) Stimulation of de novo pyrimidine synthesis by growth signaling through mTOR and S6K1. Science, 339, 1323-1328.

33 Shillingford,J.M., Piontek,K.B., Germino,G.G. and Weimbs,T. (2010) Rapamycin ameliorates PKD resulting from conditional inactivation of Pkd1. J. Am. Soc. Nephrol,. 21, 489-497.

34 Zafar,I., Ravichandran,K., Belibi,F.A., Doctor,R.B. and Edelstein,C.L. (2010) Sirolimus attenuates disease progression in an orthologous mouse model of human autosomal dominant polycystic kidney disease. Kidney Int., 78, 754-761. 
35 Serra,A.L., Poster,D., Kistler,A.D., Krauer,F., Raina,S., Young,J., Rentsch,K.M., Spanaus,K.S., Senn,O., Kristanto,P. et al. (2010) Sirolimus and kidney growth in autosomal dominant polycystic kidney disease. N. Engl. J. Med., 363, 820-829.

36 Walz,G., Budde,K., Mannaa,M., Nurnberger,J., Wanner,C., Sommerer,C., Kunzendorf,U., Banas,B., Horl,W.H., Obermuller,N. et al. (2010) Everolimus in patients with autosomal dominant polycystic kidney disease. N. Engl. J. Med., 363, 830-840.

37 Ruggenenti,P., Gentile,G., Perico,N., Perna,A., Barcella,L., Trillini,M., Cortinovis,M., Ferrer Siles,C.P., Reyes Loaeza,J.A., Aparicio,M.C. et al. (2016) Effect of Sirolimus on Disease Progression in Patients with Autosomal Dominant Polycystic Kidney Disease and CKD Stages 3b-4. Clin. J. Am. Soc. Nephrol., 11, 785-794.

38 Braun,W.E., Schold,J.D., Stephany,B.R., Spirko,R.A. and Herts,B.R. (2014) Lowdose rapamycin (sirolimus) effects in autosomal dominant polycystic kidney disease: an open-label randomized controlled pilot study. Clin. J. Am. Soc. Nephrol., 9, 881-888.

39 Soliman,A., Zamil,S., Lotfy,A. and Ismail,E. (2012) Sirolimus produced S-shaped effect on adult polycystic kidneys after 2-year treatment. Transplant. Proc., 44, 2936-2939.

40 Kim,H.J. and Edelstein,C.L. (2012) Mammalian target of rapamycin inhibition in polycystic kidney disease: From bench to bedside. Kidney Res. Clin. Pract., 31, 132-138.

41 Kong,A.M., Speed,C.J., O'Malley,C.J., Layton,M.J., Meehan,T., Loveland,K.L., Cheema,S., Ooms,L.M. and Mitchell,C.A. (2000) Cloning and characterization of a 72-kDa inositol-polyphosphate 5-phosphatase localized to the Golgi network. J. Biol. Chem., 275, 24052-24064.

42 Kisseleva,M.V., Wilson,M.P. and Majerus,P.W. (2000) The isolation and characterization of a cDNA encoding phospholipid-specific inositol polyphosphate 5phosphatase. J. Biol. Chem., 275, 20110-20116.

43 Hakim,S., Dyson,J.M., Feeney,S.J., Davies,E.M., Sriratana,A., Koenig,M.N., Plotnikova,O.V., Smyth,I.M., Ricardo,S.D., Hobbs,R.M. et al. (2016) Inpp5e suppresses polycystic kidney disease via inhibition of PI3K/Akt-dependent mTORC1 signaling. Hum. Mol. Genet., 25, 2295-2313.

44 Bielas,S.L., Silhavy,J.L., Brancati,F., Kisseleva,M.V., Al-Gazali,L., Sztriha,L., Bayoumi,R.A., Zaki,M.S., Abdel-Aleem,A., Rosti,R.O. et al. (2009) Mutations in INPP5E, encoding inositol polyphosphate-5-phosphatase E, link phosphatidyl inositol signaling to the ciliopathies. Nat. Genet., 41, 1032-1036.

45 Brooks,B.P., Zein,W.M., Thompson,A.H., Mokhtarzadeh,M., Doherty,D.A., Parisi,M., Glass,I.A., Malicdan,M.C., Vilboux,T., Vemulapalli,M. et al. (2018) Joubert Syndrome: Ophthalmological Findings in Correlation with Genotype and Hepatorenal Disease in 99 Patients Prospectively Evaluated at a Single Center. Ophthalmology, 125, 1937-1952.

46 Conduit,S.E., Hakim,S., Feeney,S.J., Ooms,L.M., Dyson,J.M., Abud,H.E. and Mitchell,C.A. (2018) $\beta$-catenin ablation exacerbates polycystic kidney disease progression. Hum. Mol. Genet., 28, 230-244.

47 Shao,X., Johnson,J.E., Richardson,J.A., Hiesberger,T. and Igarashi,P. (2002) A minimal Ksp-cadherin promoter linked to a green fluorescent protein reporter gene exhibits tissue-specific expression in the developing kidney and genitourinary tract. J. Am. Soc. Nephrol., 13, 1824-1836.

48 Shao,X., Somlo,S. and Igarashi,P. (2002) Epithelial-specific Cre/lox recombination in the developing kidney and genitourinary tract. J. Am. Soc. Nephrol., 13, 1837-1846.

49 Lin,F., Hiesberger,T., Cordes,K., Sinclair,A.M., Goldstein,L.S., Somlo,S. and Igarashi,P. (2003) Kidney-specific inactivation of the KIF3A subunit of kinesin-II inhibits renal ciliogenesis and produces polycystic kidney disease. Proc. Natl. Acad. Sci. U. S. A., 100, 5286-5291. 
50 Zhu,J., Yu,Y., Ulbrich,M.H., Li,M.H., Isacoff,E.Y., Honig,B. and Yang,J. (2011) Structural model of the TRPP2/PKD1 C-terminal coiled-coil complex produced by a combined computational and experimental approach. Proc. Natl. Acad. Sci. U. S. A., 108, 10133-10138.

51 Piontek,K.B., Huso,D.L., Grinberg,A., Liu,L., Bedja,D., Zhao,H., Gabrielson,K., Qian,F., Mei,C., Westphal,H. et al. (2004) A functional floxed allele of Pkd1 that can be conditionally inactivated in vivo. J. Am. Soc. Nephrol., 15, 3035-3043.

52 Yu,J., Carroll,T.J. and McMahon,A.P. (2002) Sonic hedgehog regulates proliferation and differentiation of mesenchymal cells in the mouse metanephric kidney. Development, 129, $5301-5312$.

53 Paul,B.M., Vassmer,D., Taylor,A., Magenheimer,L., Carlton,C.G., Piontek,K.B., Germino,G.G. and Vanden Heuvel,G.B. (2011) Ectopic expression of Cux1 is associated with reduced p27 expression and increased apoptosis during late stage cyst progression upon inactivation of Pkd1 in collecting ducts. Dev. Dyn., 240, 1493-1501.

54 Paulsen,R.D., Soni,D.V., Wollman,R., Hahn,A.T., Yee,M.C., Guan,A., Hesley,J.A., Miller,S.C., Cromwell,E.F., Solow-Cordero,D.E. et al. (2009) A genome-wide siRNA screen reveals diverse cellular processes and pathways that mediate genome stability. Mol. Cell, 35, 228-239.

55 Fukasawa,K. (2007) Oncogenes and tumour suppressors take on centrosomes. Nat. Rev. Cancer, 7, 911-924.

56 Dodson,H., Bourke,E., Jeffers,L.J., Vagnarelli,P., Sonoda,E., Takeda,S., Earnshaw,W.C., Merdes,A. and Morrison,C. (2004) Centrosome amplification induced by DNA damage occurs during a prolonged G2 phase and involves ATM. EMBO J., 23, 38643873 .

57 Sierra Potchanant,E.A., Cerabona,D., Sater,Z.A., He,Y., Sun,Z., Gehlhausen,J. and Nalepa,G. (2017) INPP5E Preserves Genomic Stability through Regulation of Mitosis. Mol. Cell Biol., 37, e00500-00516.

58 Lee,E.J. (2016) Cell Proliferation and Apoptosis in ADPKD. Adv. Exp. Med. Biol., 933, 25-34.

59 Zhou,J.X. and Li,X. (2015) Li,X. (ed.), In Polycystic Kidney Disease. Codon Publications, Brisbane (AU), in press.

60 Woo,D. (1995) Apoptosis and loss of renal tissue in polycystic kidney diseases. $N$. Engl. J. Med., 333, 18-25.

61 Tao,Y., Zafar,I., Kim,J., Schrier,R.W. and Edelstein,C.L. (2008) Caspase-3 gene deletion prolongs survival in polycystic kidney disease. J. Am. Soc. Nephrol., 19, 749-755.

62 Mathur,D., Stratikopoulos,E., Ozturk,S., Steinbach,N., Pegno,S., Schoenfeld,S., Yong,R., Murty,V.V., Asara,J.M., Cantley,L.C. et al. (2017) PTEN Regulates Glutamine Flux to Pyrimidine Synthesis and Sensitivity to Dihydroorotate Dehydrogenase Inhibition. Cancer Discov., 7, 380-390.

63 Fragkos,M., Ganier,O., Coulombe,P. and Mechali,M. (2015) DNA replication origin activation in space and time. Nat. Rev. Mol. Cell Biol., 16, 360-374.

64 Ong,A.C., Devuyst,O., Knebelmann,B. and Walz,G. (2015) Autosomal dominant polycystic kidney disease: the changing face of clinical management. Lancet, 385, 19932002.

65 Rowe,I., Chiaravalli,M., Mannella,V., Ulisse,V., Quilici,G., Pema,M., Song,X.W., Xu,H., Mari,S., Qian,F. et al. (2013) Defective glucose metabolism in polycystic kidney disease identifies a new therapeutic strategy. Nat. Med., 19, 488-493.

66 Gattone,V.H., 2nd, Sinders,R.M., Hornberger,T.A. and Robling,A.G. (2009) Late progression of renal pathology and cyst enlargement is reduced by rapamycin in a mouse model of nephronophthisis. Kidney Int., 76, 178-182. 
67 Fischer,D.C., Jacoby,U., Pape,L., Ward,C.J., Kuwertz-Broeking,E., Renken,C., Nizze,H., Querfeld,U., Rudolph,B., Mueller-Wiefel,D.E. et al. (2009) Activation of the AKT/mTOR pathway in autosomal recessive polycystic kidney disease (ARPKD). Nephrol. Dial. Transplant, 24, 1819-1827.

68 Park,E.Y., Kim,B.H., Lee,E.J., Chang,E., Kim,D.W., Choi,S.Y. and Park,J.H. (2014) Targeting of receptor for advanced glycation end products suppresses cyst growth in polycystic kidney disease. J. Biol. Chem., 289, 9254-9262.

69 Liu,Y., Pejchinovski,M., Wang,X., Fu,X., Castelletti,D., Watnick,T.J., Arcaro,A., Siwy,J., Mullen,W., Mischak,H. et al. (2018) Dual mTOR/PI3K inhibition limits PI3Kdependent pathways activated upon mTOR inhibition in autosomal dominant polycystic kidney disease. Sci. Rep., 8, 5584.

70 Liu,K., Graves,J.D., Scott,J.D., Li,R. and Lin,W.C. (2013) Akt switches TopBP1 function from checkpoint activation to transcriptional regulation through phosphoserine binding-mediated oligomerization. Mol. Cell Biol., 33, 4685-4700.

71 Shtivelman,E., Sussman,J. and Stokoe,D. (2002) A role for PI 3-kinase and PKB activity in the G2/M phase of the cell cycle. Curr. Biol., 12, 919-924.

72 King,F.W., Skeen,J., Hay,N. and Shtivelman,E. (2004) Inhibition of Chk1 by activated PKB/Akt. Cell Cycle, 3, 634-637.

73 Distefano,G., Boca,M., Rowe,I., Wodarczyk,C., Ma,L., Piontek,K.B., Germino,G.G., Pandolfi,P.P. and Boletta,A. (2009) Polycystin-1 regulates extracellular signal-regulated kinase-dependent phosphorylation of tuberin to control cell size through mTOR and its downstream effectors S6K and 4EBP1. Mol. Cell Biol., 29, 2359-2371.

74 Moiseeva,T., Hood,B., Schamus,S., O'Connor,M.J., Conrads,T.P. and Bakkenist,C.J. (2017) ATR kinase inhibition induces unscheduled origin firing through a Cdc7-dependent association between GINS and And-1. Nat. Commun., 8, 1392.

75 Shechter,D., Costanzo,V. and Gautier,J. (2004) ATR and ATM regulate the timing of DNA replication origin firing. Nat. Cell Biol., 6, 648-655.

76 Toledo,L.I., Altmeyer,M., Rask,M.B., Lukas,C., Larsen,D.H., Povlsen,L.K., BekkerJensen,S., Mailand,N., Bartek,J. and Lukas,J. (2013) ATR prohibits replication catastrophe by preventing global exhaustion of RPA. Cell, 155, 1088-1103.

77 Sokka,M., Koalick,D., Hemmerich,P., Syvaoja,J.E. and Pospiech,H. (2018) The ATRActivation Domain of TopBP1 Is Required for the Suppression of Origin Firing during the $\mathrm{S}$ Phase. Int. J. Mol. Sci., 19, E2376.

78 Liu,K., Paik,J.C., Wang,B., Lin,F.T. and Lin,W.C. (2006) Regulation of TopBP1 oligomerization by Akt/PKB for cell survival. EMBO J, 25, 4795-4807.

79 O'Reilly,K.E., Rojo,F., She,Q.B., Solit,D., Mills,G.B., Smith,D., Lane,H., Hofmann,F., Hicklin,D.J., Ludwig,D.L. et al. (2006) mTOR inhibition induces upstream receptor tyrosine kinase signaling and activates Akt. Cancer Res., 66, 1500-1508.

80 Guertin,D.A. and Sabatini,D.M. (2007) Defining the role of mTOR in cancer. Cancer Cell, 12, 9-22.

81 Giles,R.H., Ajzenberg,H. and Jackson,P.K. (2014) 3D spheroid model of mIMCD3 cells for studying ciliopathies and renal epithelial disorders. Nat. Protoc., 9, 2725-2731.

82 Berenjeno,I.M., Pineiro,R., Castillo,S.D., Pearce,W., McGranahan,N., Dewhurst,S.M., Meniel,V., Birkbak,N.J., Lau,E., Sansregret,L. et al. (2017) Oncogenic PIK3CA induces centrosome amplification and tolerance to genome doubling. Nat. Commun., 8, 1773.

83 Venot,Q., Blanc,T., Rabia,S.H., Berteloot,L., Ladraa,S., Duong,J.P., Blanc,E., Johnson,S.C., Hoguin,C., Boccara,O. et al. (2018) Targeted therapy in patients with PIK3CA-related overgrowth syndrome. Nature, 558, 540-546. 
84 Bello-Reuss,E., Holubec,K. and Rajaraman,S. (2001) Angiogenesis in autosomaldominant polycystic kidney disease. Kidney Int., 60, 37-45.

85 Reed,B.Y., Masoumi,A., Elhassan,E., McFann,K., Cadnapaphornchai,M.A., Maahs,D.M., Snell-Bergeon,J.K. and Schrier,R.W. (2011) Angiogenic growth factors correlate with disease severity in young patients with autosomal dominant polycystic kidney disease. Kidney Int., 79, 128-134.

86 Nichols,M.T., Gidey,E., Matzakos,T., Dahl,R., Stiegmann,G., Shah,R.J., Grantham,J.J., Fitz,J.G. and Doctor,R.B. (2004) Secretion of cytokines and growth factors into autosomal dominant polycystic kidney disease liver cyst fluid. Hepatology, 40, 836-846.

87 Maya-Mendoza,A., Petermann,E., Gillespie,D.A., Caldecott,K.W. and Jackson,D.A. (2007) Chk1 regulates the density of active replication origins during the vertebrate $\mathrm{S}$ phase. EMBO J., 26, 2719-2731.

88 Viniegra,J.G., Martinez,N., Modirassari,P., Hernandez Losa,J., Parada Cobo,C., Sanchez-Arevalo Lobo,V.J., Aceves Luquero,C.I., Alvarez-Vallina,L., Ramon y Cajal,S., Rojas,J.M. et al. (2005) Full activation of PKB/Akt in response to insulin or ionizing radiation is mediated through ATM. J. Biol. Chem., 280, 4029-4036.

89 Caporali,S., Levati,L., Starace,G., Ragone,G., Bonmassar,E., Alvino,E. and D'Atri,S. (2008) AKT is activated in an ataxia-telangiectasia and Rad3-related-dependent manner in response to temozolomide and confers protection against drug-induced cell growth inhibition. Mol. Pharmacol., 74, 173-183.

90 Bozulic,L., Surucu,B., Hynx,D. and Hemmings,B.A. (2008) PKBalpha/Akt1 acts downstream of DNA-PK in the DNA double-strand break response and promotes survival. Mol Cell, 30, 203-213.

91 Chien,A.J., Cockerill,A., Fancourt,C., Schmidt,E., Moasser,M.M., Rugo,H.S., Melisko,M.E., Ko,A.H., Kelley,R.K., Korn,W.M. et al. (2016) A phase 1b study of the Aktinhibitor MK-2206 in combination with weekly paclitaxel and trastuzumab in patients with advanced HER2-amplified solid tumor malignancies. Breast Cancer Res. Treat., 155, 521530 .

92 Hudis,C., Swanton,C., Janjigian,Y.Y., Lee,R., Sutherland,S., Lehman,R., Chandarlapaty,S., Hamilton,N., Gajria,D., Knowles,J. et al. (2013) A phase 1 study evaluating the combination of an allosteric AKT inhibitor (MK-2206) and trastuzumab in patients with HER2-positive solid tumors. Breast Cancer Res., 15, R110.

93 Sheridan,A.M., Schwartz,J.H., Kroshian,V.M., Tercyak,A.M., Laraia,J., Masino,S. and Lieberthal,W. (1993) Renal mouse proximal tubular cells are more susceptible than MDCK cells to chemical anoxia. Am. J. Physiol., 265, F342-350.

94 Dyson,J.M., Conduit,S.E., Feeney,S.J., Hakim,S., DiTommaso,T., Fulcher,A.J., Sriratana,A., Ramm,G., Horan,K.A., Gurung,R. et al. (2017) INPP5E regulates phosphoinositide-dependent cilia transition zone function. J. Cell Biol., 216, 247-263.

95 Lehmann,H., Vicari,D., Wild,P.J. and Frew,I.J. (2015) Combined Deletion of Vhl and Kif3a Accelerates Renal Cyst Formation. J. Am. Soc. Nephrol., 26, 2778-2788. 


\section{Legends to Figures}

\section{Figure 1: DNA damage accumulates in the cystic epithelium}

A-C. Kidney sections from (A) P7 or (B) P21 Inpp $5 e^{+/+} ;$KspCre and Inpp5e $e^{f l / f l} ;$ KspCre mice stained with $\gamma \mathrm{H} 2 \mathrm{AX}$ antibodies (green), counter stained with collecting duct marker DBA (red) and DAPI (blue) and imaged by confocal microscopy. Arrows indicate $\gamma \mathrm{H} 2 \mathrm{AX}$ immunopositive collecting duct nuclei. Bars indicate $10 \mu \mathrm{m}$. (C) Graph shows the percentage of collecting duct cells positive for $\gamma \mathrm{H} 2 \mathrm{AX}$ immunoreactivity relative to total nuclei number at $\mathrm{P} 21$. Bars represent mean $\pm \mathrm{SEM}, \mathrm{n}=3-5$ mice of each genotype, at least 207 cells from 10 random fields scored per mouse, $* \mathrm{p}<0.05$.

D. Kidney sections from P21 Inpp5 $e^{+/+} ;$KspCre and Inpp $5 e^{f l / f l} ; K s p C r e$ mice stained with $H \& E$, arrows indicate multinucleated cells, dotted line outlines multinucleated cell in inset image. Bar indicates $20 \mu \mathrm{m}$, images are representative of $\mathrm{n}=5$ mice of each genotype.

E. pRECs isolated from P16 Inpp $5 e^{+/+} ; K s p C r e$ and Inpp $5 e^{f l f l} ; K s p C r e$ kidneys were immunostained with $\gamma$-tubulin antibodies and DAPI and imaged by confocal microscopy. Graph shows the percentage of cells exhibiting $>2$ centrosomes. Bars represent mean $\pm \mathrm{SEM}$, $\mathrm{n}=4$ cell lines of each genotype, each derived from an individual mouse, with at least 100 cells scored per cell line, ${ }^{*} \mathrm{p}<0.05$.

F. Kidney sections from P11 Pkd $1^{f l / f l}$ and $P k d l^{f l f l}$;Hoxb7Cre mice stained with $\gamma \mathrm{H} 2 \mathrm{AX}$ antibodies (green), counter stained with collecting duct marker DBA (red) and DAPI (blue) and imaged by confocal microscopy. Arrows indicate $\gamma \mathrm{H} 2 \mathrm{AX}$ immunopositive collecting duct nuclei. Bar indicates $10 \mu \mathrm{m}$. (See Figure S1E for quantification).

G. Kidney sections from P11Pkdl ${ }^{f l f l}$ and $P k d l^{f l f f l}$;Hoxb7Cre mice stained with H\&E, arrows indicate multinucleated cells, dotted line outlines multinucleated cell in inset image. Bar indicates $20 \mu \mathrm{m}$, images are representative of $\mathrm{n}=5$ mice of each genotype. 


\section{Figure 2: Proliferation and replication forks are increased in PKD renal epithelial cells}

A. Kidney sections from (top) P7 or (bottom) P21 Inpp $5 e^{+/+} ; K s p C r e$ and Inpp $5 e^{f l f l} ; K s p C r e$ mice stained with PCNA antibodies (red), counter stained with collecting duct marker DBA (green) and DAPI (blue) and imaged by confocal microscopy. Arrows indicate PCNA immunopositive collecting duct nuclei. Bar indicates $10 \mu \mathrm{m}$. Graphs show the percentage of collecting duct cells positive for PCNA immunoreactivity relative to total nuclei number. Bars represent mean \pm SEM, $n=3-5$ mice of each genotype, at least 114 cells from 5-10 random fields scored per mouse, statistical significance was determined using (left) one-way ANOVA ( $\mathrm{p}=0.0021$ ) followed by Tukey's post hoc test or (right) Student's t-test, ${ }^{* *} \mathrm{p}<0.01$, $* * * * \mathrm{p}<0.0001$

B. pRECs isolated from P16 Inpp $5 e^{+/+} ;$KspCre and Inpp $5 e^{f l / f l} ;$ KspCre kidneys were pulsed with BrdU for 45 minutes, co-stained with BrdU (green) and $\gamma \mathrm{H} 2 \mathrm{AX}$ (red) antibodies and DAPI (blue) and imaged by confocal microscopy. BrdU labels cells in S phase as it is incorporated into newly synthesized DNA, the intensity of the nuclear BrdU signal is proportional to the number of replication forks. Arrows indicate BrdU immunopositive nuclei. Bar indicates $50 \mu \mathrm{m}$. Graph (left) shows the BrdU MFI, the results are expressed relative to an Inpp5 $e^{+/+}$; KspCre cell line, which was arbitrarily assigned a value of one. Bars represent mean \pm SEM, $n=3$ cell lines of each genotype, each derived from an individual mouse, with at least 35 cells scored per cell line. Graph (right) shows the percentage of $\gamma \mathrm{H} 2 \mathrm{AX}$ positive cells that were BrdU positive. Bars represent mean $\pm \mathrm{SEM}, \mathrm{n}=3$ cell lines of each genotype, each derived from an individual mouse, with at least 600 cells scored per cell line, $* \mathrm{p}<0.05, * * \mathrm{p}<0.01$.

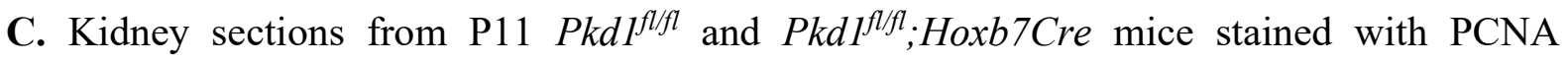
antibodies (red), counter-stained with collecting duct marker DBA (green) and DAPI (blue) and imaged by confocal microscopy. Arrows indicate PCNA immunopositive collecting duct 
nuclei. Bar indicates $10 \mu \mathrm{m}$. Graph shows the percentage of collecting duct cells positive for PCNA immunoreactivity relative to total nuclei number. Bars represent mean \pm SEM, $n=5$ mice of each genotype, at least 290 cells from 10 random fields scored per mouse, **** $\mathrm{p}<0.0001$.

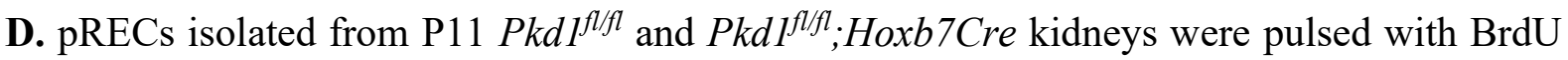
for 45 minutes, co-stained with BrdU (green) and $\gamma \mathrm{H} 2 \mathrm{AX}$ (red) antibodies and DAPI (blue) and imaged by confocal microscopy. Arrows indicate BrdU immunopositive nuclei. Bar indicates $30 \mu \mathrm{m}$. Graph (left) shows the BrdU MFI, the results are expressed relative to a $P k d 1^{f l f l}$ cell line, which was arbitrarily assigned a value of one. Bars represent mean $\pm \mathrm{SEM}$, $\mathrm{n}=3$ cell lines of each genotype, each derived from an individual mouse, with at least 50 cells scored per cell line. Graph (right) shows the percentage of $\gamma \mathrm{H} 2 \mathrm{AX}$ positive cells that were BrdU positive. Bars represent mean \pm SEM, $n=3$ REC lines each derived from an individual mouse for each genotype in which at least 468 cells scored per cell line, ${ }^{*} \mathrm{p}<0.05,{ }^{* *} \mathrm{p}<0.01$.

\section{Figure 3: AKT/mTORC1 signaling is activated in PKD models}

A. P21 Inpp $5 e^{+/+} ; K s p C r e$ and Inpp $5 e^{f l f f l} ; K s p C r e$ kidney lysates were immunoblotted with pPRAS40(T246), PRAS40 or GAPDH antibodies. Each lane represents lysate from an individual mouse. (See Figure S3C for quantification)

B. Kidney sections from P21 Inpp $5 e^{+/+} ;$KspCre and Inpp $5 e^{f l / f l} ;$ KspCre mice stained with pAKT(S473) antibodies, counter stained with haematoxylin and imaged by brightfield microscopy. Arrows indicate pAKT(S473) immunopositive nuclei. Bar indicates $10 \mu \mathrm{m}$. Images are representative of $n=3$ mice of each genotype.

C. P21 Inpp $5 e^{+/+} ; K s p C r e$ and Inpp $5 e^{f l f l} ; K s p C r e$ kidney lysates were immunoblotted with pS6K(T389), S6K or GAPDH antibodies. Each lane represents lysate from an individual mouse. (See Figure S3D for quantification) 
D-F. P11 Pkdl $1^{f l f l}$ and $P k d l^{f l f l}$;Hoxb7Cre kidney lysates were immunoblotted with (D) pAKT(T308), pAKT(S473), AKT, (E) pPRAS40(T246), PRAS40, (F) pS6K(T389), S6K or GAPDH antibodies. Each lane represents lysate from an individual mouse. (See Figure S4A, C-D for quantification)

\section{Figure 4: Inhibitory phosphorylation of TOPBP1 is increased in PKD models}

A. Kidney sections from (left) P7 or (right) P21 Inpp5 $e^{+/+} ;$KspCre and Inpp $5 e^{f l / f l} ;$ KspCre mice stained with pTOPBP1(S1159) antibodies, counter-stained with haematoxylin and imaged by brightfield microscopy. Arrows indicate pTOPBP1(S1159) immunopositive nuclei in the cystic epithelium. Bar indicates $50 \mu \mathrm{m}$. Images are representative of $n=3-4$ mice of each genotype.

B. Inpp $5 e^{+/+} ; K s p C r e$ and Inpp $5 e^{f l f l} ; K s p C r e$ pRECs were treated vehicle or $5 \mu \mathrm{M}$ AktX for 24 hours, stained with pTOPBP1(S1159) antibodies (green) and DAPI (blue) and imaged by confocal microscopy. Bar indicates $50 \mu \mathrm{m}$. Graph shows the percentage pTOPBP1(S1159) positive cells. Bars represent mean \pm SEM, $n=3-4$ cell lines for each genotype, in which each pREC line was derived from an individual mouse, with at least 511 cells scored per cell line, per condition, statistical significance was determined using two-way ANOVA (interaction $\mathrm{p}=0.0488$, row factor $\mathrm{p}=0.0365$, column factor $\mathrm{p}=0.0094$ ) followed by Tukey's post hoc test, $* \mathrm{p}<0.05$.

C. Inpp $5 e^{+/+} ;$KspCre and Inpp5 $e^{f l / f l} ; K s p C r e$ pRECs were treated with DMSO or $100 \mathrm{nM}$ Rapamycin for 24 hours, stained with pTOPBP1(S1159) antibodies (green) and DAPI (blue) and imaged by confocal microscopy. Bar indicates $50 \mu \mathrm{m}$. Graph shows the percentage pTOPBP1(S1159) positive cells. Bars represent mean \pm SEM, $n=3$ cell lines of each genotype, in which each pREC line was derived from an individual mouse, with at least 352 cells scored per cell line, per condition, statistical significance was determined using two-way 
ANOVA (interaction $\mathrm{p}=0.3288$, row factor $\mathrm{p}=0.3202$, column factor $\mathrm{p}=0.0002$ ) followed by Tukey's post hoc test, $* \mathrm{p}<0.05, * * \mathrm{p}<0.01$.

D. Kidney sections from P21 vehicle and Everolimus treated Inpp $5 e^{f l f l} ; K s p C r e$ mice stained with pTOPBP1(S1159) antibodies, counter-stained with haematoxylin and imaged by brightfield microscopy. Arrows indicate pTOPBP1(S1159) immunopositive nuclei in the cystic epithelium. Bar indicates $50 \mu$ m. Images are representative of $n=4-5$ mice of each genotype.

E. $P k d l^{f l f l}$ and $P k d l^{f l f l}$;Hoxb7Cre pRECs were stained with pTOPBP1(S1159) antibodies (green) and DAPI (blue) and imaged by confocal microscopy. Bar indicates $30 \mu \mathrm{m}$. Graph shows the percentage pTOPBP1(S1159) positive cells. Bars represent mean \pm SEM, $n=3$ cell lines of each genotype, in which each pREC line was derived from an individual mouse, with at least 532 cells scored per cell line, ${ }^{*} \mathrm{p}<0.05$.

F. Kidney sections from P11 Pkd $1^{f l f l}$ and $P k d 1^{f l f l}$;Hoxb7Cre mice stained with pTOPBP1(S1159) antibodies, counter-stained with haematoxylin and imaged by brightfield microscopy. Arrows indicate pTOPBP1(S1159) immunopositive nuclei in the cystic epithelium. Dashed circles highlight normal tubules. Bar indicates $25 \mu \mathrm{m}$. Images are representative of $n=5$ mice of each genotype.

\section{Figure 5: CAD is activated in PKD models}

A. P21 Inpp $5 e^{+/+} ; K s p C r e$ and Inpp $5 e^{f l / f l} ; K s p C r e$ kidney lysates were immunoblotted with pCAD(S1859), CAD or GAPDH antibodies. Each lane represents lysate from an individual mouse. (See Figure S6A for quantification)

B. Kidney sections from (top) P7 or (bottom) P21 Inpp $5 e^{+/+} ; K s p C r e$ and Inpp $5 e^{\text {flffl }} ;$ KspCre mice stained with $\mathrm{pCAD}(\mathrm{S} 1859)$ antibodies, counter-stained with haematoxylin and imaged by brightfield microscopy. Arrows indicate $\mathrm{pCAD}(\mathrm{S} 1859)$ immunopositive nuclei in the 
cystic epithelium. Bar indicates $50 \mu \mathrm{m}$. Images are representative of $n=3-5$ mice of each genotype.

C. Kidney lysates from P21 vehicle and Everolimus treated Inpp $5 e^{f l f f l} ;$ KspCre mice were immunoblotted with pCAD(S1859), CAD or GAPDH antibodies. Each lane represents lysate from an individual mouse. (See Figure S6B for quantification)

D. Inpp $5 e^{f l f l} ;$ KspCre pRECs were treated with DMSO, $100 \mathrm{nM}$ Rapamycin or $1 \mu \mathrm{M}$ MK2206 for 24 hours, and immunoblotted with pCAD(S1859), CAD, pS6(S235/236), S6, pAKT(T308), AKT or actin antibodies. Each lane represents lysate from an individual pREC line derived from an individual mouse.

E. Kidney sections from P21 vehicle and Everolimus treated Inpp $5 e^{f l f f l} ; K s p C r e$ mice stained with $\mathrm{pCAD}(\mathrm{S} 1859)$ antibodies, counter-stained with haematoxylin and imaged by brightfield microscopy. Arrows indicate $\mathrm{pCAD}(\mathrm{S} 1859)$ immunopositive nuclei in the cystic epithelium. Bar indicates $50 \mu \mathrm{m}$. Images are representative of $n=4-5$ mice of each genotype.

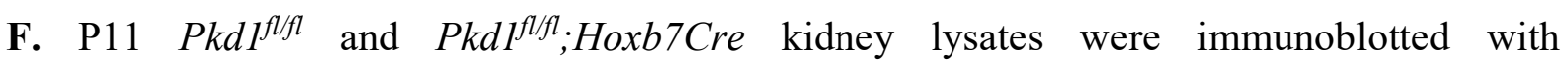
pCAD(S1859), CAD or GAPDH antibodies. Each lane represents lysate from an individual mouse. (See Figure S6C for quantification)

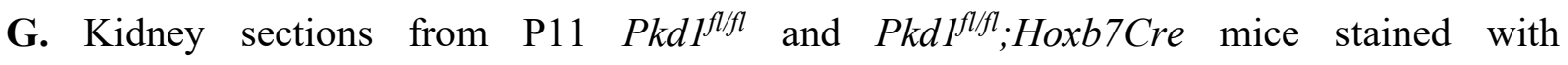
pCAD(S1859) antibodies, counter-stained with haematoxylin and imaged by brightfield microscopy. Arrows indicate $\mathrm{pCAD}(\mathrm{S} 1859)$ immunopositive nuclei in the cystic epithelium. Bar indicates $50 \mu \mathrm{m}$. Images are representative of $n=5$ mice of each genotype.

H. Pkd $1^{f l f l}$;Hoxb7Cre pRECs were treated with DMSO, $100 \mathrm{nM}$ Rapamycin or $1 \mu \mathrm{M}$ MK2206 for 24 hours, and immunoblotted with pCAD(S1859), CAD, pS6(S235/236), S6, pAKT(T308), AKT or actin antibodies. Each lane represents lysate from an individual pREC line derived from an individual mouse. 


\section{Figure 6: AKT inhibition rescues defective spheroid morphology in PKD cells in vitro}

A-B. (A) Inpp5 $e^{f l f l} ; K s p C r e$ and (B) Pkd $1^{f l f l}$;Hoxb7Cre pRECs were treated with DMSO, 100 nM Rapamycin or $1 \mu \mathrm{M}$ MK2206 for 24 hours, stained with $\gamma \mathrm{H} 2 \mathrm{AX}$ antibodies (green) and DAPI (blue) and imaged by confocal microscopy. Bar indicates $10 \mu \mathrm{m}$. Graph shows the percentage $\gamma \mathrm{H} 2 \mathrm{AX}$ positive cells. Bars represent mean $\pm \mathrm{SEM}, \mathrm{n}=4 \operatorname{Inpp} 5 e^{\text {fllfl }} ;$ KspCre or $\mathrm{n}=6$ Pkdl flfl ;Hoxb7Cre cell lines, in which each pREC line was derived from an individual mouse, with 400-600 cells scored per cell line, per condition, $* * * * \mathrm{p}<0.0001$.

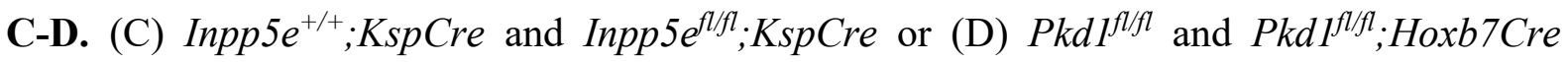
pRECs were grown in Matrigel with DMSO or $10 \mu \mathrm{M}$ MK2206, stained with phalloidin (green) and DAPI (blue) and imaged by confocal microscopy. Bars indicates $10 \mu \mathrm{m}$. Graphs show the percentage of spheroids exhibiting an open lumen. Bars represent mean \pm SEM, $n=3$ cell lines of each genotype, in which each pREC line was derived from an individual mouse, statistical significance was determined using two-way ANOVA ((A) interaction $p=0.0155$, row factor $\mathrm{p}=0.0004$, column factor $\mathrm{p}=0.0114$, (B) interaction $\mathrm{p}=0.4857$, row factor $\mathrm{p}=0.0024$, column factor $\mathrm{p}=0.0021$ ) followed by Tukey's post hoc test, $* \mathrm{p}<0.05$, $* * \mathrm{p}<0.01$.

\section{Figure 7: Model for AKT-dependent DNA damage in PKD}

AKT and mTORC1 signaling are increased in the cystic kidney. We propose increased AKT signaling in PKD inhibits the DNA repair protein and replication fork origin regulator TOPBP1 leading to increased origin firing and impaired DNA repair. DNA is most liable to damage during replication, therefore increased replication fork numbers may promote the accumulation of DNA damage. AKT also activates mTORC1 signaling promoting flux through de novo pyrimidine nucleotide synthesis which feed into the increased replication forks to drive cell proliferation. Therefore, AKT promotes DNA damage accumulation and cooperates with mTORC1 to stimulate cell proliferation in PKD. 


\section{Abbreviations}

ADPKD autosomal dominant PKD

ARPKD autosomal recessive PKD

ATR Ataxia Telangiectasia and Rad3-related

BrdU bromodeoxyuridine

BSA bovine serum albumin

FFPE formalin fixed, paraffin embedded

$\mathrm{H} \& \mathrm{E} \quad$ hematoxylin and eosin

IB immunoblot

IHC-P immunohistochemistry-paraffin

MFI mean fluorescence intensity

mTORC1 mammalian target of rapamycin complex 1

P postnatal day

PCNA proliferating cell nuclear antigen

pHistone phosphorylated histone

$\mathrm{PI}(3,4,5) \mathrm{P}_{3}$ phosphatidylinositol 3,4,5-trisphosphate

PI3K phosphoinositide 3-kinase

PKD polycystic kidney disease

SAC spindle assembly checkpoint

SDS sodium dodecyl sulphate

TOPBP1 DNA Topoisomerase II Binding Protein 1

$\mathrm{v} / \mathrm{v} \quad$ volume/volume

$\mathrm{w} / \mathrm{v} \quad$ weight/volume 
Figure 1

Conduit et al
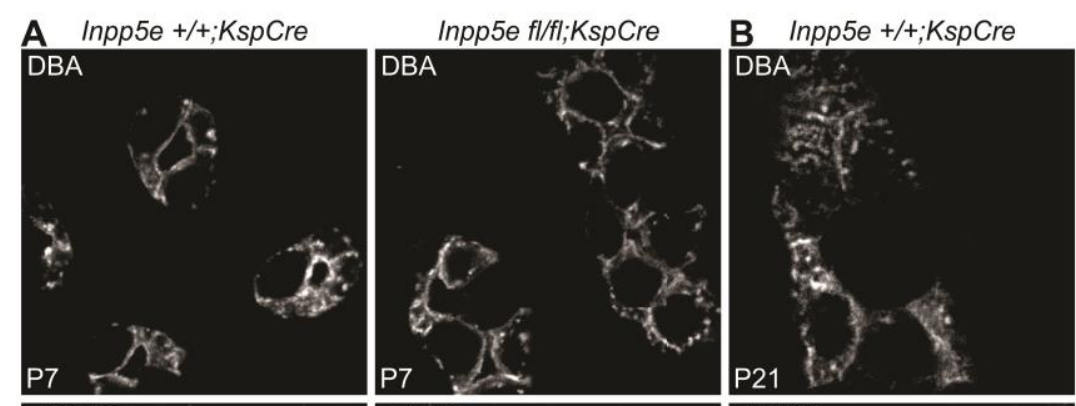

Inpp5e fl/fl;KspCre
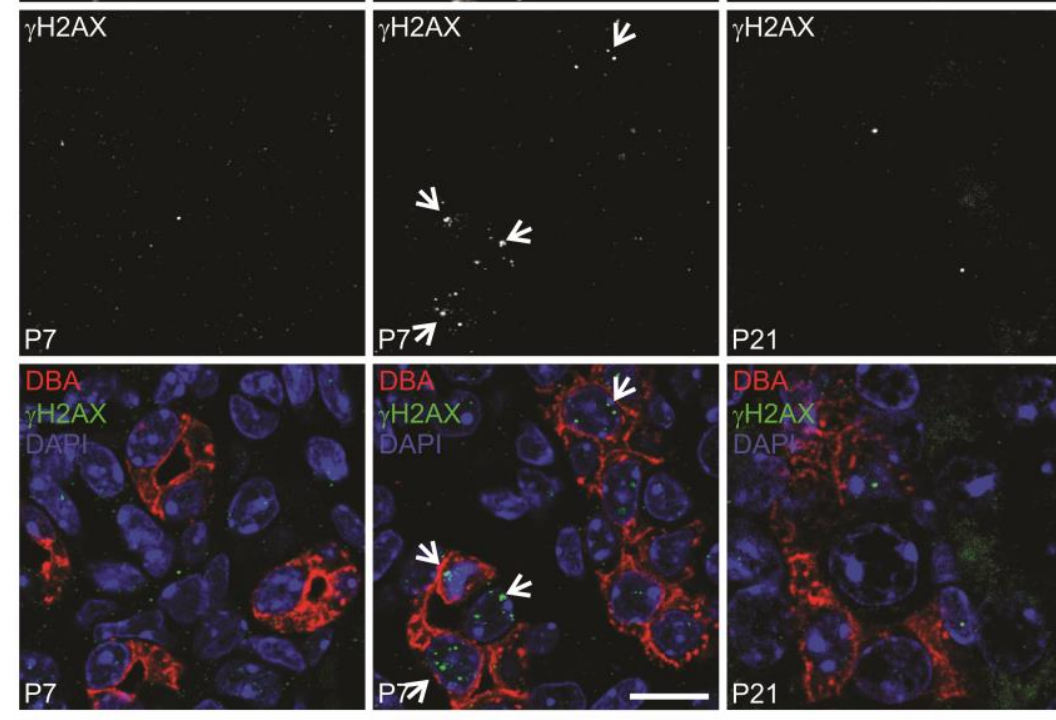

C $\quad 507 \mathrm{P} 2$
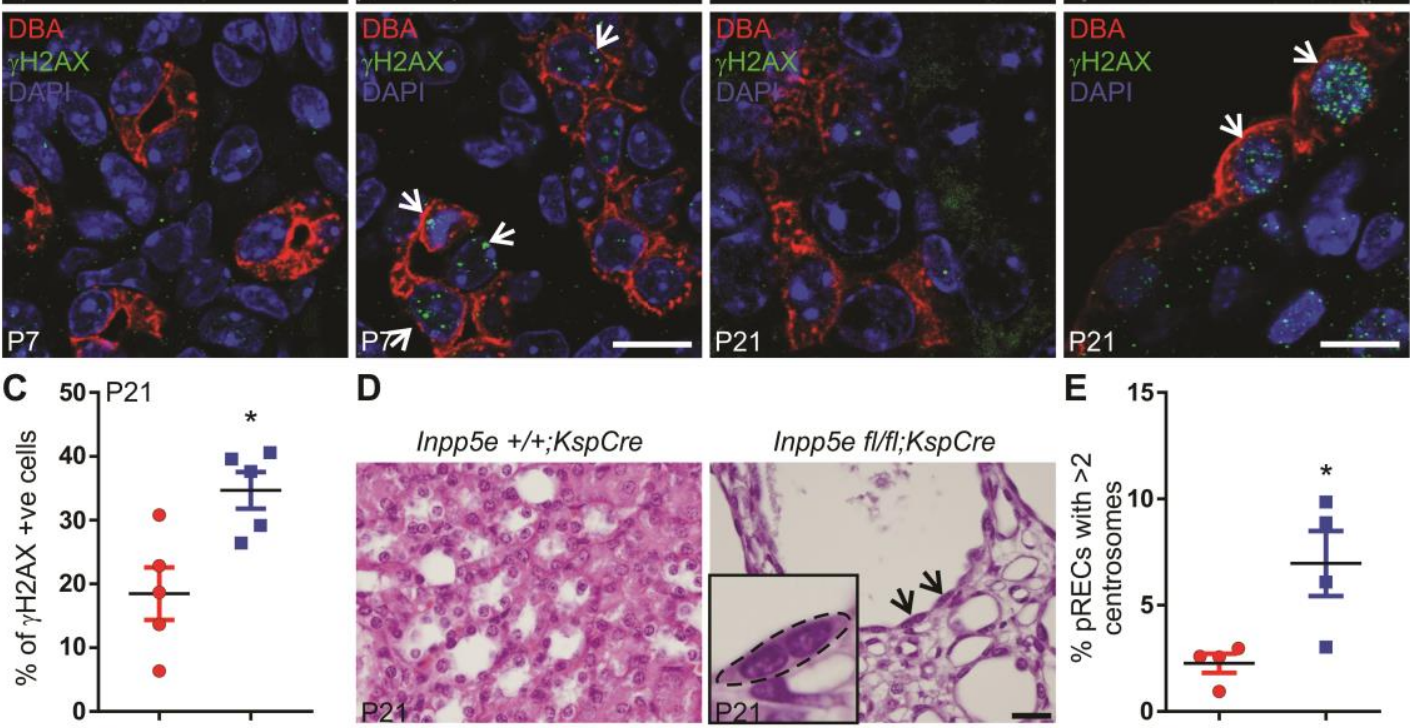

D

E
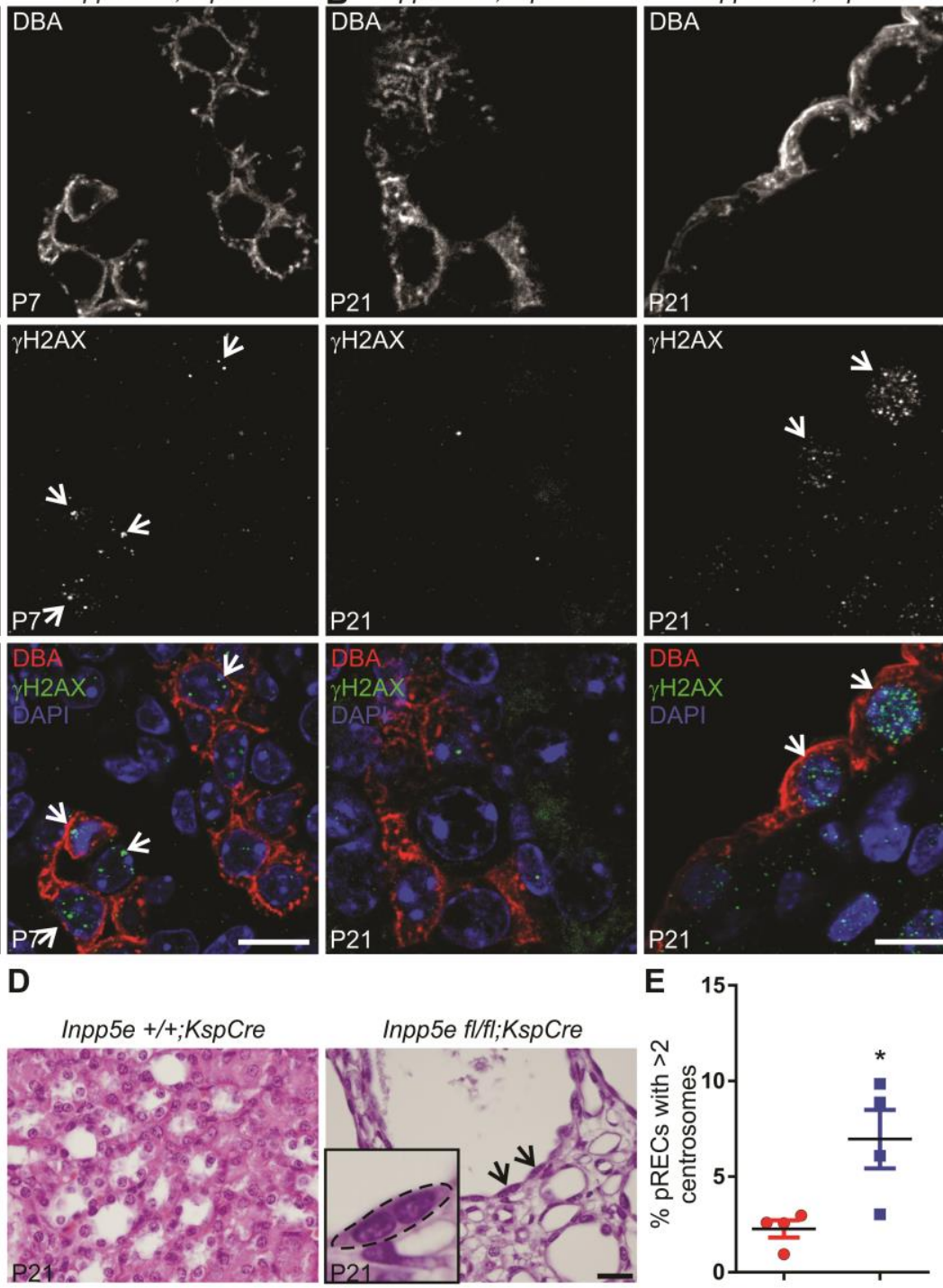

15

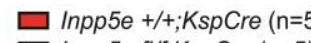

$\square$ Inpp5e fl/f;KspCre ( $\mathrm{n}=5)$
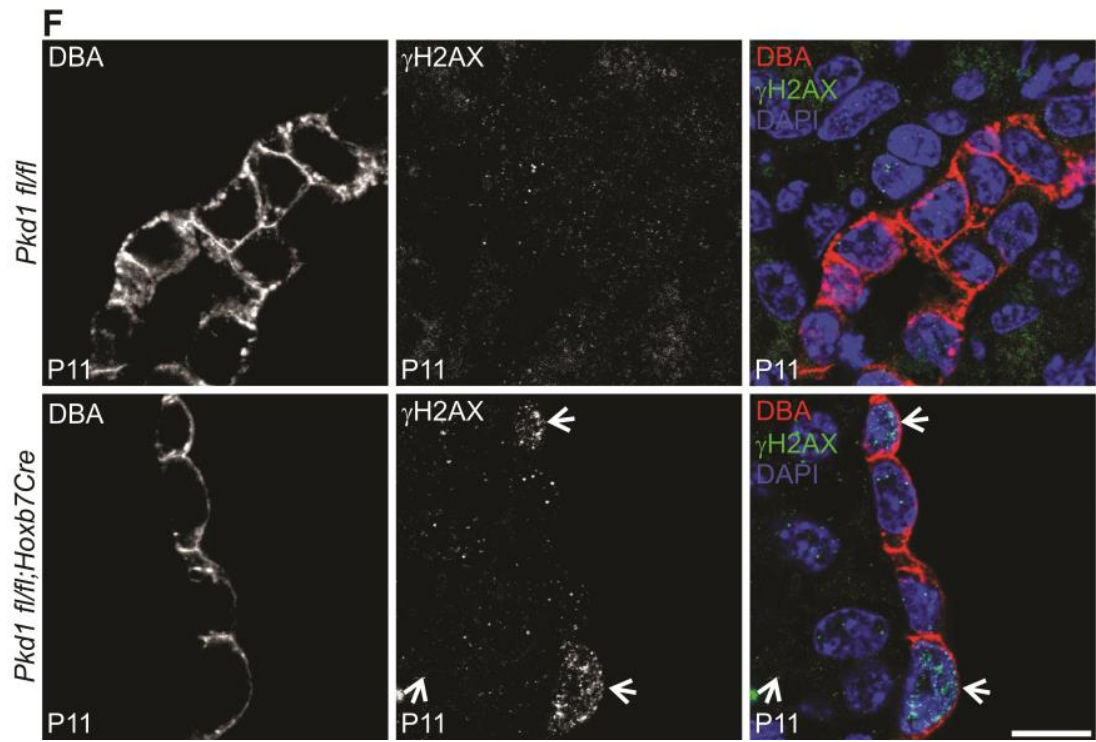

- Inpp5e flff:KspCre (n=4)

G

Pkd1 fl/fl

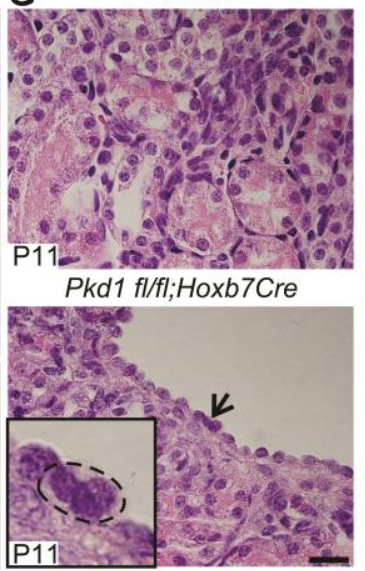


Conduit et al

Figure 2
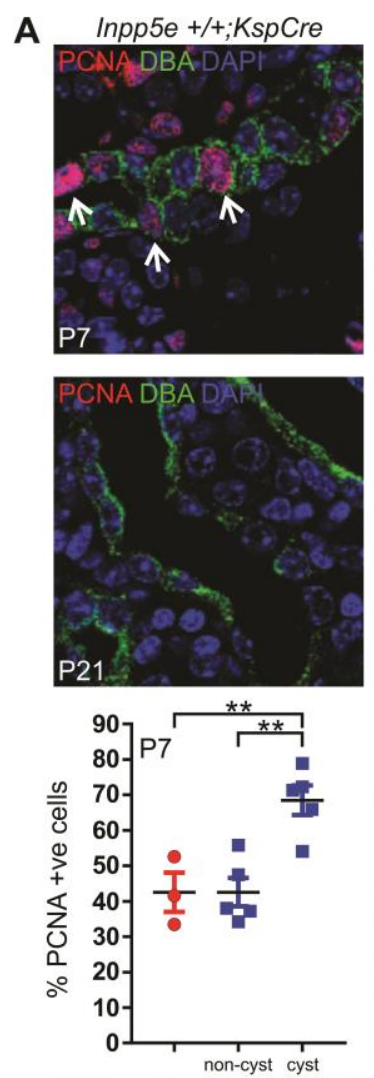
$\square$ Inpp5e $+/+; K$ spCre $(\mathrm{n}=3)$
$\square$ Inpp5e fl/f; KspCre $(\mathrm{n}=5$

\section{B}
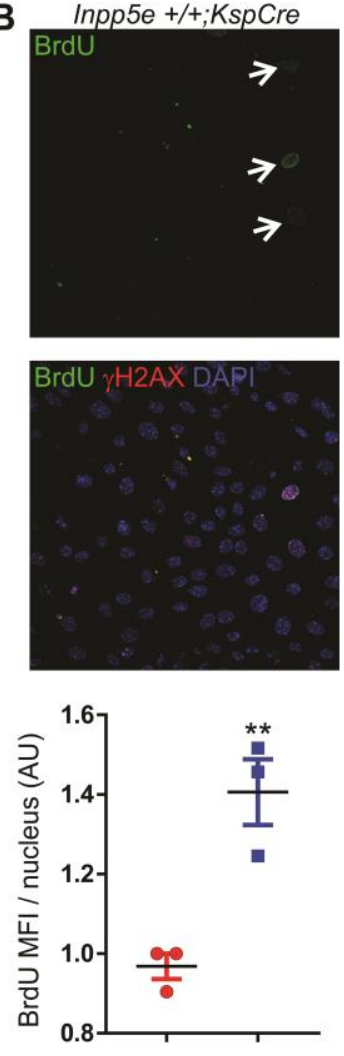

$\square \operatorname{Inpp5e}+/+; K s p C r e(\mathrm{n}=3)$ $\square$ Inpp5e fl/f; KspCre $(\mathrm{n}=3)$
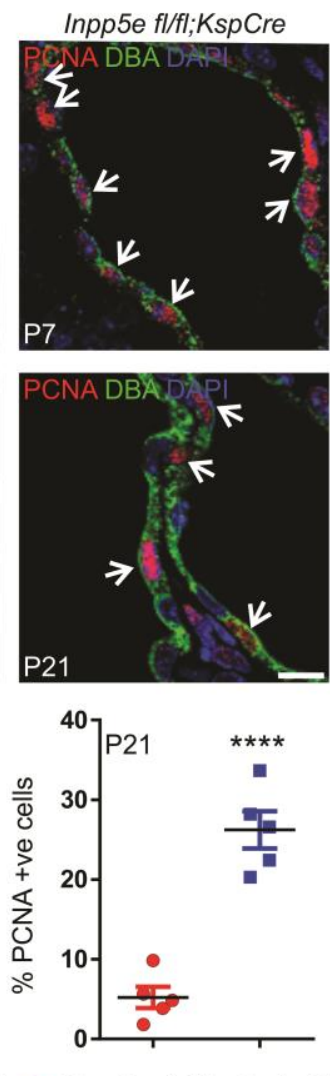

$\square \operatorname{Inpp} 5 e+1+; K s p C r e(n=5)$

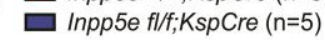

Inpp5e fl/fl;KspCre
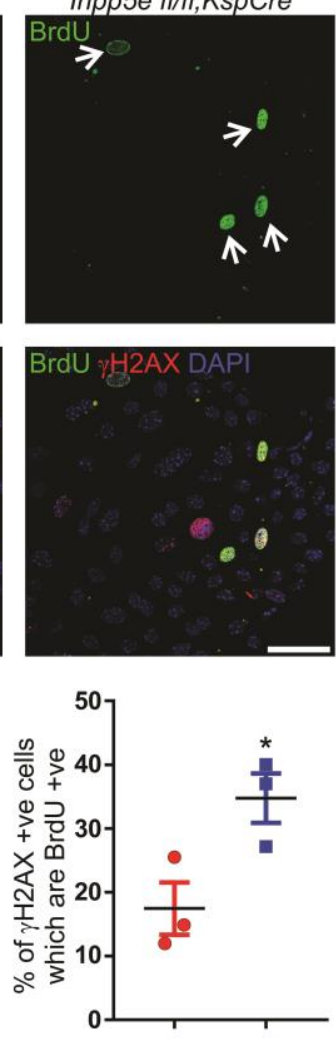

$\square$ Inpp5e +/+;KspCre $(\mathrm{n}=3)$

$\square$ Inpp5e fl/f; KspCre $(\mathrm{n}=3)$
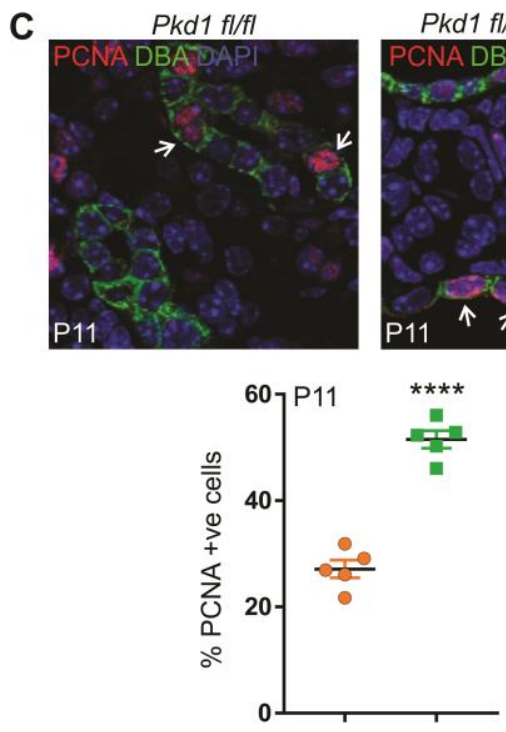

$\square P k d 1 \mathrm{fl} / \mathrm{fl}(\mathrm{n}=5)$

$\square$ Pkd1 fl/fl; Hoxb7Cre $(n=5)$
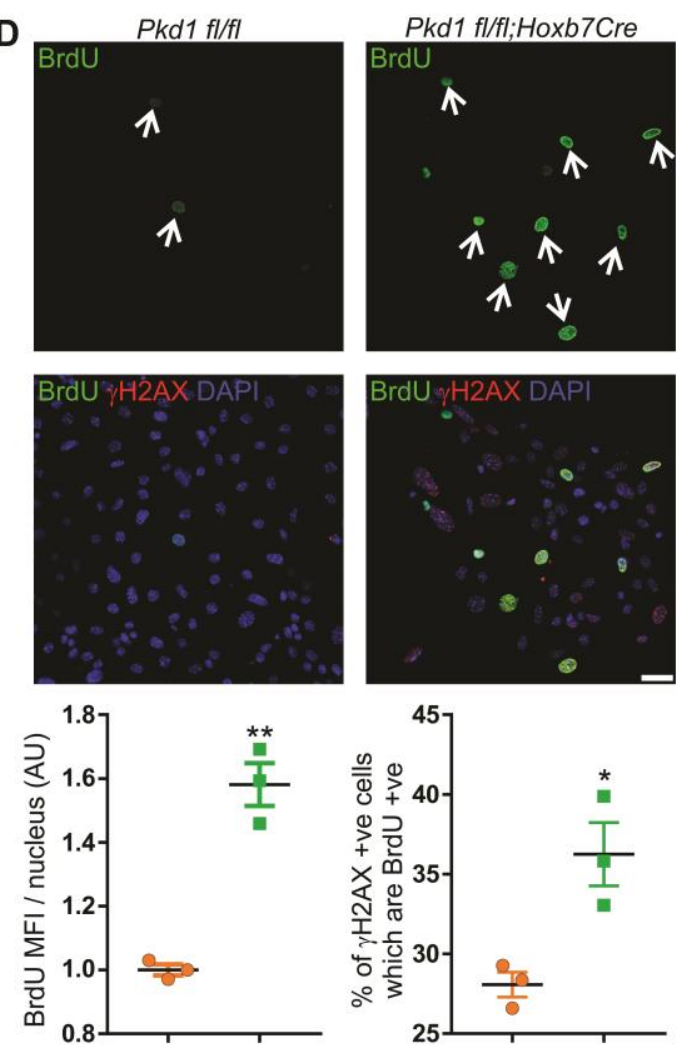

$\square P k d 1 \mathrm{fl} / \mathrm{fl}(\mathrm{n}=3)$

$\square P k d 1 \mathrm{fl} / f l(\mathrm{n}=3)$

$\square$ Pkd1 fl/fl;Hoxb7Cre $(\mathrm{n}=3) \square$ Pkd1 fl/fl; Hoxb7Cre $(\mathrm{n}=3)$

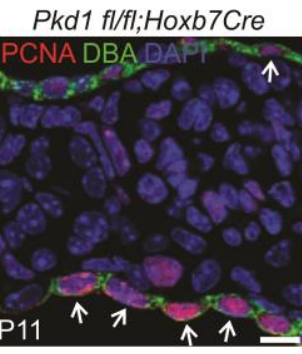

Conduit et al 
Figure 3
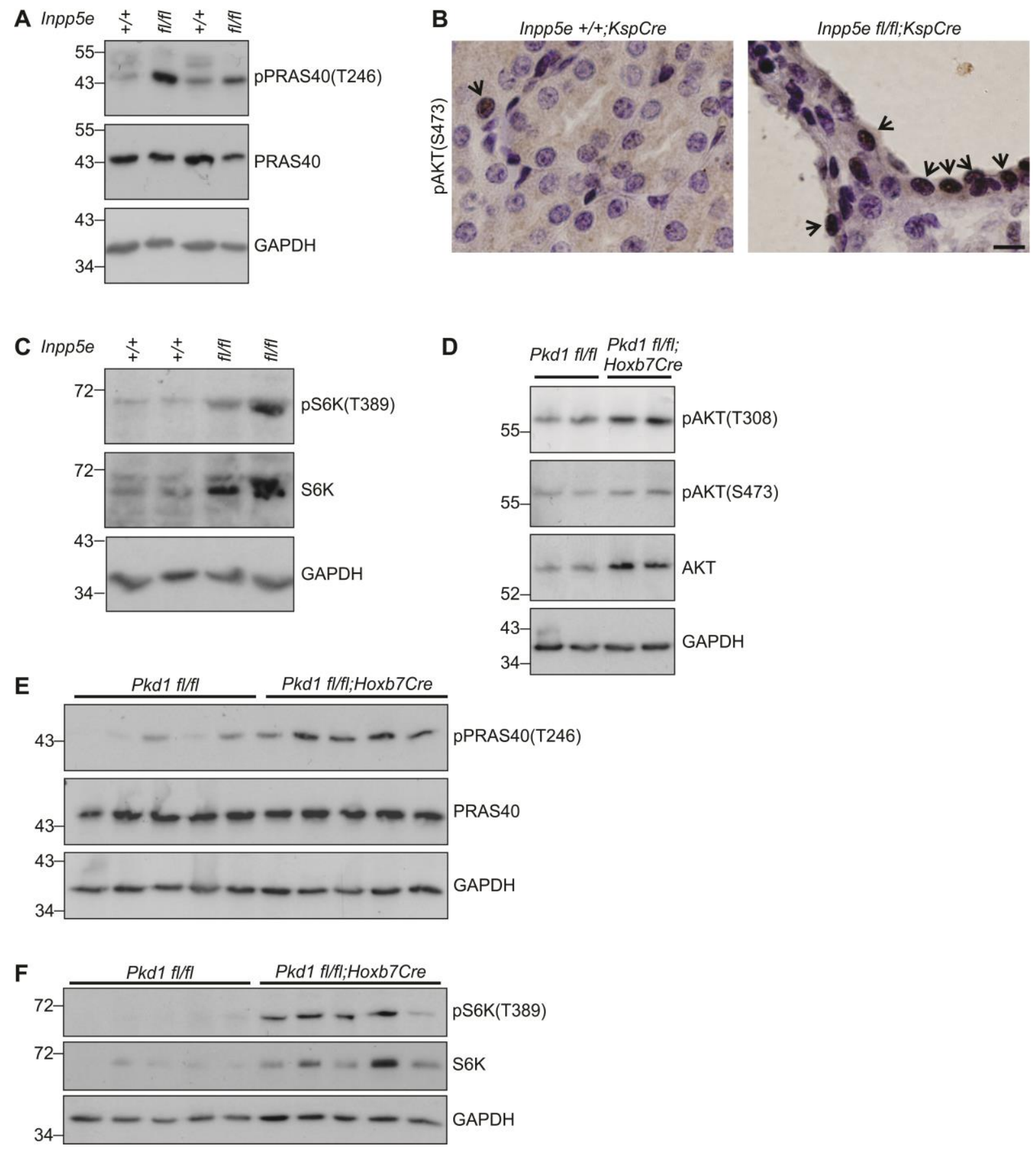
Figure 4

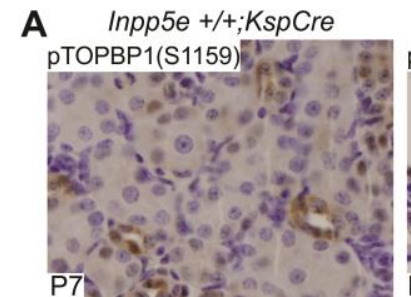

Inpp5e +/+;KspCre

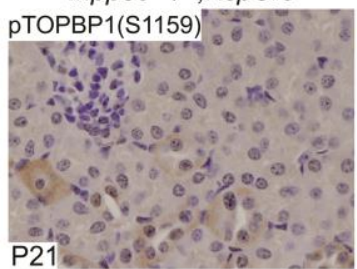

Inpp 5 e $+++;$ KspCre
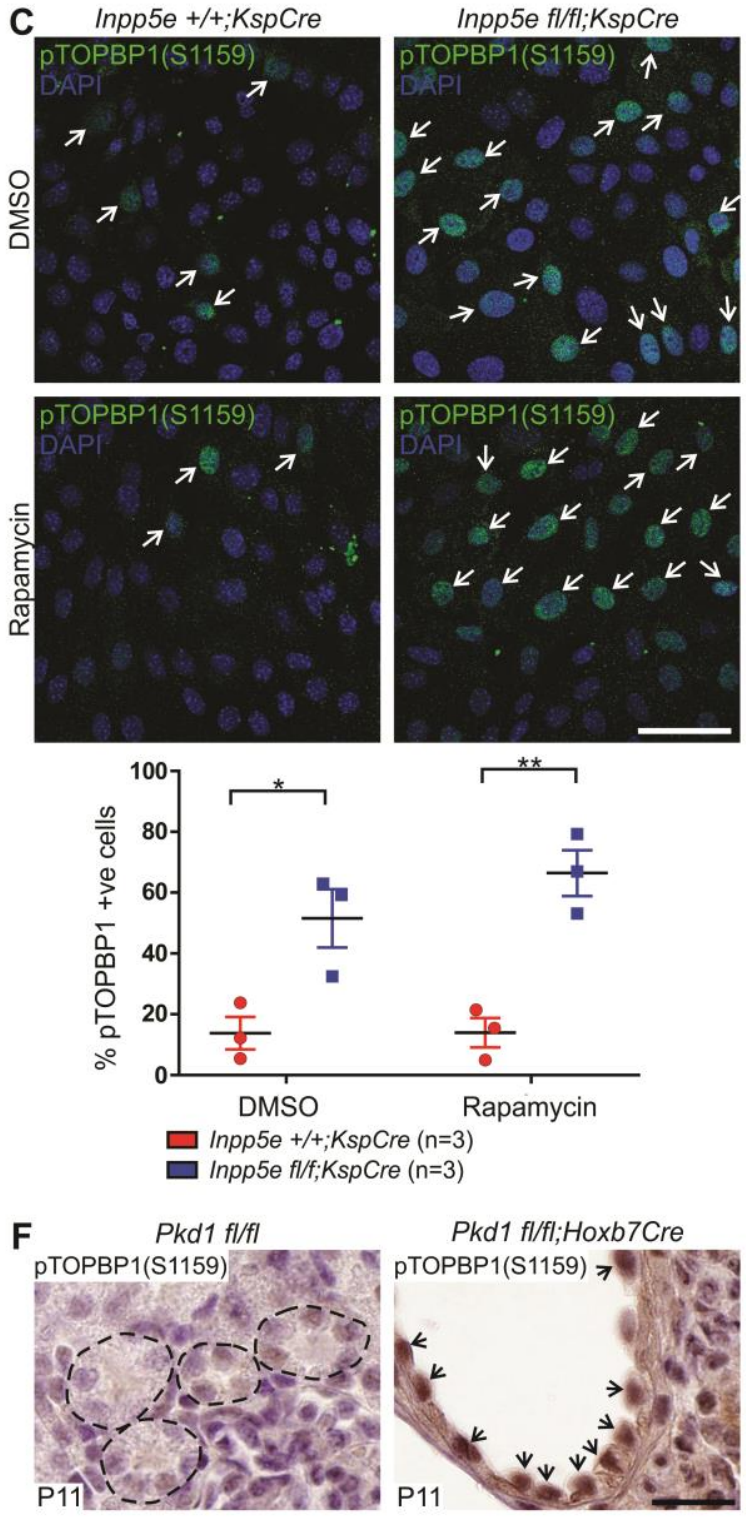

Inpp5e fl/f:KspCre $(\mathrm{n}=3)$

F $\quad P k d 1 \mathrm{fl} / f \mathrm{f}$

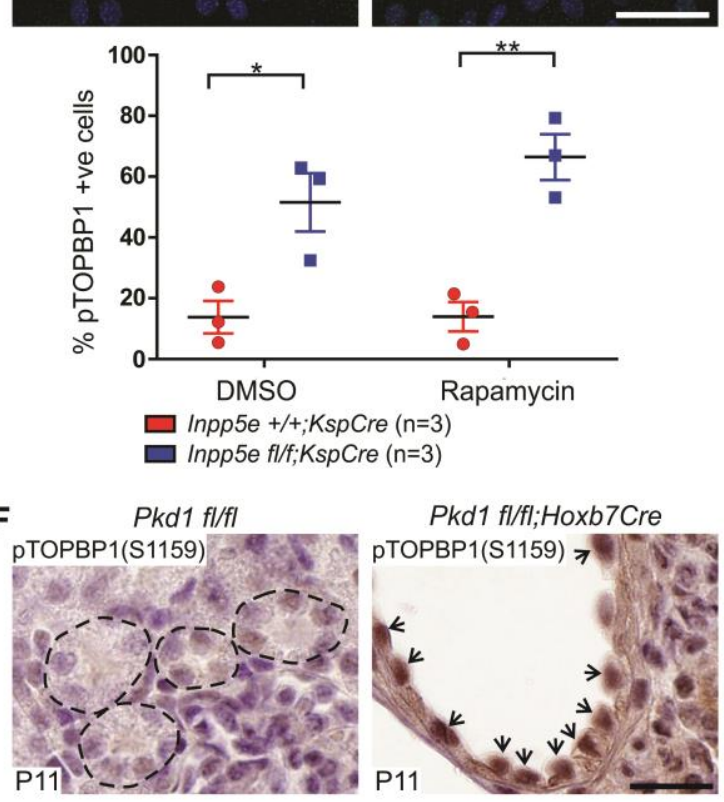

Inpp5e fl/fl;KspCre pTOPBP1(S1159)

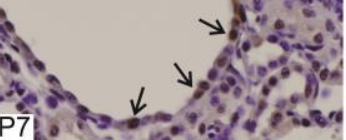
Inpp5e fl/fl;KspCre pTOPBP1(S1159)

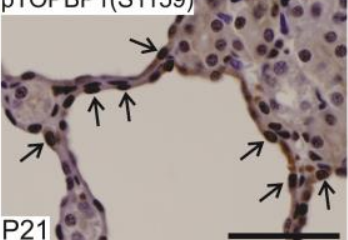

Inpp5e fl/fl; KspCre
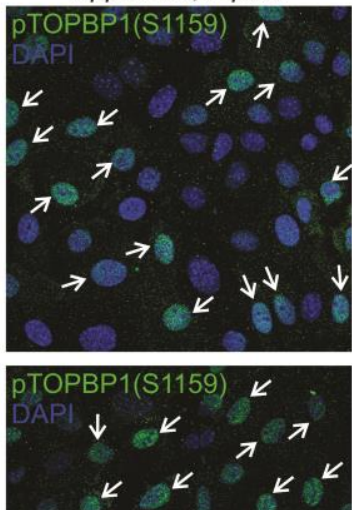

$K K K K K V$

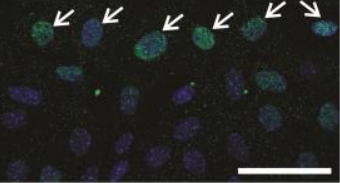

Conduit et al

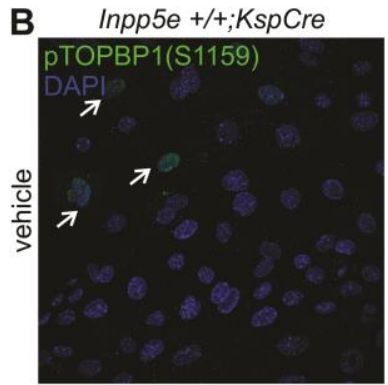

Inpp5e fl/fl;:KspCre
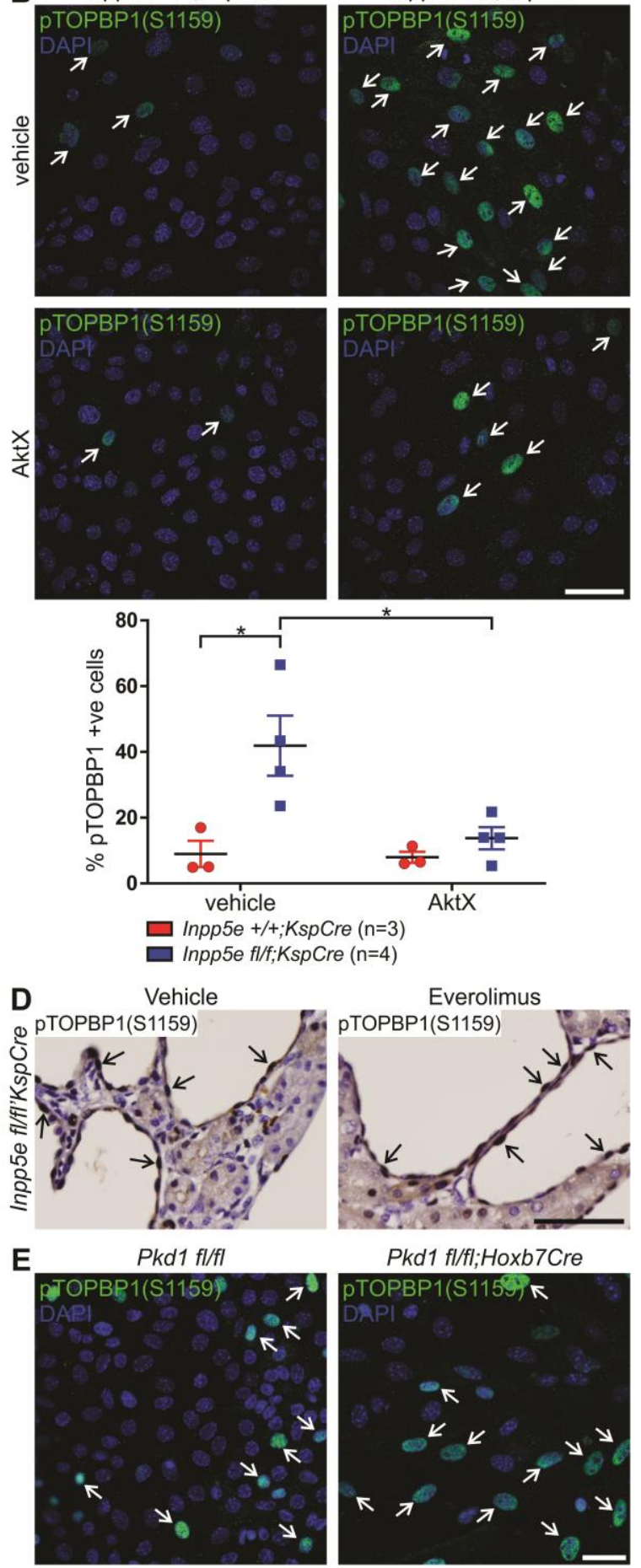

Everolimus

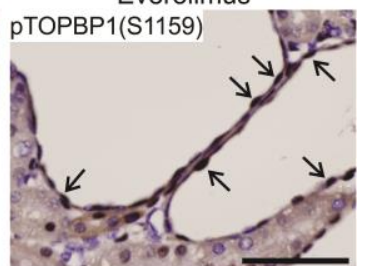

Pkd1 fl/fl; Hoxb7Cre
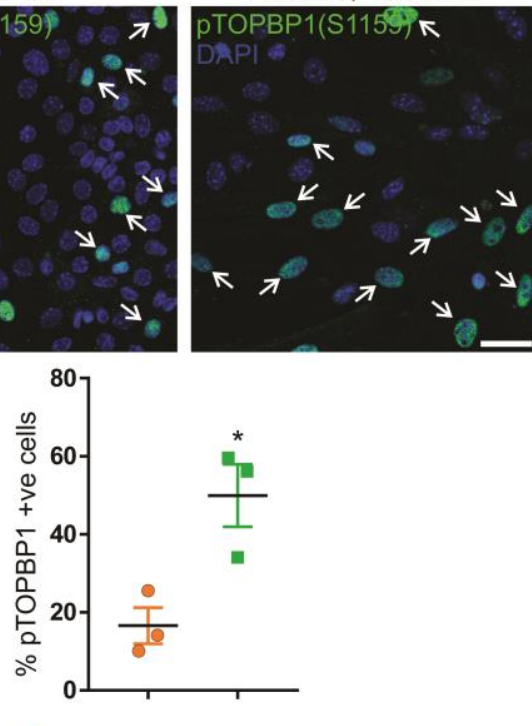

$\square P k d 1$ fl/fl $(\mathrm{n}=3)$

$\square$ Pkd1 fl/fl;Hoxb7Cre (n=3) 
Figure 5
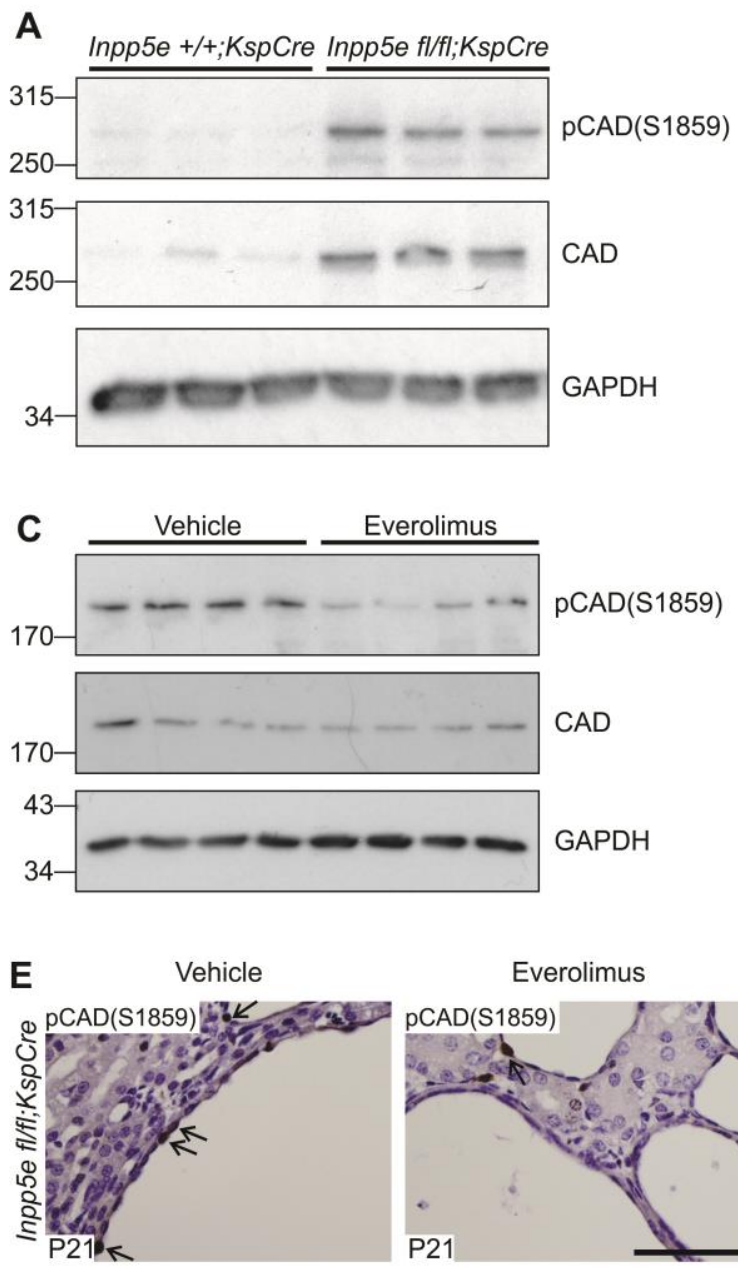

Everolimus
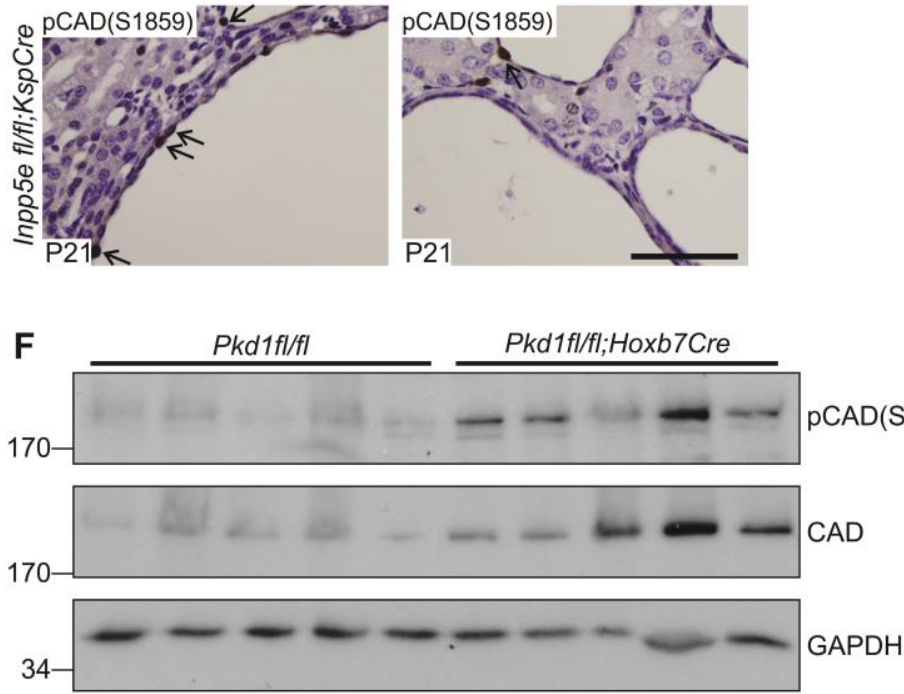

B
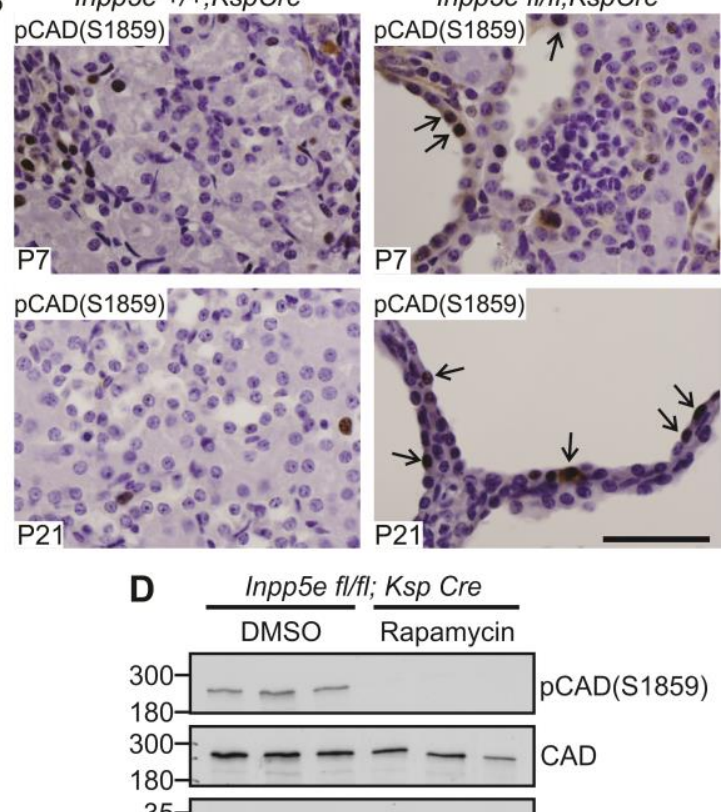

$35--\cdots$

$35---\cdots$ s6
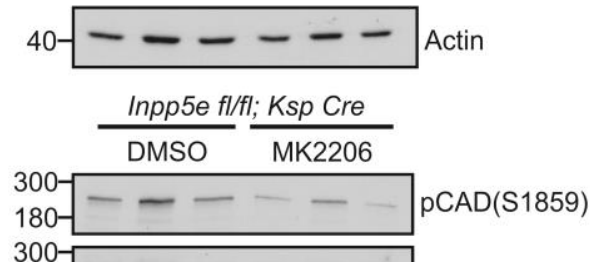

$180-\div-\cdots-\cdots$ CAD

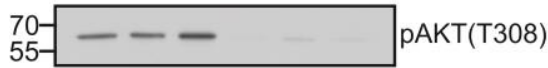

70- $----\ldots$ AKT

$40-----$ Actin

G
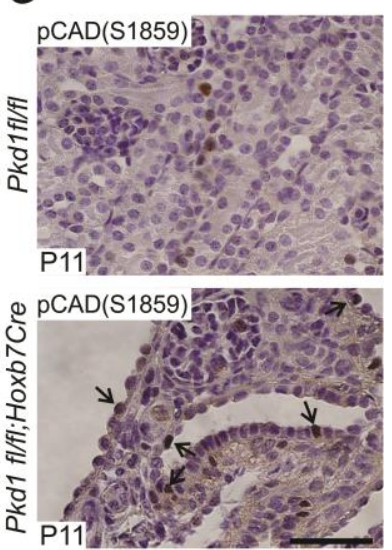
Figure 6
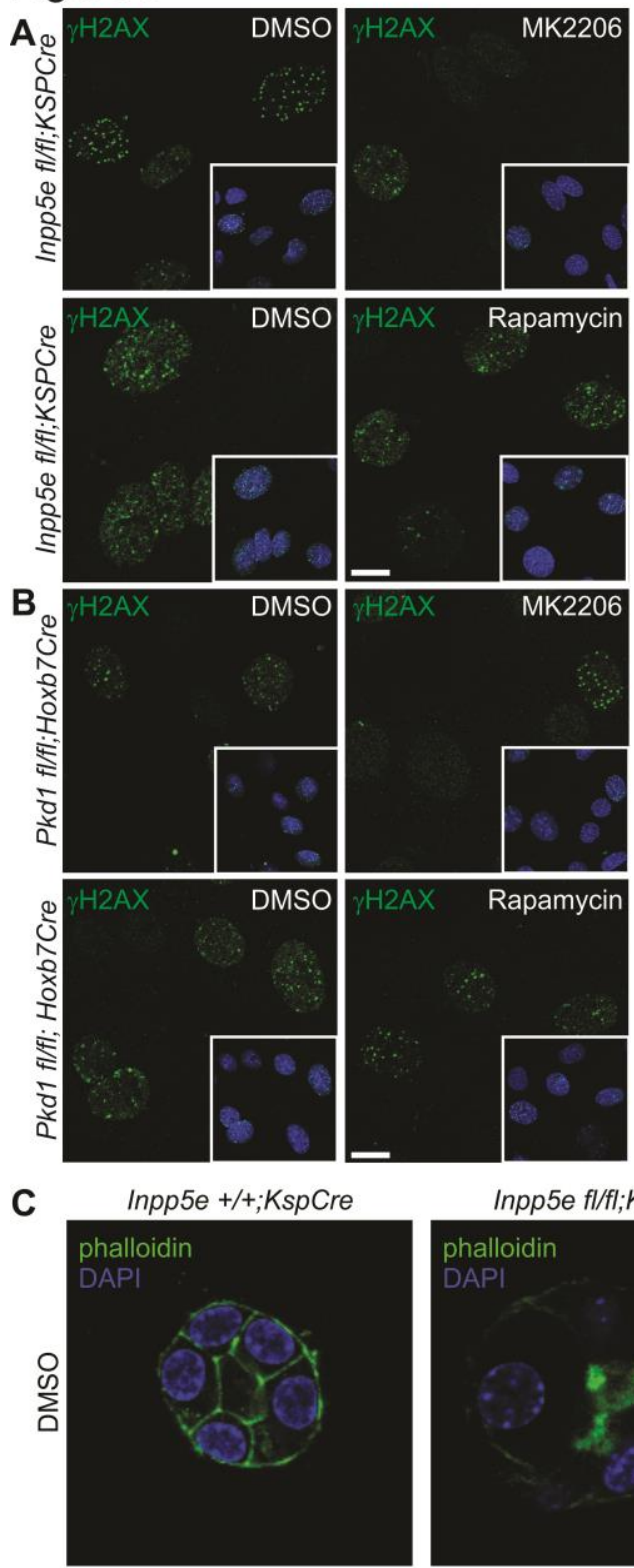

Inpp5e fl/fl;KspCre
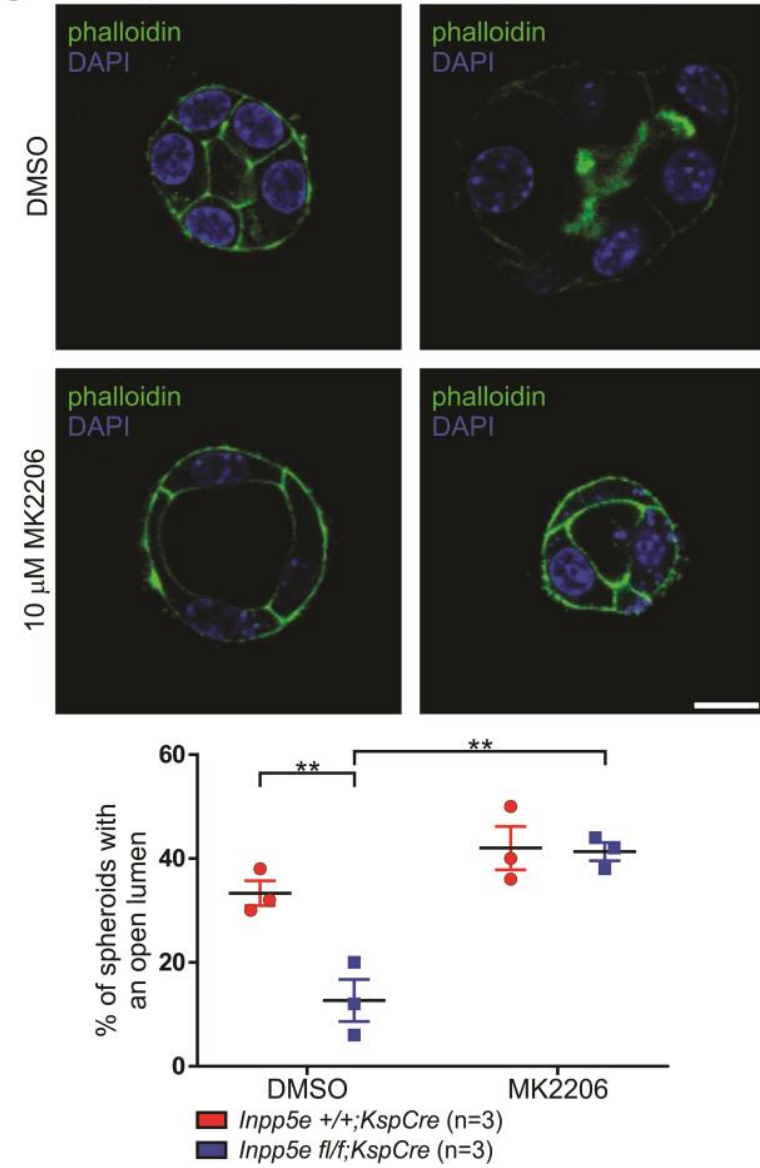

Conduit et al
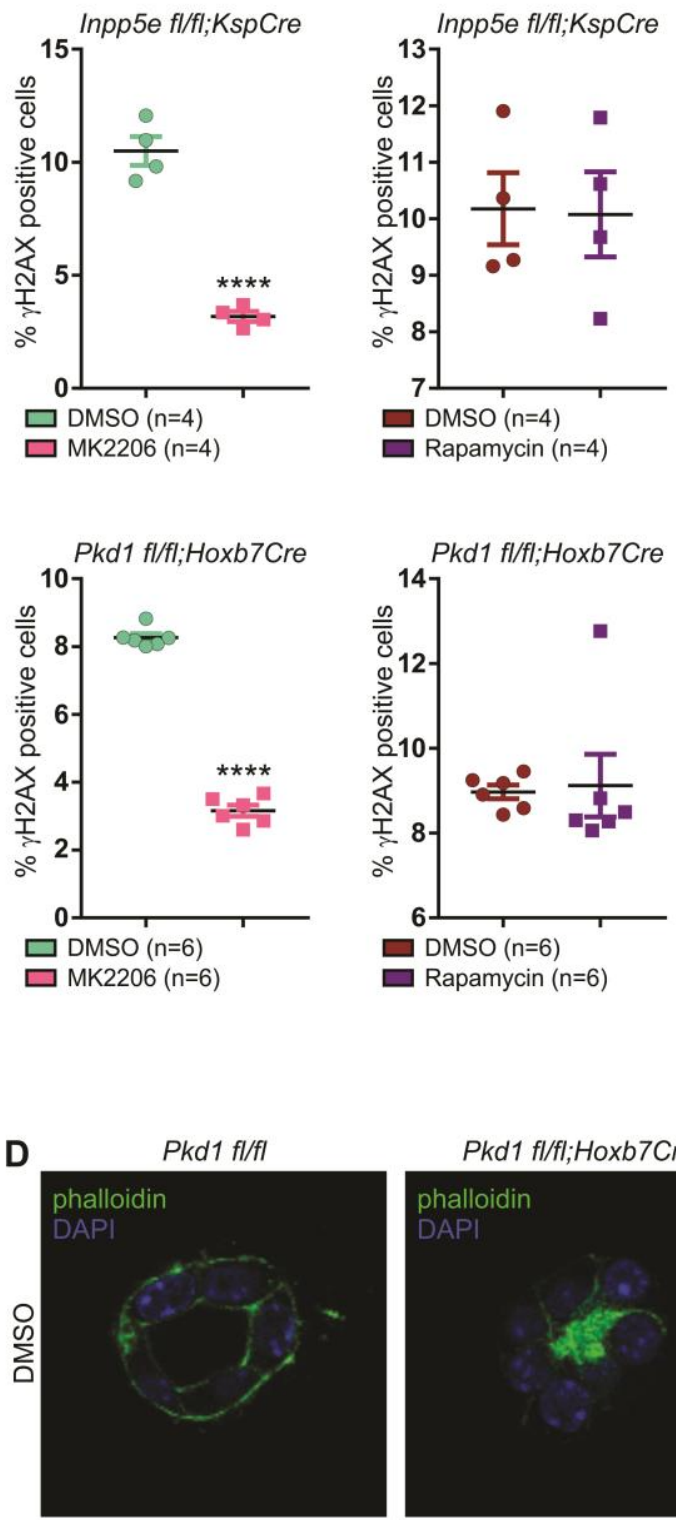

Pkd1 fl/fl;Hoxb7Cre
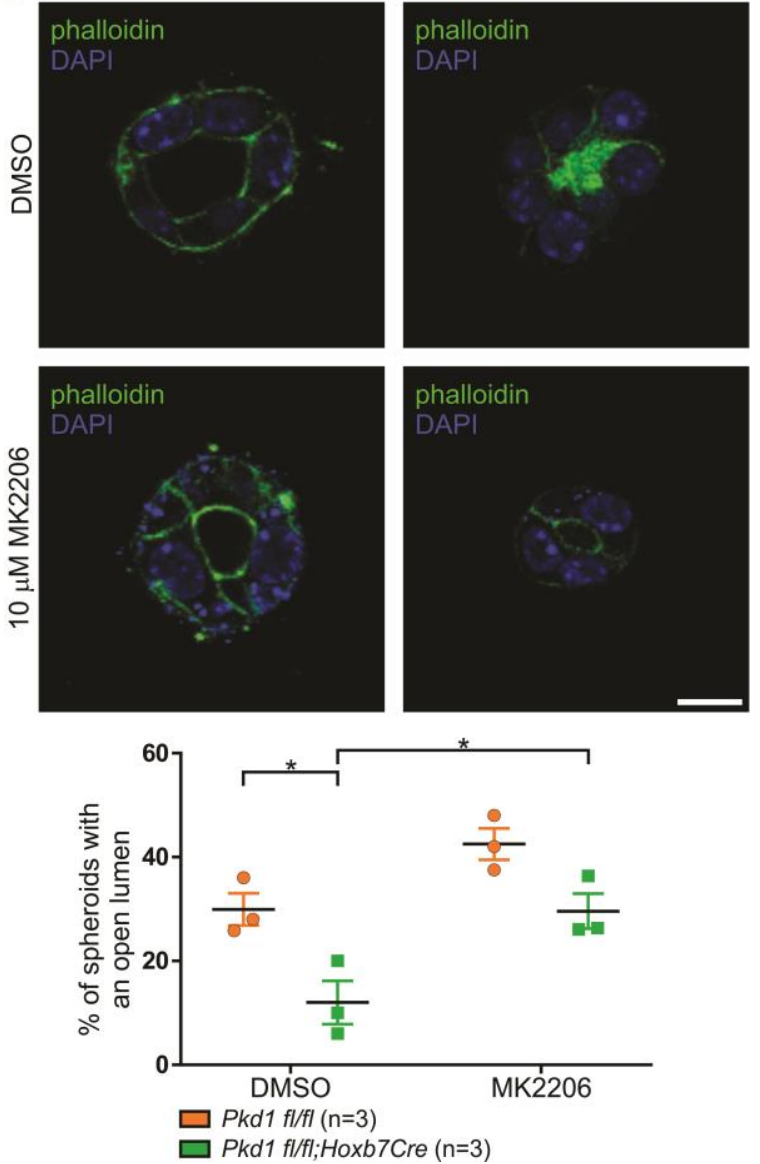
Conduit et al

Figure 7

Conduit et al

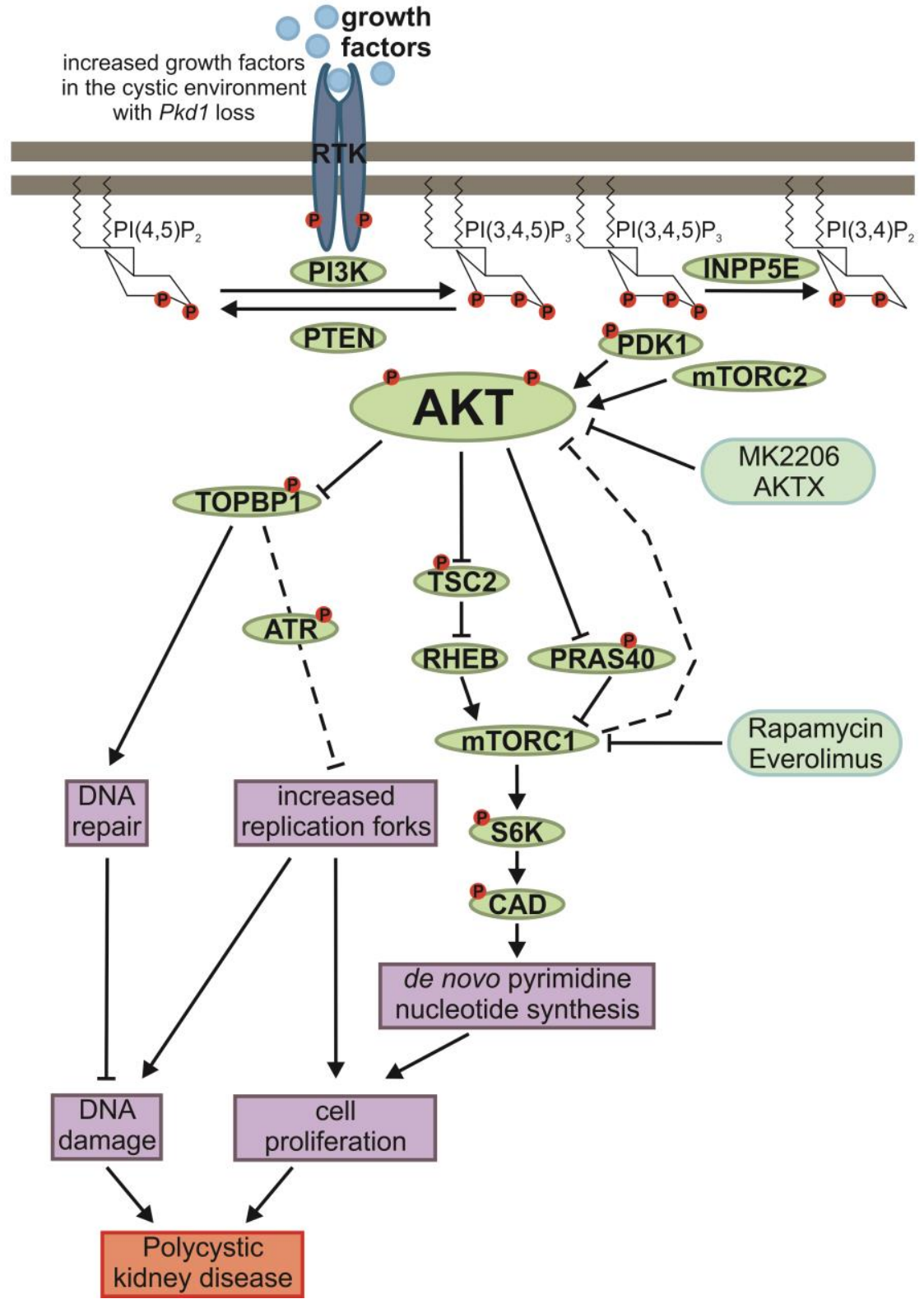


Figure S1

Conduit et al

A

Inpp5e +/+;KspCre

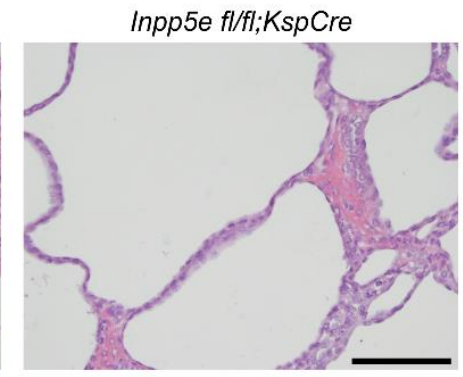

B

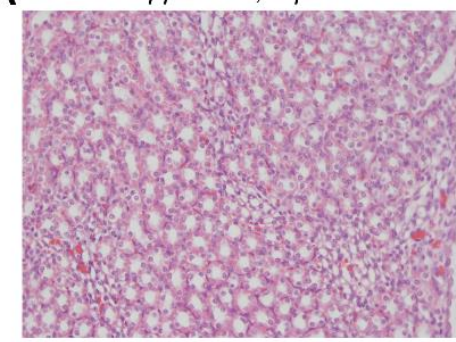

Inpp5e $+/+; K s p C r e$

Inpp5e fl/fl;KspCre
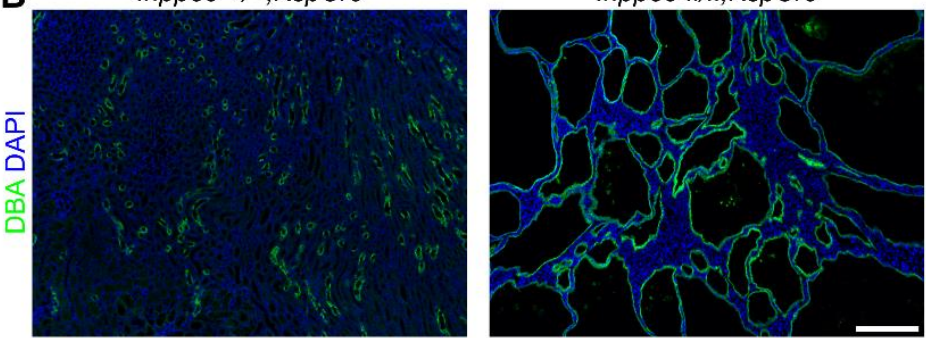

C

$P k d 1 \mathrm{fl} / f l$

Pkd1 fl/fl;Hoxb7Cre

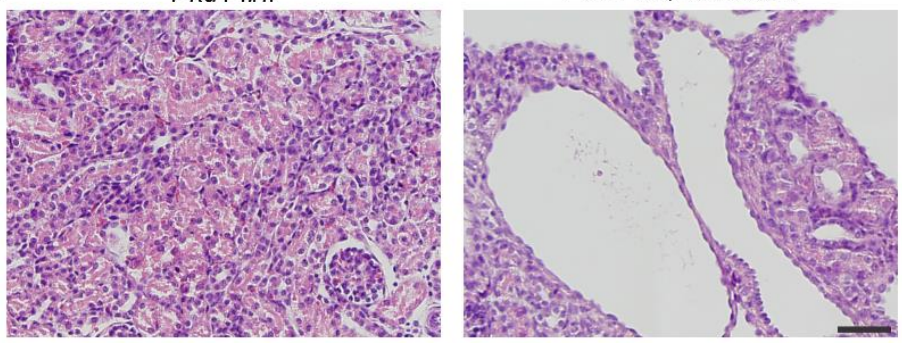

D Inpp5e +/+;KspCre Inpp5e fl/fl;KspCre

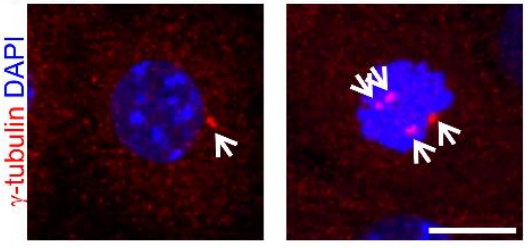

E

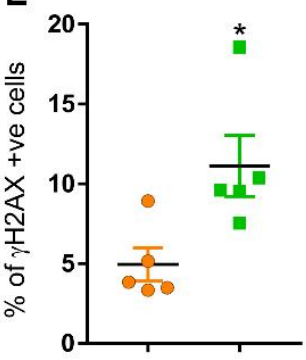

$\square P k d 1$ fl/fI $(\mathrm{n}=5)$

$\square$ Pkd1 fl/fl; Hoxb7Cre ( $\mathrm{n}=5)$

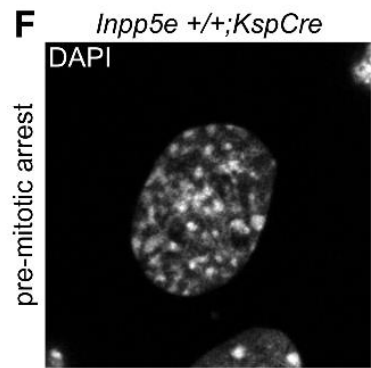

Inpp5e fl/fl;KspCre
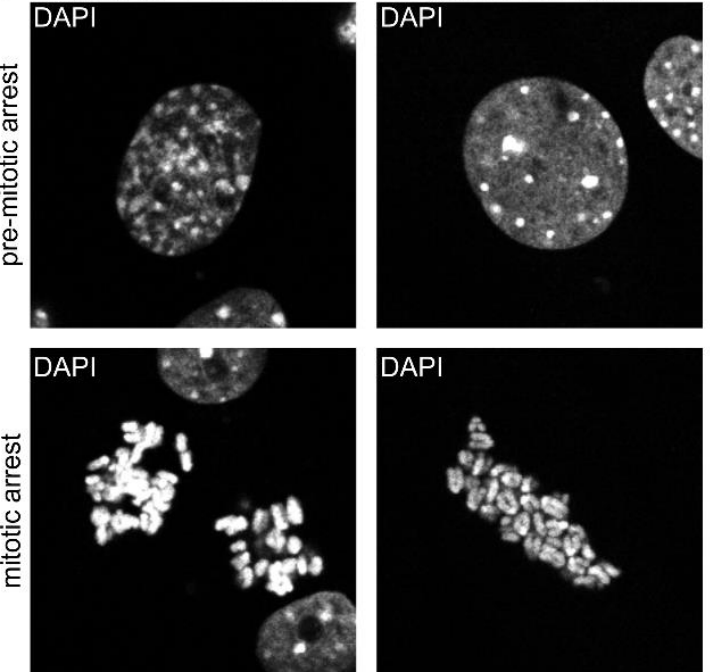

DAPI
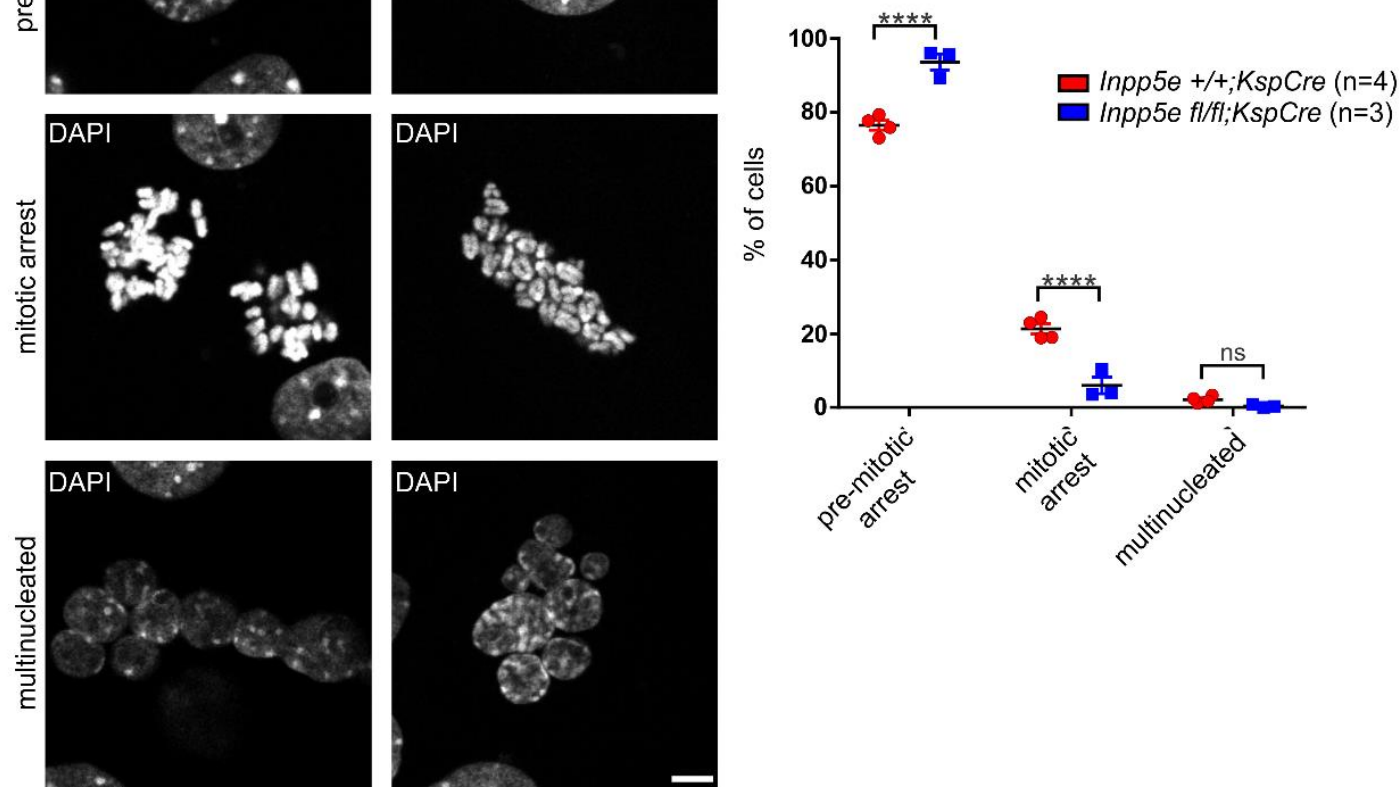

DAPI
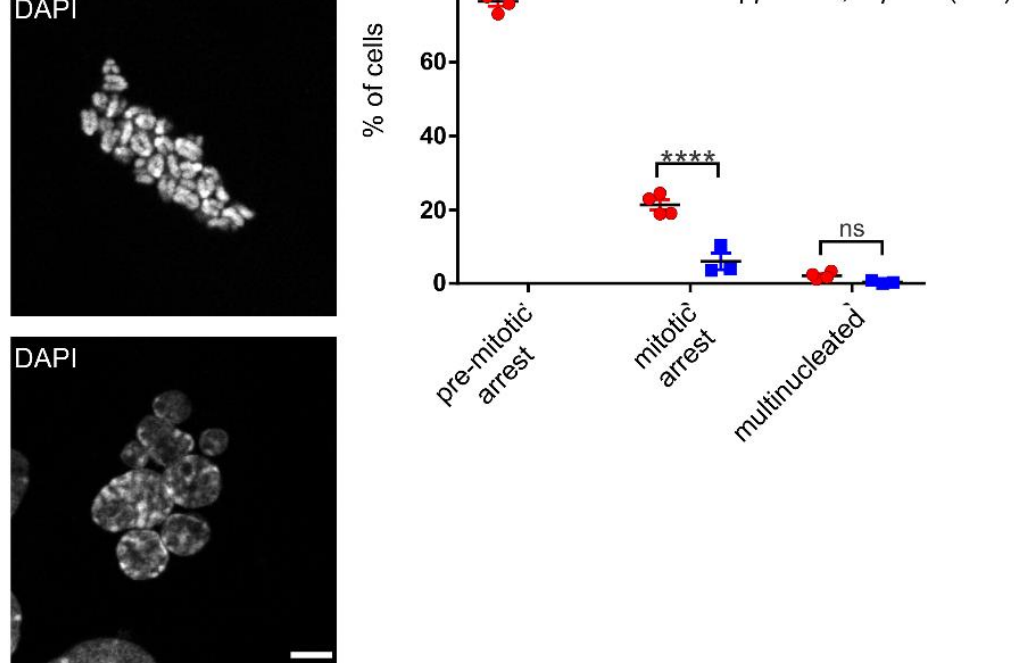


\section{Figure S1: PKD mouse models exhibit DNA damage}

A. Kidney sections from P21 Inpp $5 e^{+/+} ;$KspCre and Inpp $5 e^{f l f l} ;$ KspCre mice stained with H\&E and imaged by brightfield microscopy. Bar indicates $100 \mu \mathrm{m}$, images are representative of $n=5$ mice of each genotype.

B. Kidney sections from P21 Inpp5 $e^{+/+} ; K s p C r e$ and Inpp $5 e^{f l / f l} ; K s p C r e$ mice stained with the collecting duct marker DBA and DAPI and imaged by widefield microscopy. Bar indicates 200 $\mu \mathrm{m}$, images are representative of $\mathrm{n}=4-5$ mice of each genotype.

C. Kidney sections from P11Pkdl flfl and Pkd ${ }^{f l f f l}$;Hoxb7Cre mice stained with H\&E and imaged by brightfield microscopy. Bar indicates $50 \mu \mathrm{m}$, images are representative of $\mathrm{n}=5$ mice of each genotype.

D. pRECs isolated from P16 Inpp $5 e^{+/+} ;$KspCre and Inpp $5 e^{f l f l} ; K s p C r e$ kidneys were immunostained with $\gamma$-tubulin (red) antibodies and DAPI (blue) and imaged by confocal microscopy. Bar indicates $50 \mu \mathrm{m}$. Arrows indicate centrosomes.

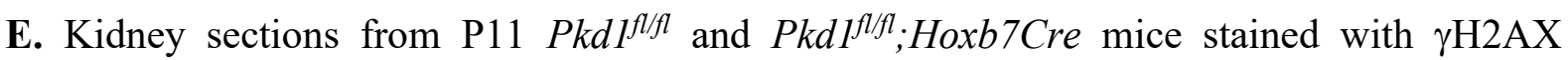
antibodies, counter stained with collecting duct marker DBA and DAPI and imaged by confocal microscopy (representative images presented in figure 1F). Graph shows the percentage of collecting duct cells positive for $\gamma \mathrm{H} 2 \mathrm{AX}$ immunoreactivity relative to total nuclei number. Bars represent mean \pm SEM, $n=5$ mice of each genotype, at least 289 cells from 10 random fields scored per mouse, $* \mathrm{p}<0.05$.

F. Inpp $5 e^{+/+} ;$KspCre and Inpp $5 e^{f l f l} ;$ KspCre pRECs were treated with $400 \mathrm{ng} / \mathrm{ml}$ Nocodozole for 8 hours to induce the spindle assembly check point, stained with DAPI and imaged by confocal microscopy. Images show representative cells exhibiting pre-mitotic arrest, mitotic arrest or multinucleation. Graph shows the percentage of cells exhibiting pre-mitotic arrest, mitotic arrest or multinucleation indicating slipping through the spindle assembly check point. Bars represent mean \pm SEM, $n=3-4$ cell lines of each genotype, each derived from an individual mouse, statistical significance was determined using two-way ANOVA (interaction $p<0.0001$, row factor $\mathrm{p}<0.0001$, column factor $\mathrm{p}>0.9999$ ) followed by Tukey's post hoc test, $* * * * \mathrm{p}<0.0001$, ns: not significant. 
Figure S2
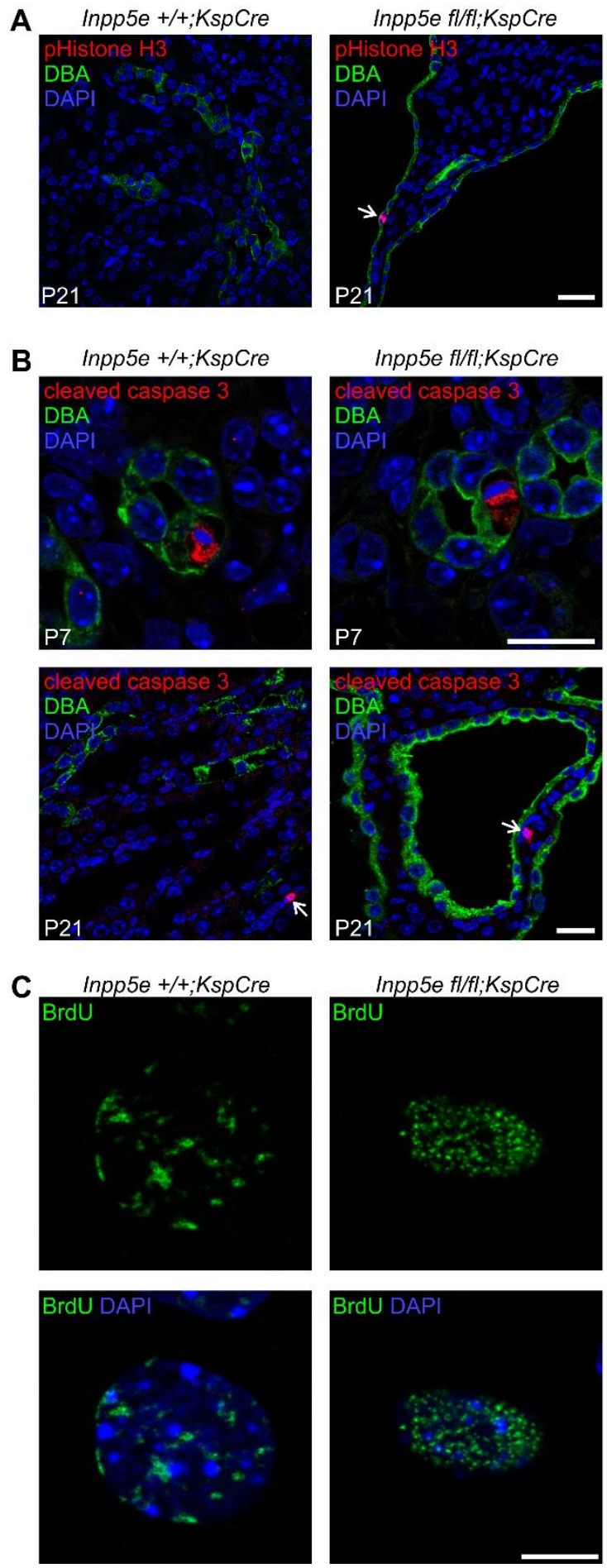

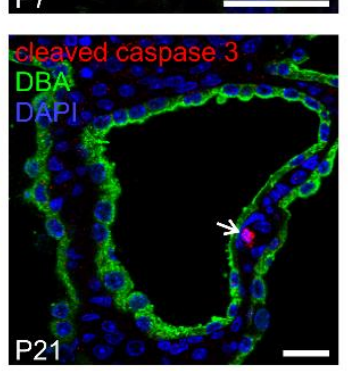

Inpp5e fl/fl;KspCre

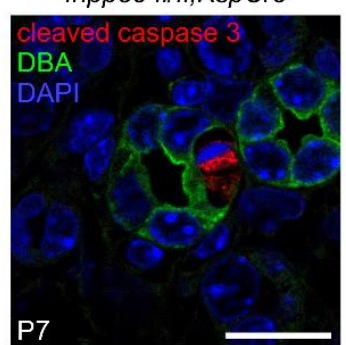

Inpp5e fl/fl;KspCre
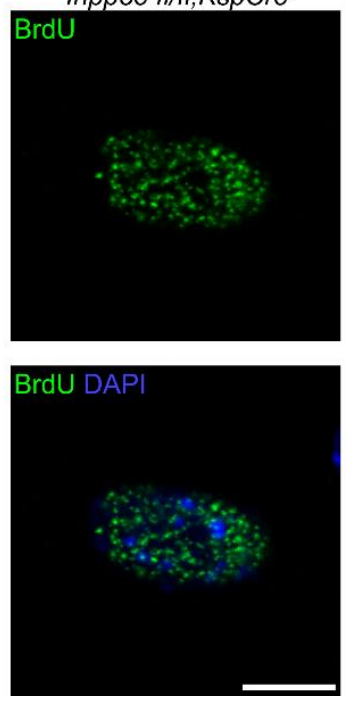

Conduit et al

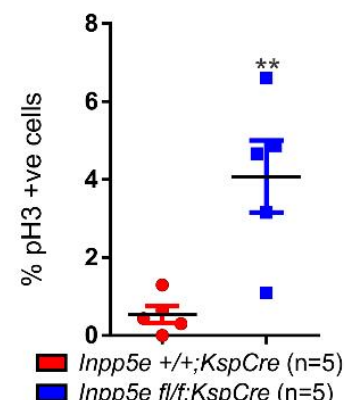

- Inpp5e fl/f;KspCre ( $\mathrm{n}=5$ )

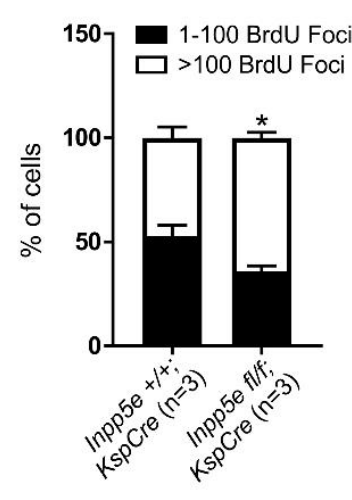


Figure S2: Inpp5e-null renal epithelial cells exhibit increased proliferation but no change in apoptosis

A. Kidney sections from P21 Inpp5 $5 e^{+/+} ;$KspCre and Inpp $5 e^{f l / f l} ; K s p C r e$ mice stained with pHistone $\mathrm{H} 3$ antibodies (red), counter stained with collecting duct marker DBA (green) and DAPI (blue) and imaged by confocal microscopy. Arrow indicates pHistone H3 immunopositive collecting duct nucleus. Bar indicates $25 \mu \mathrm{m}$. Graph shows the percentage of collecting duct cells positive for pHistone $\mathrm{H} 3$ immunoreactivity relative to total nuclei number. Bars represent mean $\pm \mathrm{SEM}, \mathrm{n}=5$ mice of each genotype, at least 182 cells from 10 random fields scored per mouse, $* * \mathrm{p}<0.01$.

B. Kidney sections from (top) P7 or (bottom) P21 Inpp $5 e^{+/+} ; K s p C r e$ and Inpp $5 e^{\text {fllfl }} ;$ KspCre mice stained with cleaved caspase 3 antibodies (red), counter-stained with collecting duct marker DBA (green) and DAPI (blue) and imaged by confocal microscopy. Arrows indicate cleaved caspase 3 immunopositive nuclei. Bar indicates (top) 10 or (bottom) $20 \mu \mathrm{m}$, images are representative of $n=3-5$ mice of each genotype.

C. pRECs isolated from P16 Inpp $5 e^{+/+} ;$KspCre and Inpp $5 e^{f l f l} ;$ KspCre kidneys were pulsed with BrdU for 45 minutes, co-stained with BrdU (green) antibodies and DAPI (blue) and imaged by confocal microscopy. Bar indicates $8 \mu \mathrm{m}$. The number of BrdU puncta per $\mathrm{S}$ phase nucleus was scored. Graph shows the percentage of cells with 1-100 or $>100$ BrdU puncta per nucleus. Bars represent mean $\pm \mathrm{SEM}, \mathrm{n}=3$ cell lines of each genotype, each derived from an individual mouse, with 40 cells scored per cell line, ${ }^{*} \mathrm{p}<0.05$. 
A

P16 Inpp5e +/+; Inpp5e fl/fl;
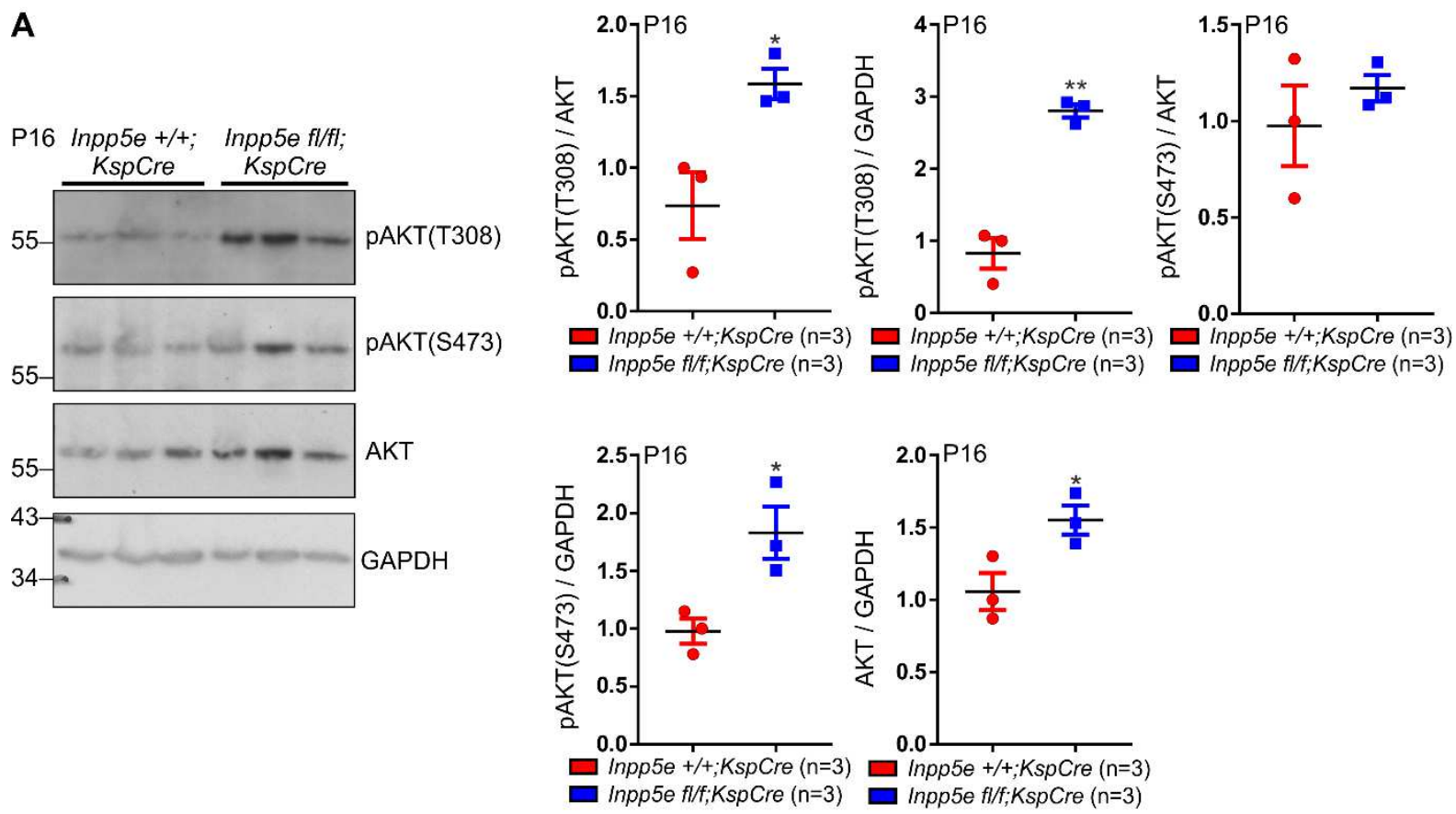

B

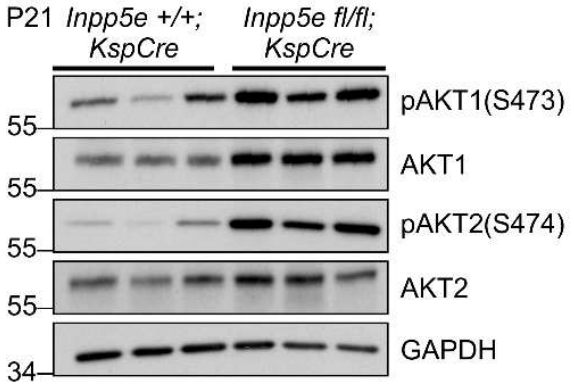

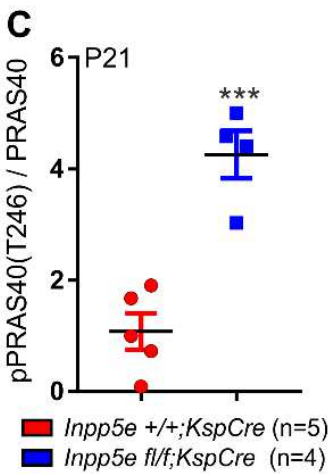

D

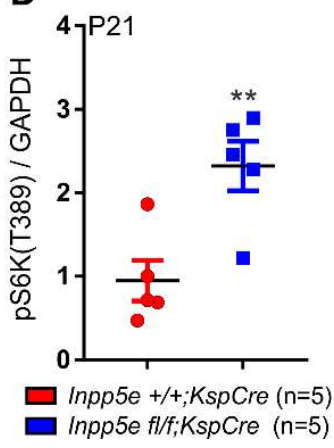

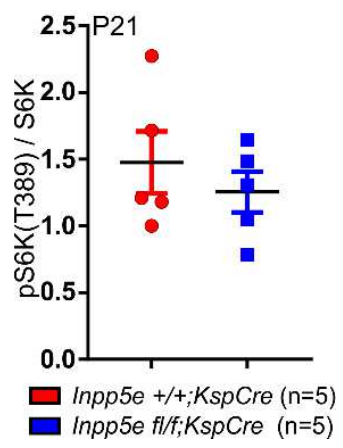




\section{Figure S3: AKT/mTORC1 signaling is increased in Inpp5e fllfl;KspCre kidneys}

A. P16 Inpp $5 e^{+/+} ; K s p C r e$ and Inpp $5 e^{f l f l} ; K s p C r e$ kidney lysates were immunoblotted with pAKT(T308), pAKT(S473), AKT or GAPDH antibodies. Each lane represents lysate from an individual mouse. Graphs show densitometric analysis. Bars represent mean $\pm \mathrm{SEM}, \mathrm{n}=3$ mice of each genotype, ${ }^{*} \mathrm{p}<0.05, * * \mathrm{p}<0.01$.

B. P21 Inpp $5 e^{+/+} ; K s p C r e$ and Inpp5 $e^{f l / f l} ; K s p C r e$ kidney lysates were immunoblotted with pAKT1(S473), AKT1, pAKT2(S474), AKT2 or GAPDH antibodies. Each lane represents lysate from an individual mouse.

C-D. P21 Inpp $5 e^{+/+} ;$KspCre and Inpp $5 e^{f l / f l} ; K s p C r e$ kidney lysates were immunoblotted with (C) pPRAS40(T246), PRAS40, (D) pS6K(T389), S6K or GAPDH antibodies, as shown in Figure 3A, C. Graphs show densitometric analysis. Bars represent mean \pm SEM, $n=4-5$ mice of each genotype, $* * p<0.01, * * * p<0.001$. 
A
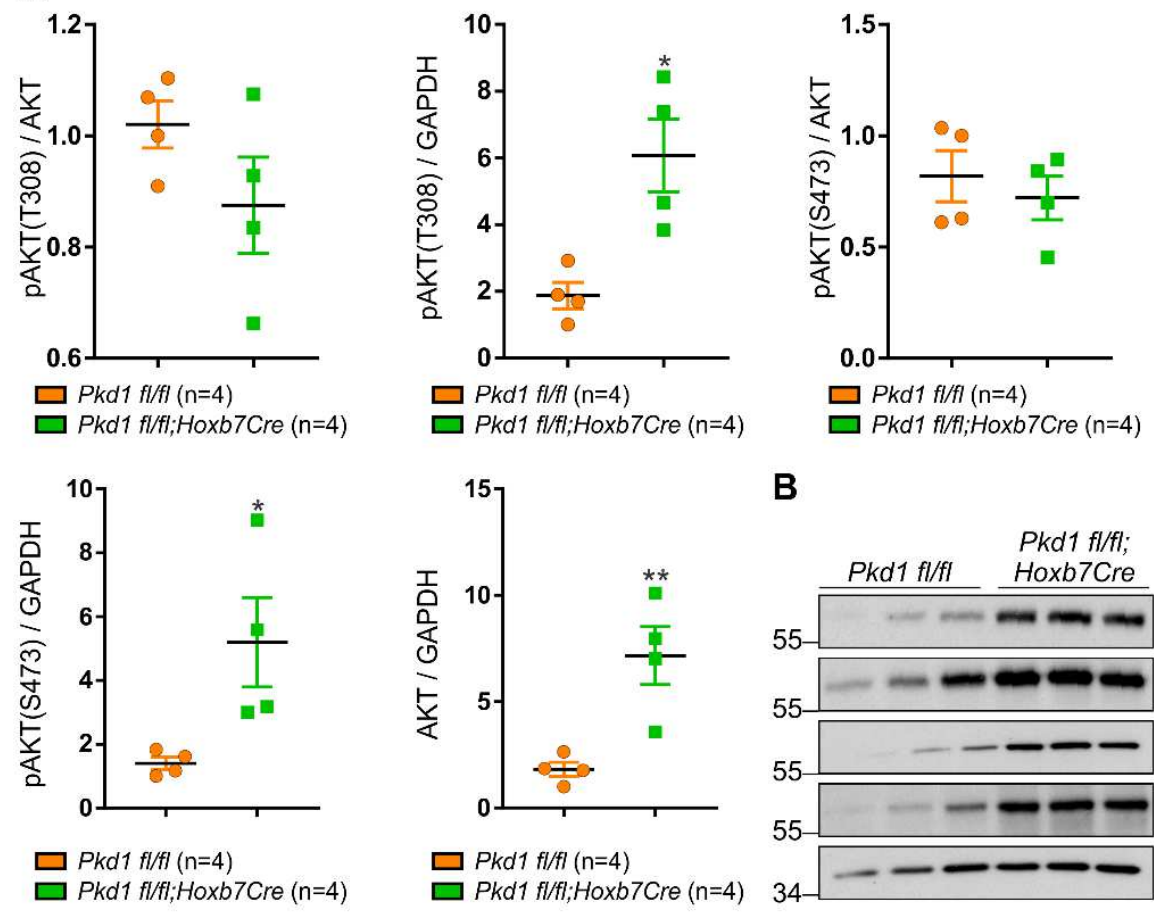

B

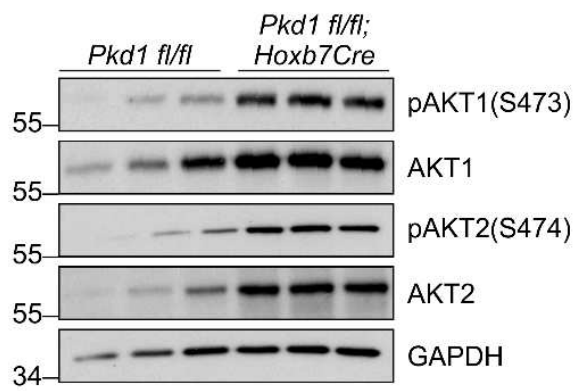

C

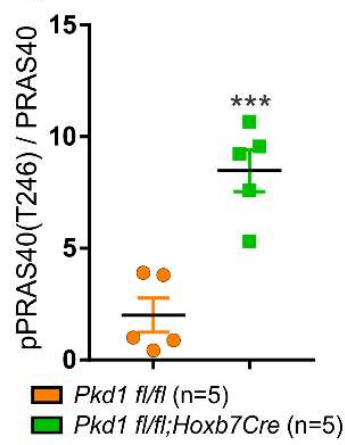

D
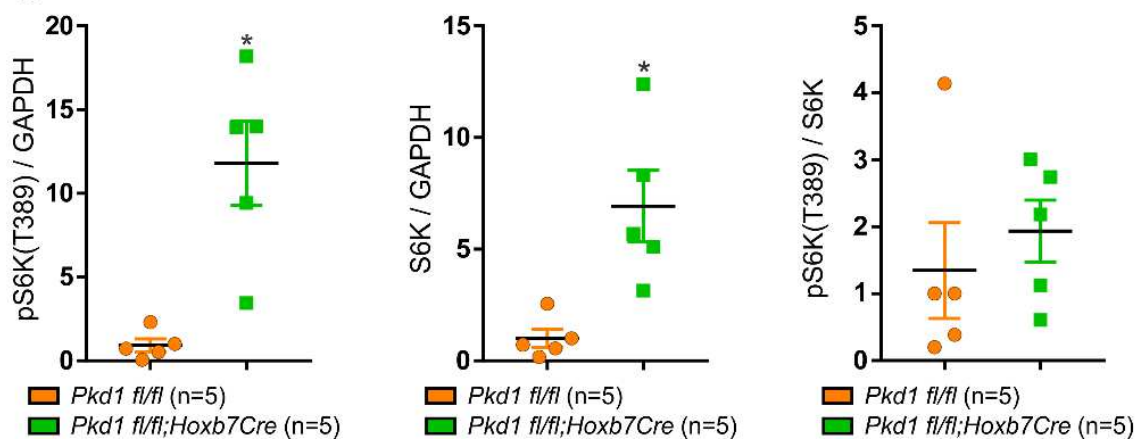
Figure S4: AKT/mTORC1 signaling is increased in Pkd1 ${ }^{f l f l}$;Hoxb7Cre kidneys

A-D. P11 Pkdl $I^{f l f l}$ and $P k d l^{f l f l}$;Hoxb7Cre kidney lysates were immunoblotted with (A) pAKT(T308), pAKT(S473), AKT, (B) pAKT1(S473), AKT1, pAKT2(S474), AKT2, (C) pPRAS40(T246), PRAS40, (D) pS6K(T389), S6K or GAPDH antibodies. Each lane represents lysates from an individual mouse. Graphs show densitometric analysis. Bars represent mean \pm SEM, $\mathrm{n}=4-5$ mice of each genotype, $* \mathrm{p}<0.05, * * \mathrm{p}<0.01, * * * \mathrm{p}<0.001$. 
Figure S5
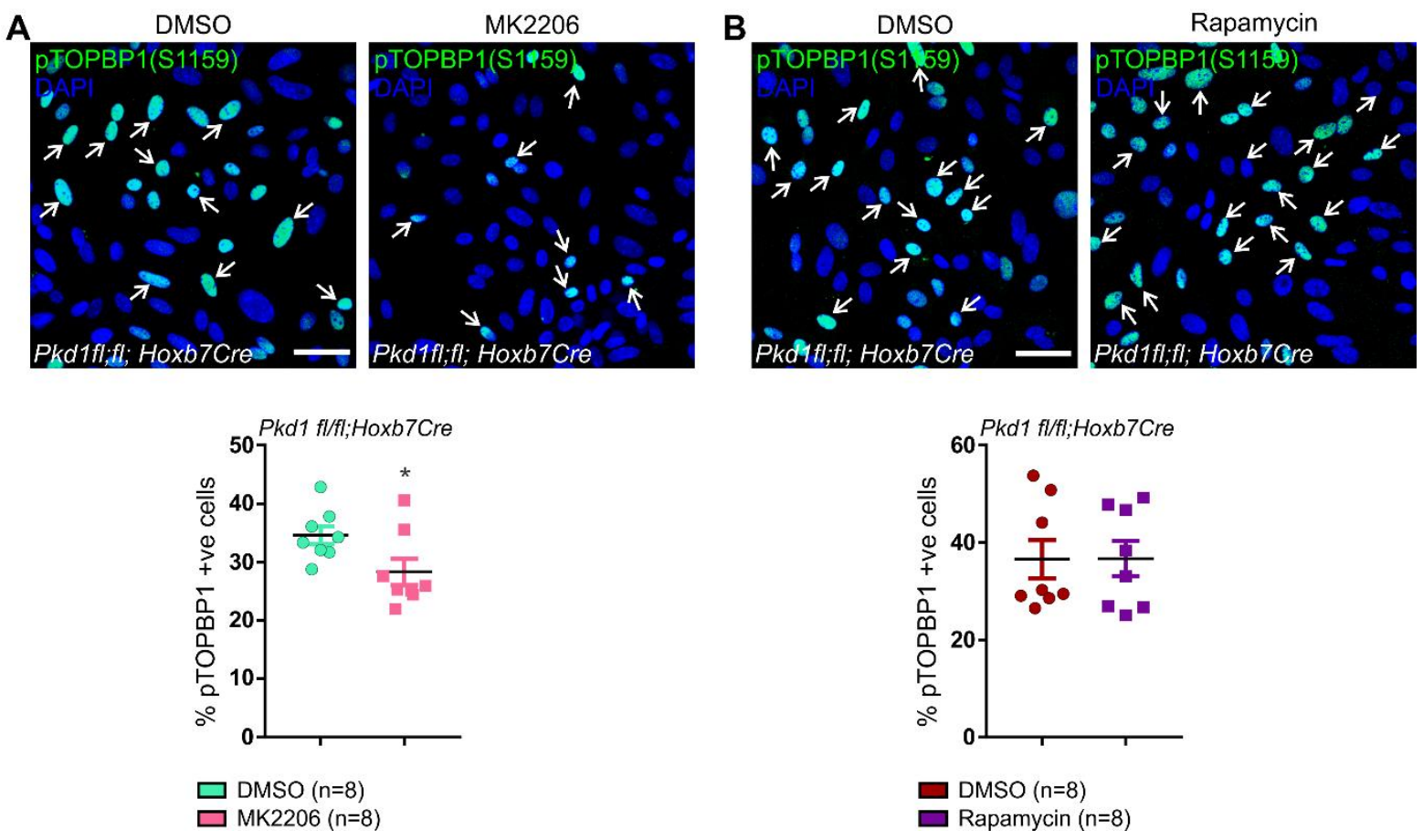

Figure S5: Pkd1 null pRECs exhibit AKT-dependent TOPBP1 phosphorylation

A-B. Pkdl flfl ;Hoxb7Cre RECs were treated with (A) DMSO or $1 \mu \mathrm{M}$ MK2206, or (B) DMSO or $100 \mathrm{nM}$ Rapamycin for 24 hours, stained with pTOPBP1(S1159) antibodies (green) and DAPI (blue) and imaged by confocal microscopy. Bar indicates $50 \mu \mathrm{m}$. Graph shows the percentage $\mathrm{pTOPBP}$ (S1159) positive cells. Bars represent mean $\pm \mathrm{SEM}, \mathrm{n}=8$ cell lines of each genotype, each derived from an individual mouse, with at least 502 cells scored per cell line, per condition, $* \mathrm{p}<0.05$. 
A
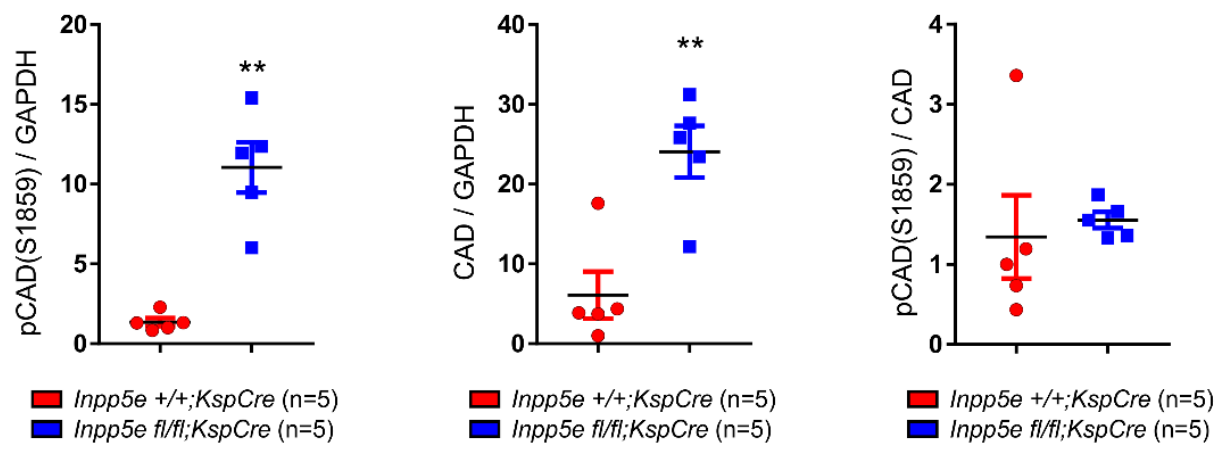

B
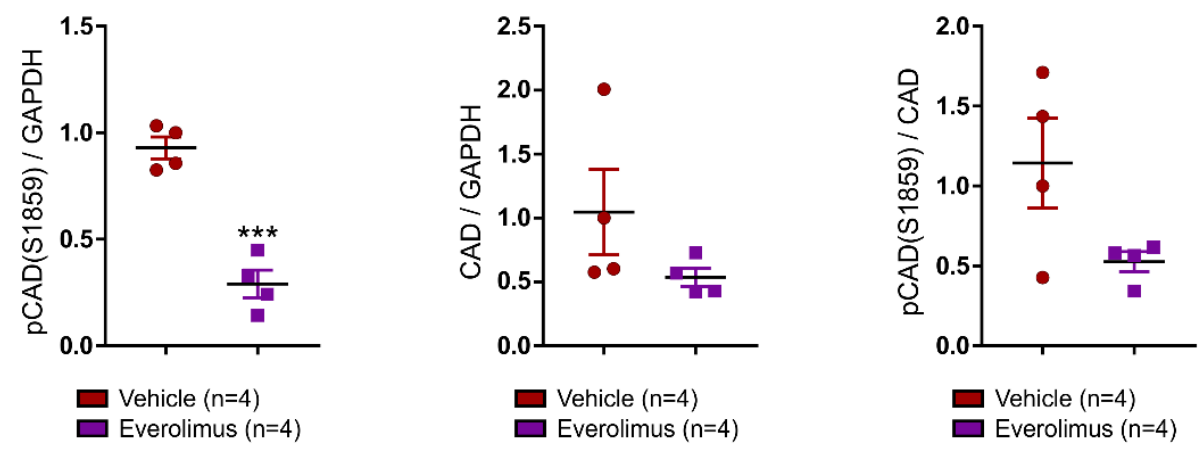

C
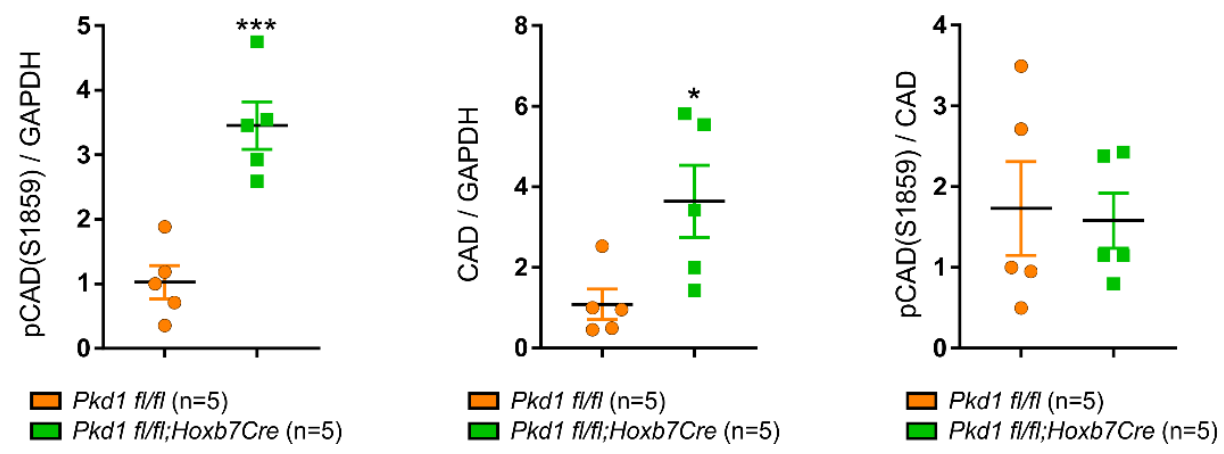

Figure S6: PKD models exhibit increased phosphorylated and total CAD

A-C. Kidney lysates from (A) P21 Inpp5 $e^{+/+} ; K s p C r e$ and Inpp 5e $e^{f l / f l} ; K s p C r e$, (B) P21 vehicle and Everolimus treated Inpp5e $e^{f l f l} ; K s p C r e$ or (C) P11 Pkd1 $1^{f l f l}$ and Pkd $1^{f l f l}$;Hoxb7Cre mice were immunoblotted with pCAD(S1859), CAD or GAPDH antibodies. Graphs show densitometric analysis. Bars represent mean \pm SEM, $n=4-5$ mice of each genotype, ${ }^{*} p<0.05$, $* * \mathrm{p}<0.01, * * * \mathrm{p}<0.001$. 
Figure S7

Conduit et al

A

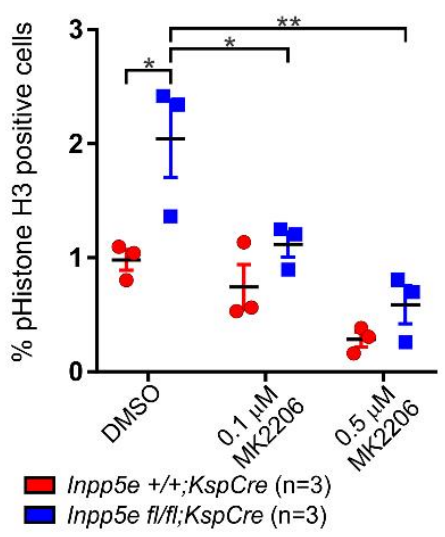

B

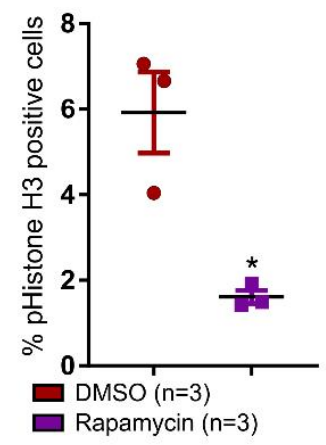

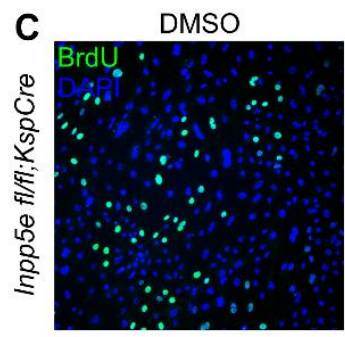

DMSO

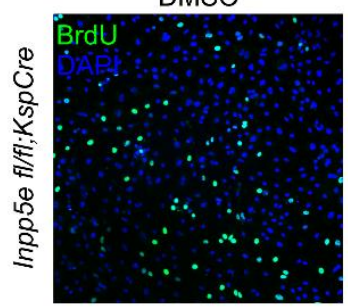

D

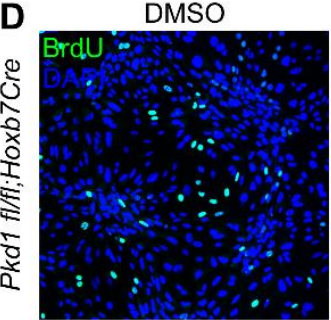

DMSO

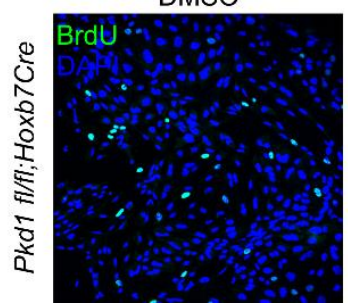

MK2206

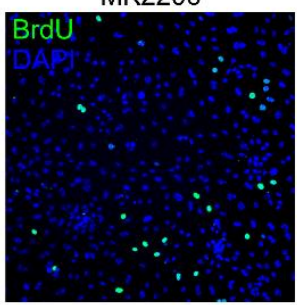

Rapamycin

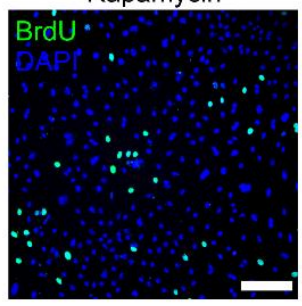

MK2206

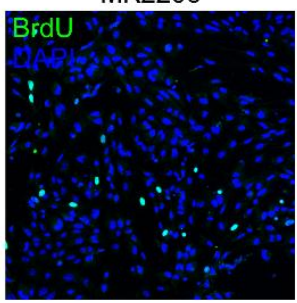

Rapamycin

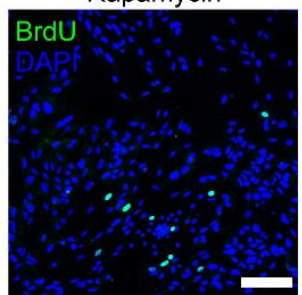

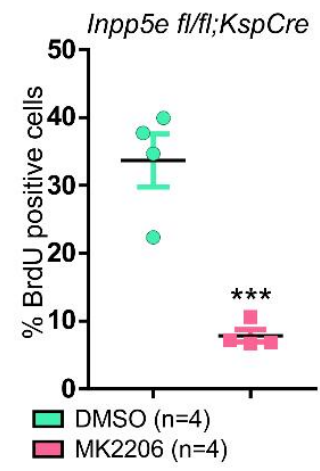
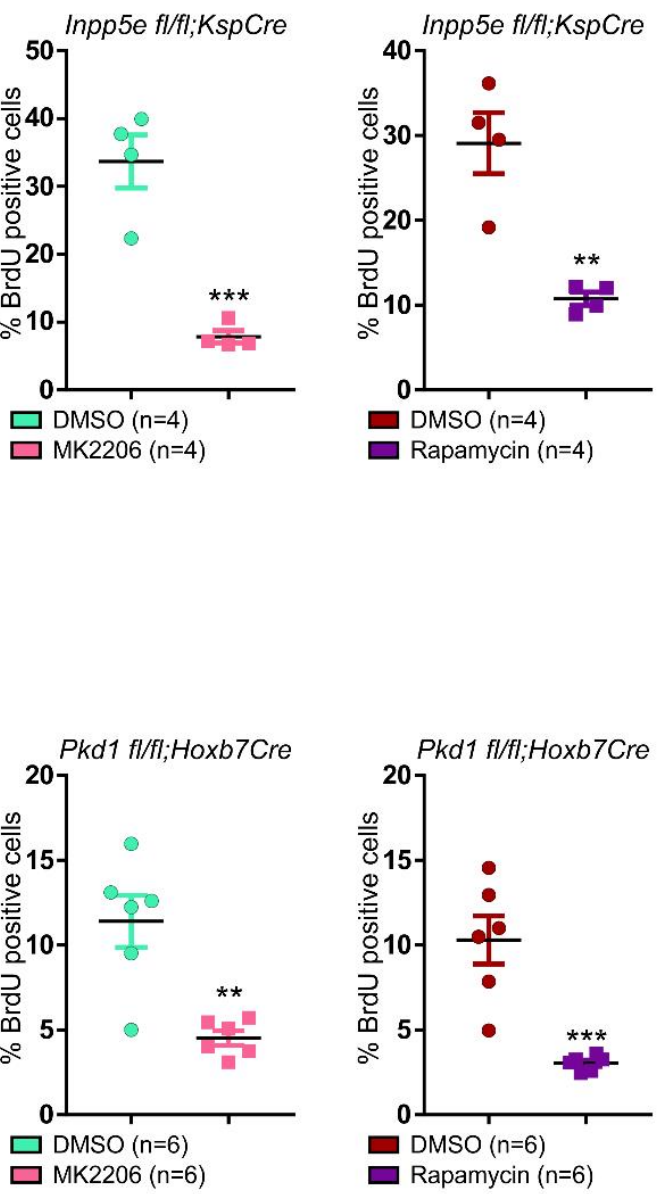


\section{Figure S7: PKD models exhibit increased phosphorylated and total CAD}

A. Inpp $5 e^{+/+} ;$KspCre and Inpp $5 e^{f l / f l} ; K s p C r e$ pRECs were treated with DMSO, $0.1 \mu \mathrm{M}$ or 0.5 $\mu \mathrm{M}$ MK2206 for 24 hours, stained with pHistone H3 antibodies and DAPI and imaged by confocal microscopy. Graph shows the percentage of pHistone H3 positive cells. Bars represent mean \pm SEM, $n=3$ cell lines of each genotype, each derived from an individual mouse, with at least 1612 cells scored per cell line, per condition, statistical significance was determined using two-way ANOVA (interaction $\mathrm{p}=0.1204$, row factor $\mathrm{p}=0.0003$, column factor $\mathrm{p}=0.0024$ ) followed by Tukey's post hoc test, ${ }^{*} \mathrm{p}<0.05,{ }^{*} \mathrm{p}<0.01$.

B. Inpp $5 e^{+/+} ;$KspCre and Inpp $5 e^{\text {fllfl }} ;$ KspCre pRECs were treated with DMSO or $100 \mathrm{nM}$ Rapamycin for 24 hours, stained with pHistone H3 antibodies and DAPI and imaged by confocal microscopy. Graph shows the percentage of pHistone $\mathrm{H} 3$ positive cells. Bars represent mean \pm SEM, $n=3$ cell lines of each genotype, each derived from an individual mouse, with at least 411 cells scored per cell line, per condition, ${ }^{*} \mathrm{p}<0.05$.

C. Inpp $5 e^{f l f l} ;$ KspCre pRECs were treated with DMSO, $1 \mu \mathrm{M}$ MK2206 or $100 \mathrm{nM}$ Rapamycin for 24 hours, pulsed with BrdU for 45 minutes stained with BrdU antibodies (green) and DAPI and imaged by confocal microscopy. Bar indicates $100 \mu \mathrm{m}$. Graph shows the percentage of BrdU positive cells. Bars represent mean \pm SEM, $n=4$ cell lines of each genotype, each derived from an individual mouse, with at least 3000 cells scored per cell line, per condition, ${ }^{* *} \mathrm{p}<0.01$, $* * * \mathrm{p}<0.001$.

D. $P k d 1^{f l f l}$;Hoxb7Cre pRECs were treated with DMSO, $1 \mu \mathrm{M}$ MK2206 or $100 \mathrm{nM}$ Rapamycin for 24 hours, pulsed with BrdU for 45 minutes stained with BrdU antibodies (green) and DAPI and imaged by confocal microscopy. Bar indicates $100 \mu \mathrm{m}$. Graph shows the percentage of BrdU positive cells. Bars represent mean \pm SEM, $n=6$ cell lines of each genotype, each derived from an individual mouse, with at least 3000 cells scored per cell line, per condition, ${ }^{* *} \mathrm{p}<0.01$, $* * * \mathrm{p}<0.001$. 